\title{
Synthesis and Properties of Perylene-Bridge-Anchor Chromophoric Compounds.
}

Ryan Harmer, ${ }^{1}$ Hao Fan, ${ }^{1 \mathrm{a}}$ Katherine Lloyd,${ }^{1}$ Samantha Doble, ${ }^{3}$ Joseph Avenoso, ${ }^{4}$ Han Yan, ${ }^{3}$ Luis G. C. Rego, ${ }^{2 *}$ Lars Gundlach, ${ }^{3,4, *}$ and Elena Galoppini ${ }^{1, *}$

${ }^{1}$ Department of Chemistry, Rutgers University, Newark, NJ 07102

${ }^{2}$ Department of Physics, Universidade Federal de Santa Catarina (UFSC), Florianopolis, Brazil, SC 88040-900

${ }^{3}$ Department of Chemistry and Biochemistry, University of Delaware, Newark, DE 19716

${ }^{4}$ Department of Physics and Astronomy, University of Delaware, Newark, DE 19716

\section{Table of Contents}

1. Reactivity of Perylene: An Orbital Theory Model

Figure S1. Six $\pi$ MO of a benzene ring. Black and white circles designate the phases of the carbon 2p orbitals.

Figure S2. Schematic HOMO and LUMO molecular orbitals of naphthalene. The HOMO is composed of two adjacent benzene $\pi 2$ orbitals of opposite phases. The LUMO is composed of two adjacent benzene $\pi 4$ orbitals of opposite phases.

Figure S3. HOMO (a) and LUMO (b) orbitals of the perylene molecule, represented as a combination of the $\mathrm{E} 1 \mathrm{~g}(\pi 2$ and $\pi 3)$ and $\mathrm{E} 2 \mathrm{u}(\pi 4$ and $\pi 5)$ frontier orbitals of the benzene molecule

Figure S4. Schematic representation of the second-order intramolecular polarization correction due to substitution of a hydrogen atom of benzene by the $\mathrm{CH}_{3}$ group, for the $\pi 2$ (a) and $\pi 4$ (b) orbitals. The same effect occurs to the $\pi 2$ and $\pi 4$ orbitals that compose the perylene molecule.

2. Structural Properties

Figure S5. Electronic density isosurfaces of the HOMO (left) and LUMO (right) molecular orbitals for compounds DiMePe (a), $\mathrm{pDiMePeC}_{2} \mathrm{H}_{4} \mathrm{COOH}$ (b), $\mathrm{pDiMePeC}_{2} \mathrm{H}_{2} \mathrm{COOH}$ (c) and $\mathrm{pDtBuPeC}_{2} \mathrm{H}_{2} \mathrm{COOH}$ (d).

Figure S6. Optimized geometry of the $\mathrm{pDiMeC}_{2} \mathrm{H}_{2} \mathrm{COOH}$ molecule. The $\mathrm{C}_{2} \mathrm{H}_{2} \mathrm{COOH}$ linker is rotated by $33.5^{\circ}$ out of the plane of the perylene framework.

Figure S7. Optimized geometry of the pDiMe $\left(\mathrm{C}_{2} \mathrm{H}_{2} \mathrm{COOH}\right)_{2}$ molecule. (a) $\mathrm{The}_{2} \mathrm{C}_{2} \mathrm{COOH}$ linkers are both rotated by $32.2^{\circ}$ (b) The distortion on the perylene framework.

\section{Experimental Methods}
a. General
p. S-7
b. Quantum Yields calculations
p. S-8

\footnotetext{
${ }^{a}$ Current address: Centre for Analysis and Synthesis, Department of Chemistry, Lund University, Box 124, SE-22100 Lund, Sweden
} 
c. For compounds 1a-6 and 8a-11b

Figures S8-S59. ${ }^{1} \mathrm{H}$ and ${ }^{13} \mathrm{C}$ NMR spectra of perylene compounds 1a-23.

\section{Reactivity of Perylene: An Orbital Theory Model}

Experimentally, it is observed that the ortho positions of perylene are less reactive than the peri positions in electrophilic aromatic substitutions. The effect can be ascribed to a shift of electronic charge, from the ortho to the peri positions, as evidenced for the frontier (HOMO and LUMO) orbitals of the perylene molecule. The origin of the effect is a strong internal polarization of the $\pi$ electron system of the outer benzene rings that compose the perylene molecule. It is rationalized in terms of a second-order mixing of the $\pi$ and $\pi^{*}$ orbitals of the composing benzene rings, as described next.

The perylene molecule exhibits a perfectly planar structure, of point group $\mathrm{D}_{2 \mathrm{~h}}$. It can also, conveniently, be treated as two naphthalene molecules bound to each other. Along this decomposition path, furthermore, it can too be understood as five benzene rings that are fused to form the perylene aromatic system. Its most basic constituent, the benzene ring, belongs to the $\mathrm{D}_{6 \mathrm{~h}}$ point group. Therefore, amongst the six $\pi$ MO of benzene $\left(\pi_{1}, \pi_{2}, \ldots, \pi_{6}\right)$, the 2D HOMO is composed of a doubly degenerate set of $E_{1 \mathrm{~g}}$ orbitals $\left(\pi_{2}\right.$ and $\left.\pi_{3}\right)$, and the 2D LUMO is composed of orbitals with $E_{2 u}$ symmetry $\left(\pi_{4}\right.$ and $\pi_{5}$ ), as shown in Figure S1. When two benzene rings adjoin to give rise to the naphthalene molecule, the symmetry of the structure descends from $D_{6 h}$ to $\mathrm{D}_{2 \mathrm{~h}}$, which leads to $\mathrm{E}_{1 \mathrm{~g}} \rightarrow \mathrm{B}_{2 \mathrm{~g}}+\mathrm{B}_{3 \mathrm{~g}}$ and $\mathrm{E}_{2 \mathrm{u}} \rightarrow \mathrm{A}_{\mathrm{u}}+\mathrm{B}_{1 \mathrm{u}}$. It also lifts the degeneracy of the 2D frontier orbitals, that is, the $1 \mathrm{D}$ HOMO of naphthalene becomes the $A_{u} \equiv \pi_{2} \oplus\left(-\pi_{2}\right)$, antisymmetric with respect to the adjoining axis, and the $1 \mathrm{D}$ LUMO becomes $\mathrm{B}_{2 \mathrm{~g}} \equiv \pi_{4} \oplus\left(-\pi_{4}\right)$, as shown in Figure S2. Similar reasoning can be applied to construct the HOMO and LUMO orbitals of perylene using the frontier orbitals of benzene, as shown in Figure S3. This scheme has been used to enlighten the nature of the frontier orbitals of graphene nano-islands and nano-ribbons. ${ }^{1}$ However, the difference of electron density between the peri and ortho positions in perylene, also observable in Figure S3, cannot be explained by this simple construction method. The effect can be explained, nonetheless, by a strong internal polarization of the outer benzene rings that compose the perylene molecule. As described by molecular orbital calculations of Libit and Hoffmann, ${ }^{2}$ when a methyl group replaces a hydrogen atom in benzene, there is considerable polarization of the benzene $\pi$ system. The ensuing second-order correction of the $\pi_{2}$ orbital of benzene yields the perturbed orbital $\pi_{2}^{\prime} \approx \pi_{2}+\mathrm{C}_{1} \pi_{1}+\mathrm{C}_{2}\left(-\pi_{4}\right)$, where $\mathrm{C}_{1}$ and $\mathrm{C}_{2}$ are positive second-order correction coefficients. As a result, electron density is shifted from the meta to the ortho and para positions of benzene, as shown in Figure S4, and likewise from the ortho to the bay and peri positions perylene. Analogous procedure can be used to rationalize the transformation undergone by the $\pi_{4}$ orbitals that constitute the LUMO of perylene, that is, $\pi^{\prime}{ }_{4} \approx \pi_{4}+\mathrm{C}_{1} \pi_{1}+\mathrm{C}_{2}\left(-\pi_{2}\right)$. 


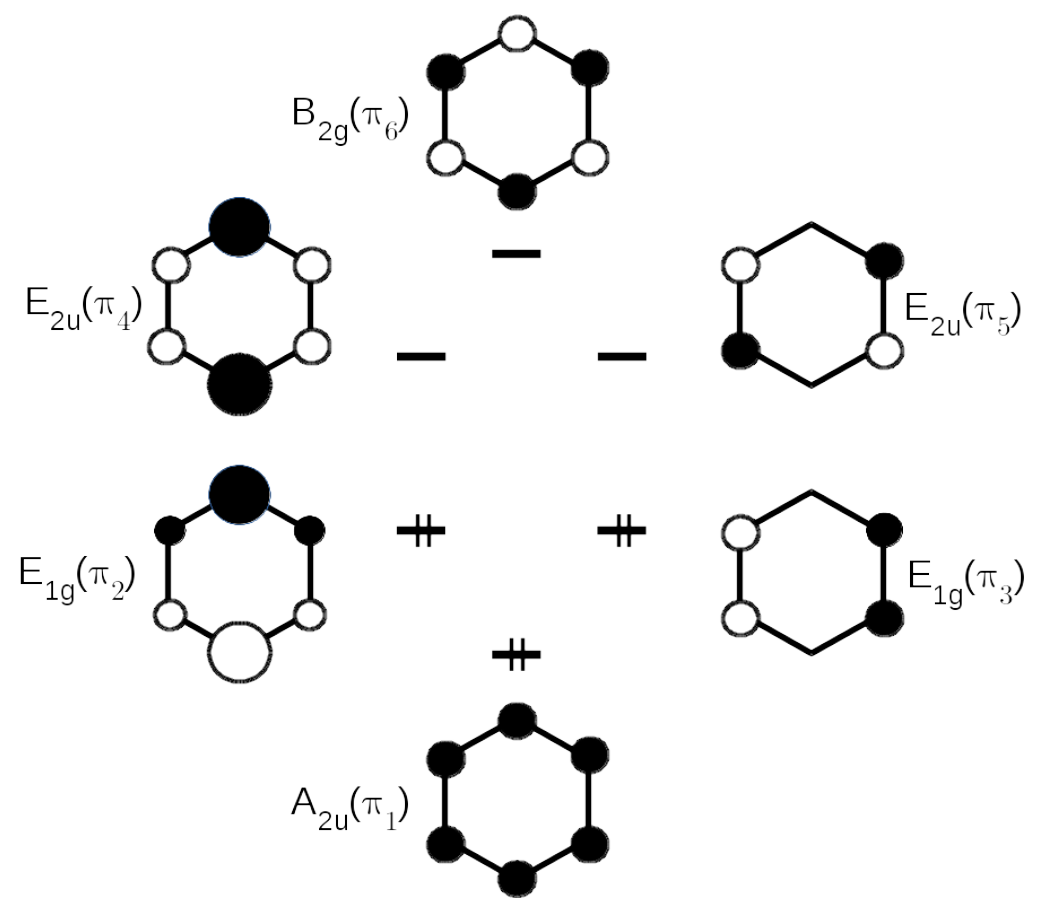

Figure S1. Six $\pi$ MO of a benzene ring. Black and white circles designate the phases of the carbon 2 p orbitals.

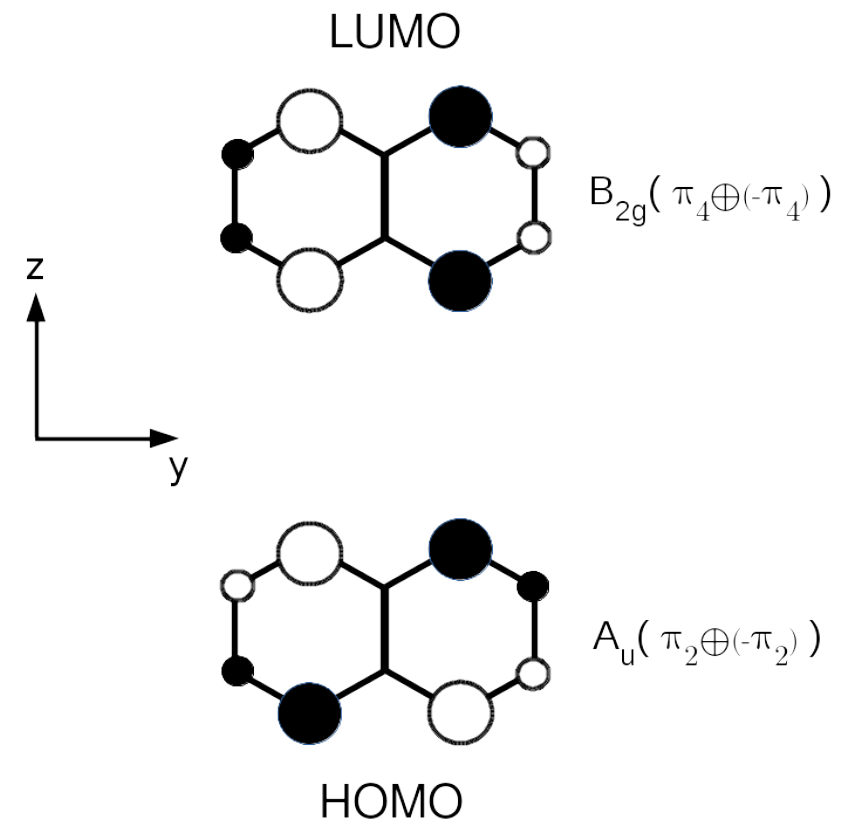

Figure S2. Schematic HOMO and LUMO molecular orbitals of naphthalene. The HOMO is composed of two adjacent benzene $\pi_{2}$ orbitals of opposite phases. The LUMO is composed of two adjacent benzene $\pi_{4}$ orbitals of opposite phases. 


\section{a)}

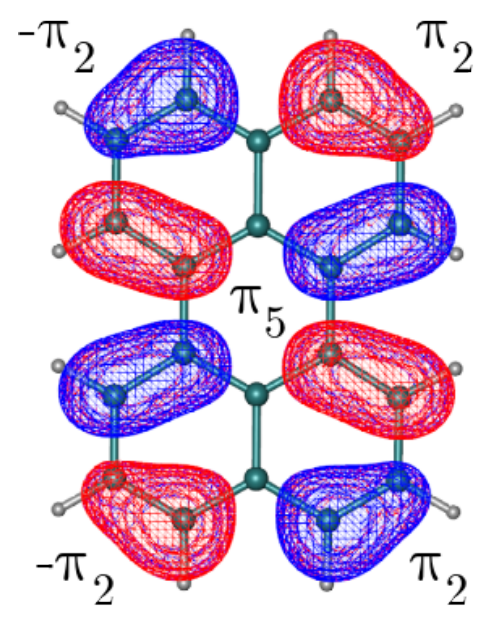

$\mathrm{HOMO}$ b)

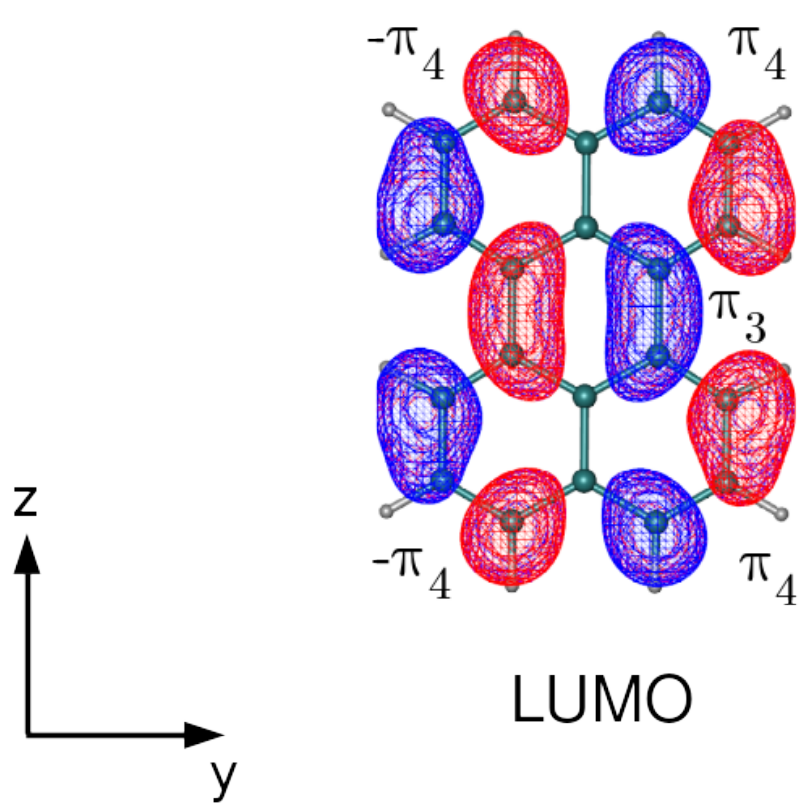

Figure S3. HOMO (a) and LUMO (b) orbitals of the perylene molecule, represented as a combination of the $E_{1 g}\left(\pi_{2}\right.$ and $\left.\pi_{3}\right)$ and $E_{2 u}\left(\pi_{4}\right.$ and $\left.\pi_{5}\right)$ frontier orbitals of the benzene molecule

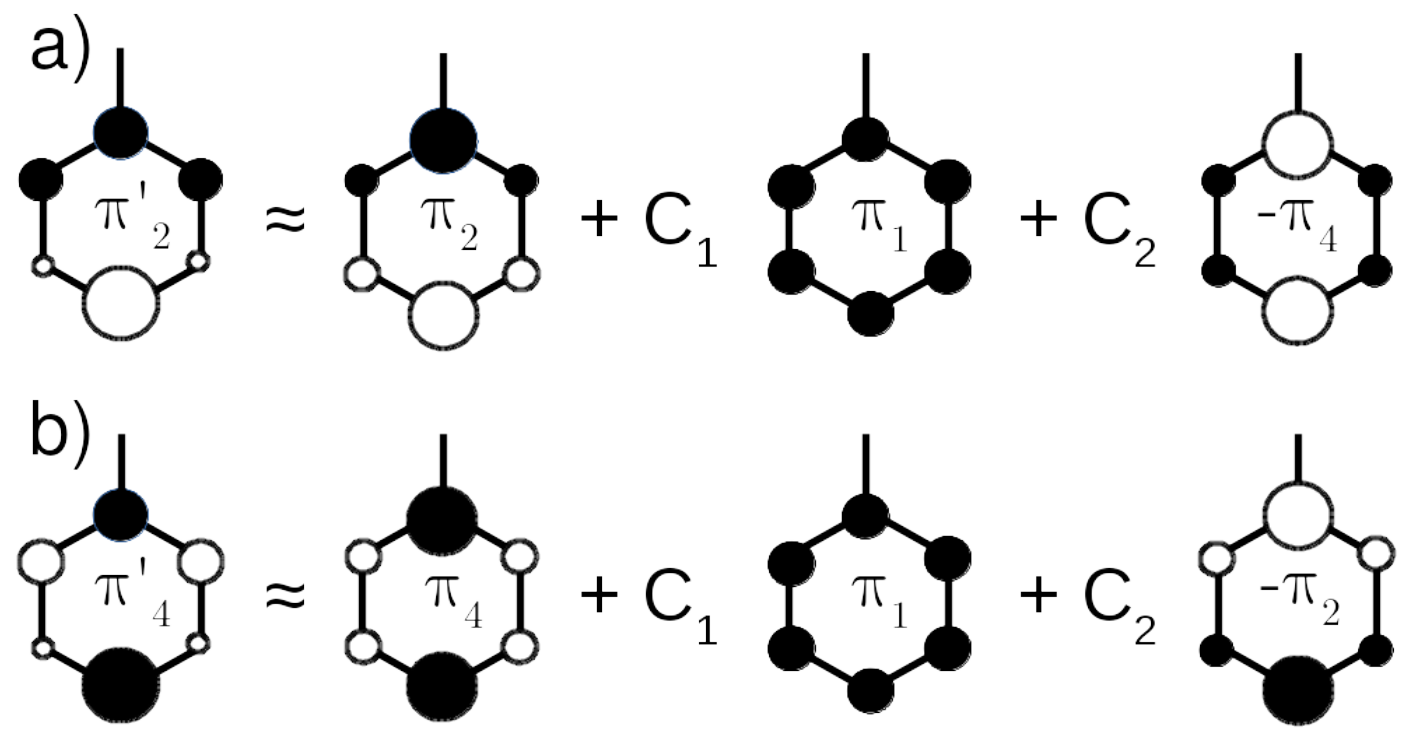

Figure S4. Schematic representation of the second-order intramolecular polarization correction due to substitution of a hydrogen atom of benzene by the $\mathrm{CH}_{3}$ group, for the $\pi_{2}$ (a) and $\pi_{4}$ (b) orbitals. The same effect occurs to the $\pi_{2}$ and $\pi_{4}$ orbitals that compose the perylene molecule. 


\section{Structural properties}

(a)

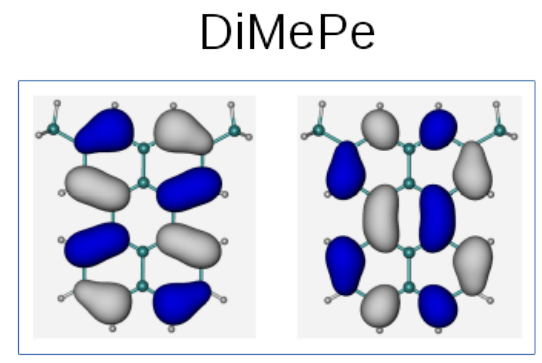

(b)
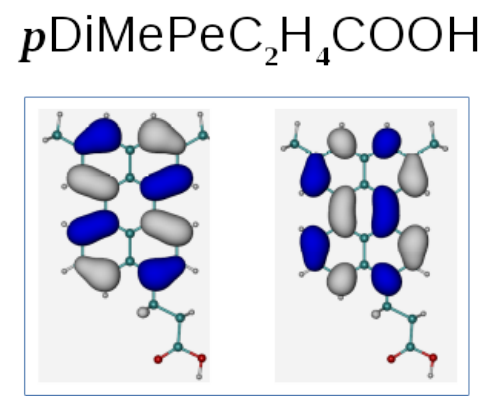

(c)

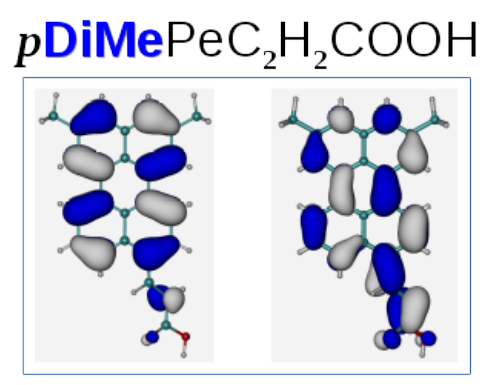

(d)

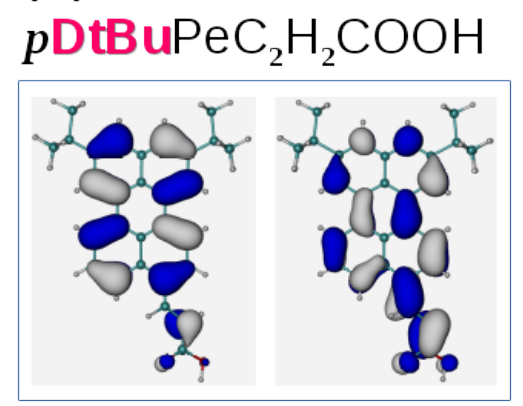

Figure S5. Electronic density isosurfaces of the HOMO (left) and LUMO (right) molecular orbitals for compounds DiMePe (a), $\mathrm{pDiMePeC}_{2} \mathrm{H}_{4} \mathrm{COOH}$ (b), $\mathrm{pDiMePeC}_{2} \mathrm{H}_{2} \mathrm{COOH}$ (c) and $\mathrm{pDtBuPeC} \mathrm{H}_{2} \mathrm{COOH}$ (d).

To investigate the structural properties of the DiMePe compounds, each molecule was optimized in the ground state using the DFT method, with the B3LYP functional and 6-31+G(d,p) basis set, with the program package Gaussian $09 .{ }^{3}$ The optimized geometries were obtained by minimizing atomic forces and displacements; the local minima were confirmed by performing frequency calculations.

The perylene molecule exhibits a perfectly planar structure. The repulsion interaction between hydrogen atoms from different naphthalene fragments does not overcome the stabilization obtained from conjugation of $\pi$ electrons. However, structural optimization of the surrogate molecules revealed the following. The attachment of the $\mathrm{C}_{2} \mathrm{H}_{4} \mathrm{COOH}$ linker in the peri position fully preserves the planarity of the perylene framework, due to the reflection symmetry of the alkyl bridge linker. However, attachment of the $\mathrm{C}_{2} \mathrm{H}_{2}$ bridge in the peri position gives rise to unbalanced steric repulsion between the hydrogen atoms of the bridge and perylene fragments. As a result, the $\mathrm{C}_{2} \mathrm{H}_{2} \mathrm{COOH}$ linker in the peri position is rotated by approximately $33.5^{\circ}$ out of the plane of the perylene framework, as shown in Figure S6. 


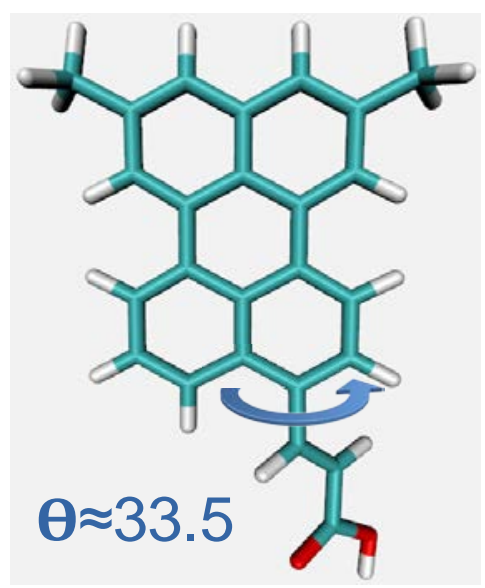

Figure S6. Optimized geometry of the pDiMeC ${ }_{2} \mathrm{H}_{2} \mathrm{COOH}$ molecule. The $\mathrm{C}_{2} \mathrm{H}_{2} \mathrm{COOH}$ linker is rotated by $33.5^{\circ}$ out of the plane of the perylene framework.

Attachment of $\mathrm{C}_{2} \mathrm{H}_{2} \mathrm{COOH}$ linkers to the peri positions $(9,10)$ produces even more steric interactions. In this case both linkers rotate by the same angle, $32.2^{\circ}$, as shown in Figure S7a. The displacement of both linkers produces a distortion on the perylene framework, as shown in Figure S7b.

\section{(a)}

(b)
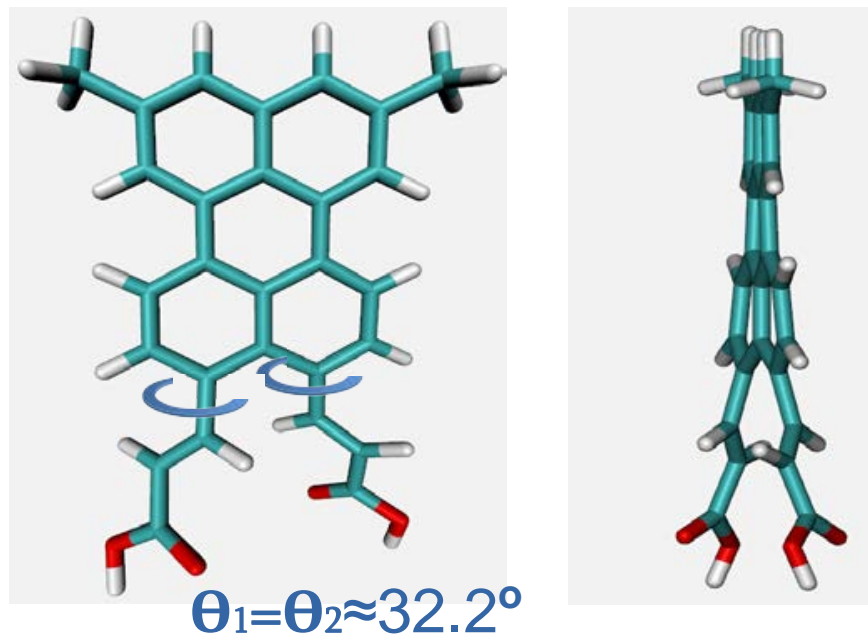

Figure S7. Optimized geometry of the pDiMe $\left(\mathrm{C}_{2} \mathrm{H}_{2} \mathrm{COOH}\right)_{2}$ molecule. (a) The $\mathrm{C}_{2} \mathrm{H}_{2} \mathrm{COOH}$ linkers are both rotated by $32.2^{\circ}$ (b) The distortion on the perylene framework.

On the other hand, the attachment of $\mathrm{C}_{2} \mathrm{H}_{2} \mathrm{COOH}$ linkers in the ortho positions of perylene preserves the planarity of the derivatized compounds, since the ortho position provides more steric freedom for the linker, as compared to the peri positions. 


\section{Experimental Methods}

\section{a. General}

Reagents and Methods: All reactions involving air- and moisture-sensitive reagents were performed under nitrogen or argon and in oven-dried or flame-dried glassware. All reactions involving perylene were conducted in the dark and by protecting the vessels from ambient light with aluminum foil. Perylene samples were stored at room temperature but protected from light. All reagents were purchased and used without further purification unless otherwise noted. NBS was recrystallized from hot water (10g NBS in $\left.100 \mathrm{~mL} \mathrm{H}_{2} \mathrm{O}\right) .{ }^{4}$ Alumina-supported $\mathrm{CuBr}_{2}$ was prepared according to a reported procedure with activated neutral aluminum oxide $\left(\mathrm{Al}_{2} \mathrm{O}_{3}\right){ }^{5}$ as follows: $\mathrm{CuBr}_{2}(10 \mathrm{~g})$ was dissolved in water $(30 \mathrm{~mL})$, and $\mathrm{Al}_{2} \mathrm{O}_{3}(20 \mathrm{~g})$ was added, and the mixture was concentrated to dryness in vacuo at $80^{\circ} \mathrm{C}$; the reagent was stored at room temperature and protected from ambient light (amber container) for several weeks and used as needed. Solvents were purchased anhydrous from Sigma unless otherwise indicated. Hexanes employed for column chromatography were glass distilled. "Freshly distilled THF” refers to THF (anhydrous, stabilizer free) first purified with an MBRAUN Solvent Purification System, then distilled over sodium/benzophenone ketyl immediately prior to use. “Anhydrous THF” refers to commercially available THF (anhydrous, Sigma) and “THF from purification system” refers to THF (anhydrous, stabilizer free) purified with a MBRAUN Solvent Purification System. Silica gel column chromatography was performed on silica gel with particle size $=40-63 \mu \mathrm{m}$, pore size $=60 \AA$. Thin layer chromatography was carried out on silica gel w/UV254 aluminum-backed or plastic-backed sheets (200 $\mu \mathrm{m}$ thick), and monitored using UV light. ${ }^{1} \mathrm{H}-\mathrm{NMR}$ spectra were collected on a Varian

INOVA NMR spectrometer operating at $599.896 \mathrm{MHz} .{ }^{13} \mathrm{C}-\mathrm{NMR}$ spectra were collected on a Varian INOVA NMR spectrometer operating at $151 \mathrm{MHz}$. Solvent is Chloroform- $d$ unless 
otherwise specified. Chemical shifts $(\delta)$ are reported relative to TMS $(\delta 0.00 \mathrm{ppm})$ or the central line of the solvent: Chloroform- $d\left(\delta 7.26 \mathrm{ppm}\right.$ for ${ }^{1} \mathrm{H}$ and $\delta 77.16 \mathrm{ppm}$ for $\left.{ }^{13} \mathrm{C}\right)$, THF- $d_{8}(\delta 1.72$ and $3.58 \mathrm{ppm}$ for ${ }^{1} \mathrm{H}$ and 67.21 and $25.31 \mathrm{ppm}$ for $\left.{ }^{13} \mathrm{C}\right)$ DMSO- $d_{6}\left(\delta 2.50 \mathrm{ppm}\right.$ for ${ }^{1} \mathrm{H}$ and $\delta 39.52$ ppm for ${ }^{13} \mathrm{C}$ ), Methanol- $d_{4}\left(\delta 3.31 \mathrm{ppm}\right.$ for ${ }^{1} \mathrm{H}$ and $\delta 49.00 \mathrm{ppm}$ for $\left.{ }^{13} \mathrm{C}\right)$ and spin-spin coupling constants $(J)$ are reported in Hz. Yields refer to isolated products.

\section{b. Quantum yield calculation}

A PhotonControl UV-vis fiber spectrometer was used to acquire the steady state absorption and fluorescence spectra used to calculate the quantum yields. The samples were related to the perylene standard by the equation

$$
\Phi_{F(x)}=\left(\frac{A_{s}}{A_{x}}\right)\left(\frac{F_{x}}{F_{s}}\right)\left(\frac{n_{x}}{n_{S}}\right) \Phi_{F(s)}
$$

where $\Phi_{\mathrm{F}}$ is the quantum yield, A is the absorbance at the excitation wavelength (405 nm), F is the integrated fluorescence intensity, and $n$ is the refractive index of THF. The subscripts S and X refer to the standard and dilute sample, respectively.

\section{c. Synthesis for compounds 1a-6 and 8a-11b.}

2,7-di-tert-Butylnaphthalene (1a): A flame-dried r.b. flask was charged with naphthalene (20 g, $156 \mathrm{mmol}$ ), and tert-butyl chloride ( $57.9 \mathrm{~g}, 625 \mathrm{mmol}$ ) which upon heating to $45^{\circ} \mathrm{C}$, formed a melt. $\mathrm{AlCl}_{3}$ (250 mg, $1.87 \mathrm{mmol}$ ) was then added in small portions while stirring, causing a vigorous reaction with the evolution of gaseous hydrogen chloride. The reaction mixture turned brown and solidified within minutes, and the temperature was maintained at $45^{\circ} \mathrm{C}$ for $1.5 \mathrm{~h}$. The formation of the 2,6- and 2,7-di-tert-butyl regioisomers was monitored by GC-MS. Unreacted tert- 
butyl chloride was removed in vacuo. The solid residue was dissolved in hot ethanol (300 mL), and thiourea (21 g) was added to the solution. The mixture was refluxed until thiourea fully dissolved. After cooling the solution, the precipitate was filtered and collected, then the process was repeated twice, first with $21 \mathrm{~g}$ and then with $8 \mathrm{~g}$ of thiourea added to the mother liquor. Finally, after removal of the solvent, the crude product was sonicated and triturated with $\mathrm{H}_{2} \mathrm{O}$ and extracted several times with hexanes. The combined organic layers were washed with $\mathrm{H}_{2} \mathrm{O}$, brine, dried over $\mathrm{MgSO}_{4}$ and filtered. The solvent was removed in vacuo, and the resulting yellow solid was recrystallized with $\mathrm{MeOH}$ to yield 1a as white crystal (4.82 g, 13\%). This reaction was repeated multiple times and yields were consistently in the $12-14 \%$ range. ${ }^{1} \mathrm{H}$ NMR $\delta 7.77-7.72(\mathrm{~m}, 4 \mathrm{H})$, 7.52 (d, $J=8.5,1.9 \mathrm{~Hz}, 2 \mathrm{H}), 1.42$ (s, 18H). ${ }^{13} \mathrm{C}$ NMR $\delta$ 148.63, 133.41, 129.97, 127.14, 124.29, 123.06, 34.97, 31.44.

1-Bromo-3,6-di-tert-Butylnaphthalene (2): A flame-dried r.b. flask was charged with $1 \mathrm{a}$ (1 g, $4.17 \mathrm{mmol})$, alumina-supported $\mathrm{CuBr}_{2}\left(14 \mathrm{~g}, \sim 21 \mathrm{mmol}\right.$ of $\left.\mathrm{CuBr}_{2}\right)$ and anhydrous $\mathrm{CCl}_{4}(40 \mathrm{~mL})$ under nitrogen and heated to $85^{\circ} \mathrm{C}$ for $2 \mathrm{~h}$. The reaction completion was monitored by TLC and GC-MS. The mixture was filtered, and the solid was rinsed with $\mathrm{CHCl}_{3}$. The combined filtrate was dried in vacuo to yield 2 as a pale-yellow oil (1.2 g, 90\%), which was directly used in the next step without further purification. ${ }^{1} \mathrm{H}$ NMR $\delta 8.09$ (d, $\left.J=8.8 \mathrm{~Hz}, 1 \mathrm{H}\right), 7.79$ (s, 1H), 7.73 (s, 1H), 7.71 (s, 1H), 7.62 (d, $J=8.9,2.0 \mathrm{~Hz}, 1 \mathrm{H}), 1.42$ (s, 9H), 1.40 (s, 9H). ${ }^{13} \mathrm{C}$ NMR $\delta$ 149.66, 149.54, 134.63, 128.70, 128.37, 126.60, 125.77, 123.53, 123.32, 122.49, 35.08, 34.98, 31.38.

3,6-di-tert-butyl-1,1'-Binaphthalene (3): A flame-dried r.b. flask was charged with 2 (2.0 g, $6.26 \mathrm{mmol})$, naphthalen-1-ylboronic acid (1.29 g, $7.51 \mathrm{mmol})$, toluene (10 mL), 1-butanol (5 mL) and $2 \mathrm{~N} \mathrm{Cs}_{2} \mathrm{CO}_{3}$ aq. solution $(6.3 \mathrm{~mL})$ under nitrogen. $\mathrm{Pd}\left(\mathrm{PPh}_{3}\right)_{4}(0.501 \mathrm{mmol}, 579 \mathrm{mg})$ was added under nitrogen flow and the mixture was heated to reflux with vigorous stirring for $3 \mathrm{~d}$. After 
cooling to room temperature, the mixture was diluted with brine and extracted with ethyl acetate (20 mL x 3). The combined organic layers were washed with $\mathrm{H}_{2} \mathrm{O}$, brine, dried over $\mathrm{Na}_{2} \mathrm{SO}_{4}$ and filtered, and the solvent was removed in vacuo. The resulting crude product was purified via column chromatography (silica gel, hexanes) to yield 3 as a colorless, glassy, solid (2.0 g, 87\%) ${ }^{1} \mathrm{H}$ NMR $\delta 7.94(\mathrm{~d}, J=8.2 \mathrm{~Hz}, 2 \mathrm{H}), 7.85$ (d, $\left.J=6.4,1.9 \mathrm{~Hz}, 2 \mathrm{H}\right), 7.59$ (dd, $\left.J=8.2,6.9 \mathrm{~Hz}, 1 \mathrm{H}\right)$, 7.53 (s, 1H), 7.50 (d, 1H), $7.48-7.45$ (m, 2H), $7.35-7.27$ (m, 3H), 1.44 (s, 9H), 1.39 (s, 9H). ${ }^{13} \mathrm{C}$ NMR $\delta$ 148.57, 148.15, 139.20, 137.75, 133.72, 133.10, 129.47, 128.26, 128.00, 127.84, 126.86, $126.45,126.04,125.97,125.88,125.50,124.40,123.31,123.06,35.06,34.90,31.47,31.40$.

2,5-di-tert-Butylperylene (4): This step was carried out under argon and with rigorous exclusion of moisture, using a glass-coated stirring bar (Teflon reacts with alkali metals). A flame dried 250 mL 2-neck r.b. flask was charged with 3 (500 mg, $1.37 \mathrm{mmol}$ ) and stabilized lithium powder (SLMP ${ }^{\circledR}$ from FMC Co., $288 \mathrm{mg}, 41.1 \mathrm{mmol}$ ) under argon. In a separate flask, freshly distilled THF (41 mL) was degassed by freeze-pump-thaw, charged with Argon, then added to the reaction flask via cannula, under argon. The reaction mixture was then slowly (over $45 \mathrm{~min}$ ) heated to 50 ${ }^{\circ} \mathrm{C}$ and kept at $50{ }^{\circ} \mathrm{C}$ for $5 \mathrm{~h}$. The color gradually changed from yellow, green, red-brown to deep violet, indicating the formation of the radical anion. After cooling to room temperature, the reaction was quenched by adding anhydrous $\mathrm{CdCl}_{2}$ (3.76 g, $15 \mathrm{mmol}$ ) in small portions under positive argon flow. The color of the suspension changed to yellow with a blue fluorescence. The suspension was stirred for $1 \mathrm{~h}$, then acidified with $\mathrm{H}_{2} \mathrm{SO}_{4}$ (5N, aq.). The suspension was filtered, and metallic cadmium powder was rinsed with acetone. The combined organic layers were evaporated in vacuo and the crude product was taken up in ethyl acetate. The combined ethyl acetate extracts were washed with acidified water, brine and dried over $\mathrm{Na}_{2} \mathrm{SO}_{4}$. The solvent was then removed in vacuo, and the crude product was purified via column chromatography (silica gel, 
hexanes : ethyl acetate $=30: 1)$ to yield 4 as an orange solid. $(250 \mathrm{mg}, 50 \%){ }^{1} \mathrm{H}$ NMR $\delta 8.24$ (s, 2H), 8.21 (d, $J=7.4 \mathrm{~Hz}, 2 \mathrm{H}$ ), 7.66 (d, $J=7.9 \mathrm{~Hz}, 2 \mathrm{H}), 7.63$ (s, 2H), 7.48 (dd, $J=7.8,7.8 \mathrm{~Hz}, 2 \mathrm{H}$ ), 1.47 (s, 18H). ${ }^{13} \mathrm{C}$ NMR $\delta 148.98,134.90,134.75,131.61,130.41,127.59,126.37,125.39,123.46$, 119.82, 118.28, 34.93, 31.31.

The same procedure was repeated using potassium metal. A flame dried $500 \mathrm{~mL}$ 2-neck r.b. flask was charged with 3 ( $2.07 \mathrm{~g}, 5.64 \mathrm{mmol}$ ), $300 \mathrm{~mL}$ of freshly distilled THF (see above), and a freshly cut piece of potassium metal (450 mg, $11.54 \mathrm{mmol}$ ) which was rinsed with pentane, followed by THF and then added to the reaction mixture under positive argon flow. The mixture was refluxed under argon for $18 \mathrm{~h}$ during which the color changed from yellow to deep violet. After cooling to room temperature, any small potassium metal in excess was collected with tweezers and cautiously quenched with isopropyl alcohol under nitrogen in a separate container. The reaction was quenched by the addition $\mathrm{CdCl}_{2}(25.38 \mathrm{~g}, 138.45 \mathrm{mmol})$ in small portions until fluorescence was observed from the flask. The reaction was than acidified to litmus by $\mathrm{H}_{2} \mathrm{SO}_{4}$. (2N, aq.). Excess organic solvent was removed in vacuo, and the remaining aqueous mixture was extracted with $\mathrm{CH}_{2} \mathrm{Cl}_{2}$. The combined organic layers were washed with dilute acid, brine, then dried over $\mathrm{Na}_{2} \mathrm{SO}_{4}$. Crystallization from $\mathrm{CH}_{2} \mathrm{Cl}_{2}: \mathrm{MeOH}$ afforded a first crop of deep red/orange crystals of 4 (900 mg). The mother liquor was concentrated and column chromatography (silica gel, hexanes : ethyl acetate $=30: 1$ ) yielded additional $800 \mathrm{mg}$ of 4 as an orange solid. Total yield: $1.8 \mathrm{~g}, 87 \%$. The NMR data was identical to that of samples obtained via the other method.

2,5-di-tert-Butylperylene (4) (Friedel-Crafts Alkylation): In a flame-dried two-neck r.b. flask, perylene (1.0 g, $3.96 \mathrm{mmol})$ was dissolved in chilled 1,2-dichlorobenzene (100 mL, previously dried over $4 \AA$ molecular sieves), and the solution was cooled to $0{ }^{\circ} \mathrm{C}$ under argon. Anhydrous $\mathrm{AlCl}_{3}$ (528 mg, $3.96 \mathrm{mmol}$ ) was added in portions under positive argon flow, changing the color 
of the mixture from yellow with blue fluorescence to dark green, followed by the dropwise addition of $t$ - $\mathrm{BuCl}(32.5 \mathrm{~mL}, 297 \mathrm{mmol})$ over about 10 minutes. The green mixture was allowed to warm up to r.t. and stirred for $24 \mathrm{~h}$ under argon. The reaction was quenched by pouring the mixture into ice cold water. The organic layer was separated, and the solvent was removed in vacuo. The resulting green residue was taken up in $\mathrm{CH}_{2} \mathrm{Cl}_{2}$, washed with water and dried over $\mathrm{Na}_{2} \mathrm{SO}_{4}$. The combined organic layers were concentrated in vacuo and the crude solid was purified via column chromatography ( $\mathrm{Al}_{2} \mathrm{O}_{3}$, cyclohexane) yielding 4 as a yellow-orange solid (167 mg, $\left.12 \%\right), 4:{ }^{1} \mathrm{H}$ NMR $\delta 8.24$ (s, 2H), 8.21 (d, J = 7.5 Hz, 2H), 7.65 (d, 2H), 7.63 (s, 2H), 7.47 (dd, $J=8.2,7.3 \mathrm{~Hz}$, 2H), 1.47 (s, 18H). ${ }^{13} \mathrm{C}$ NMR $\delta 149.14,135.06,134.91,131.77,130.57,129.31,127.74,126.53$, 125.55, 123.62, 119.98, 118.44, 35.08, 31.46. HRMS (ESI): calculated for $\mathrm{C}_{28} \mathrm{H}_{28}, 364.2186$ [M]+ ; found, $364.2133[\mathrm{M}]+$.

From the column were also separated 2,5,8,11-tetra-tert-butylperylene as a yellow solid (4a, 942 mg, $50 \%$ ), and 2,5,8-tri-tert-butylperylene as a yellow solid (4b, $33 \mathrm{mg}, 2 \%)$, along with mixtures of $\mathbf{4 a}$ and $\mathbf{4 b}$ (512 mg), and $\mathbf{4 b}$ and $\mathbf{4}$ (601 mg). Yields were calculated with respect to perylene starting material. 4a: ${ }^{1} \mathrm{H}$ NMR $\delta 8.24$ (s, 4H), 7.62 (s, 4H), 1.50 (s, 36H). ${ }^{13} \mathrm{C}$ NMR $\delta$ 148.87, 135.04, 130.93, 125.93, 123.43, 117.83, 35.05, 31.52. HRMS (ESI): calculated for $\mathrm{C}_{36} \mathrm{H}_{44}$, $476.3438[\mathrm{M}]+$; found, $476.3400[\mathrm{M}]+.4 \mathrm{~b}:{ }^{1} \mathrm{H}$ NMR $\delta 8.29$ (s, 1H), $8.24(\mathrm{~s}, 1 \mathrm{H}), 8.22(\mathrm{~s}, 1 \mathrm{H})$, 8.15 (d, $J=7.6,1.0 \mathrm{~Hz}, 1 \mathrm{H}), 7.65-7.60$ (m, 4H), 7.45 (dd, $J=7.7,7.7 \mathrm{~Hz}, 1 \mathrm{H}), 1.50$ - 1.49 (m, 18H), 1.47 (s, 9H). ${ }^{13} \mathrm{C}$ NMR $\delta$ 149.04, 148.99, 148.88, 135.09, 134.98, 131.43, 131.29, 130.86, 130.66, 127.79, 126.53, 123.54, 123.51, 123.43, 123.37, 119.35, 118.52, 118.32, 117.98, 117.84, 35.07, 31.51, 31.48.HRMS (ESI): calculated for $\mathrm{C}_{32} \mathrm{H}_{36}, 420.2812$ [M]+ ; found, 420.2786 [M]+.

8,11-di-tert-Butylperylene-3-carbaldehyde (5): A flame-dried two-neck r.b. flask, was charged with 4 (200 mg, $0.274 \mathrm{mmol}$ ) under nitrogen, and 1,2-dichlorobenzene (anhydrous, 60 
$\mathrm{mL})$. The reaction vessel was then cooled in an ice bath. $\mathrm{TiCl}_{4}(90 \mu \mathrm{L}, 0.357 \mathrm{mmol})$ and $\mathrm{Cl}_{2} \mathrm{CHOCH}_{3}(65 \mu \mathrm{L}, 0.357 \mathrm{mmol})$ were added via syringe in one portion, while stirring. The reaction was stirred for one hour. The ice bath was removed, and the reaction mixture was allowed to warm to r.t. and stirred at r.t. for 2 h. The reaction mixture was diluted with ethyl acetate (50 $\mathrm{mL})$, then washed with $\mathrm{HCl}(5 \%$, aq., $50 \mathrm{~mL}), \mathrm{H}_{2} \mathrm{O}(4 \times 20 \mathrm{~mL})$ and brine $(20 \mathrm{~mL})$. The organic layer was separated, dried over $\mathrm{Na}_{2} \mathrm{SO}_{4}$ and filtered. The solvent was removed in vacuo, and the crude product was purified via column chromatography (silica gel, hexane: ethyl acetate; 9:1) to yield 5 as a bright red solid (114 mg, 50\%) ${ }^{1} \mathrm{H}$ NMR $\delta 10.34$ (s, 1H), 9.19 (d, $\left.J=8.4 \mathrm{~Hz}, 1 \mathrm{H}\right), 8.41$ - 8.33 (m, 4H), 7.97 (d, J = 7.8 Hz, 1H), 7.78 (s, 1H), 7.75 - 7.69 (m, 2H), 1.50 (s, 9H), 1.49 (s, $9 \mathrm{H})$.

8,11-di-tert-Butylperylene-3-carboxylic acid (6): A 2-neck r.b. flask was charged with 5 (50 mg, $0.128 \mathrm{mmol}), \mathrm{H}_{2} \mathrm{O}(5 \mathrm{~mL})$, anhydrous pyridine (2.5 mL), and then $\mathrm{KMnO}_{4}$ (61 mg, 0.383 mmol) under nitrogen. The reaction mixture was stirred at room temperature for 3 days, then pyridine was removed in vacuo. To the resulting suspension, was added $\mathrm{H}_{2} \mathrm{O}(10 \mathrm{~mL})$, then heated to $100{ }^{\circ} \mathrm{C}$ and filtered. The filtrate was carefully acidified with conc. $\mathrm{HCl}$ to form a red suspension. The solid was collected by vacuum filtration, washed sequentially with $\mathrm{H}_{2} \mathrm{O}$ and pentane, then dried in vacuo to yield 6 as a red solid (23 mg, 44\%). ${ }^{1} \mathrm{H}$ NMR (600 MHz, DMSO-d6) $\delta 8.81$ (d, $J=8.5 \mathrm{~Hz}, 1 \mathrm{H}), 8.56$ (d, $J=7.5 \mathrm{~Hz}, 1 \mathrm{H}), 8.53$ (d, $J=8.1 \mathrm{~Hz}, 1 \mathrm{H}), 8.45$ (s, 1H), 8.42 (s, 1H), 8.12 (d, $J=7.9 \mathrm{~Hz}, 1 \mathrm{H}), 7.83$ (s, 1H), 7.78 (s, 1H), 7.66 (dd, $J=8.6,7.5 \mathrm{~Hz}, 1 \mathrm{H}), 1.46$ (s, $18 \mathrm{H}) .{ }^{13} \mathrm{C}$ NMR (151 MHz, DMSO-d $) \delta$ 206.47, 174.41, 170.33, 168.64, 149.25, 149.11, 134.71, 134.15, 132.52, 130.90, 130.36, 129.57, 128.95, 128.63, 127.85, 125.44, 124.81, 124.23, 123.82, 120.92, 120.06, 119.63, 119.30, 34.84, 30.99. 
Methyl 4-(8,11-di-tert-butylperylen-3-yl)benzoate (8a): A flame dried two-neck r.b. flask was charged with 7 (340 mg, $0.77 \mathrm{mmol}$ ), (4-(methoxycarbonyl)phenyl)boronic acid (207 mg, 1.15 mmol), toluene $(1.5 \mathrm{~mL}), 1$-butanol $(0.75 \mathrm{~mL})$ and a $\mathrm{Cs}_{2} \mathrm{CO}_{3}$ aqueous solution $(2 \mathrm{~N}, 0.75 \mathrm{~mL})$ under nitrogen. $\mathrm{Pd}\left(\mathrm{PPh}_{3}\right)_{4}(44.5 \mathrm{mg}, 0.039 \mathrm{mmol})$ was then added under nitrogen flow and the mixture was refluxed with vigorous stirring for $3 \mathrm{~d}$. After cooling to room temperature, the mixture was diluted with brine and extracted with ethyl acetate (20 mL X 3). The combined organic layers were washed with $\mathrm{H}_{2} \mathrm{O}$ and brine, dried over $\mathrm{Na}_{2} \mathrm{SO}_{4}$ and filtered, and the solvent was removed in vacuo. Column chromatography (silica gel, hexanes : ethyl acetate $=10: 1$ ) of the solid residue yielded 8a as a bright yellow solid (232 mg, 61\%). ${ }^{1} \mathrm{H}$ NMR $\delta 8.30-8.24(\mathrm{~m}, 4 \mathrm{H}), 8.18(\mathrm{~d}, J=$ $8.3 \mathrm{~Hz}, 2 \mathrm{H}), 7.69$ (d, $J=8.4,0.9 \mathrm{~Hz}, 1 \mathrm{H}), 7.68-7.65$ (m, 2H), 7.62 (d, $J=8.2 \mathrm{~Hz}, 2 \mathrm{H}), 7.47$ 7.41 (m, 2H), 3.99 (s, 3H), 1.49 (s, 18H).HRMS (ESI): calculated for $\mathrm{C}_{34} \mathrm{H}_{3} \mathrm{O}_{2}, 499.2637$ $[\mathrm{M}+\mathrm{H}]^{+}$; found, $499.26397[\mathrm{M}+\mathrm{H}]^{+}$

4-(8,11-di-tert-Butylperylen-3-yl)benzoic acid (8b): To a solution of 8a (100 mg, $0.2 \mathrm{mmol})$ in methanol $(5 \mathrm{~mL}), \mathrm{KOH}$ solution $(1 \mathrm{~N}$ in water, $5 \mathrm{~mL})$ was added in one portion. The mixture was heated to reflux and stirred overnight. After cooling to room temperature, the mixture was acidified with $\mathrm{HCl}$ (10\% aq.) resulting in a bright yellow powder suspension. The suspension was collected by filtration, washed with water, and hexane to yield $\mathbf{8 b}$ (90 mg, 90\%). ${ }^{1} \mathrm{H}$ NMR $\delta 8.32$ - 8.24 (m, 6H), 7.71 (d, $J=8.4 \mathrm{~Hz}, 1 \mathrm{H}), 7.69-7.64$ (m, 4H), $7.49-7.43$ (m, 2H), 1.50 (d, $J=2.7$ Hz, 18H). ${ }^{13} \mathrm{C}$ NMR $\delta 171.74,149.35,149.33,146.94,138.47,134.86,132.89,132.12,132.00$, 130.57, 130.40, 130.35, 129.62, 128.28, 127.84, 126.92, 125.46, 125.41, 123.95, 123.82, 120.35, 119.65, 118.81, 118.67, 35.16, 31.52. HRMS (ESI): calculated for $\mathrm{C}_{33} \mathrm{H}_{32} \mathrm{O}_{2}, 484.2402$ [M] ${ }^{+}$; found, $484.24068[\mathrm{M}]^{+}$ 
4-(8,11-di-tert-Butylperylen-3-yl)aniline (9): A two-neck r.b. flask was charged with 7 (330 mg, 0.746 mmol), 4-(4,4,5,5-tetramethyl-1,3,2-dioxaborolan-2-yl)aniline (196 mg, 0.896 mmol), $1.41 \mathrm{~mL}$ of toluene, and $0.71 \mathrm{~mL}$ of 1 -butanol, and an aqueous solution of $\mathrm{K}_{2} \mathrm{CO}_{3}$ (206 mg in 0.72 $\mathrm{mL}$ of $\left.\mathrm{H}_{2} \mathrm{O}\right)$ under nitrogen. $\mathrm{Pd}\left(\mathrm{PPh}_{3}\right)_{4}(72 \mathrm{mg}, 8 \%)$ was added under nitrogen flow and the reaction was allowed to reflux at $120^{\circ} \mathrm{C}$ for 3 days. After cooling to room temperature, the mixture was filtered through a thin pad of Celite, extracted with ethyl acetate, washed with brine, dried over $\mathrm{Na}_{2} \mathrm{SO}_{4}$ and concentrated in vacuo. Purification of the residue via column chromatography (silica gel, hexanes: ethyl acetate $=10: 1$ ), yielded 9 as a brown solid (197mg, 58\%). ${ }^{1} \mathrm{H}$ NMR $\delta \delta$ $8.31-8.23$ (m, 4H), 7.85 (d, $J=8.4,0.9 \mathrm{~Hz}, 1 \mathrm{H}), 7.67-7.64$ (m, 2H), $7.46-7.41$ (m, 2H), 7.35 (d, $J=8.3 \mathrm{~Hz}, 2 \mathrm{H}), 6.83(\mathrm{~d}, J=8.3 \mathrm{~Hz}, 2 \mathrm{H}), 3.83(\mathrm{~s}, 2 \mathrm{H}), 1.50$ (s, 18H). ${ }^{13} \mathrm{C}$ NMR $\delta 171.23$, 149.15, 149.11, 145.84, 140.00, 134.80, 133.39, 131.77, 131.10, 131.01, 130.83, 130.70, 130.42, 129.58, 127.52, 126.21, 126.18, 125.41, 123.41, 123.26, 120.02, 119.77, 118.36, 118.06, 115.04, 60.48, 35.04, 31.43.

9-(4-Azidophenyl)-2,5-di-tert-butylperylene (10): A two-neck r.b. flask was charged with a solution of 9 (100 mg, $0.220 \mathrm{mmol}$ ) in 1,4-dioxane (2 mL) followed by the addition of $\mathrm{H}_{2} \mathrm{SO}_{4}$ (4N, aq., $2 \mathrm{~mL}$ ). The flask was then outfitted with a small addition funnel, degassed and backfilled with nitrogen, then the mixture was stirred for $30 \mathrm{~min}$ in an ice bath. Once sufficiently cooled, a sodium nitrite solution (18 $\mathrm{mg}, 0.263 \mathrm{mmol}$ in $5 \mathrm{ml} \mathrm{H}_{2} \mathrm{O}$ ) was added dropwise via addition funnel and the reaction was stirred for $45 \mathrm{~min}$ in an ice bath. Finally, a solution of $\mathrm{NaN}_{3}$ (17 $\left.\mathrm{mg}, 0.263 \mathrm{mmol}\right)$ in $\mathrm{H}_{2} \mathrm{O}(5 \mathrm{~mL})$ was added dropwise via addition funnel and the mixture allowed to stir in an ice bath and slowly warm to room temperature (overnight). The reaction mixture was then extracted with ethyl acetate, and the combined organic layers were washed with brine, dried over $\mathrm{Na}_{2} \mathrm{SO}_{4}$ and concentrated in vacuo. Purification of the crude product via column chromatography (silica gel, 
hexanes : ethyl acetate $=10: 1)$, gave $\mathbf{1 0}$ as a dark brown glassy solid (36 mg, 34\%). $\underline{\text { CAUTION: }}$ organic azides and $\mathrm{NaN}_{3}$ may decompose explosively. Azide waste should not come in contact with concentrated acids or metals. ${ }^{1} \mathrm{H}$ NMR $\delta \delta 8.28-8.23(\mathrm{~m}, 4 \mathrm{H}), 7.71(\mathrm{~d}, J=8.4 \mathrm{~Hz}, 1 \mathrm{H})$, 7.65 (s, 2H), 7.52 (d, $J=8.4 \mathrm{~Hz}, 2 \mathrm{H}), 7.47-7.39$ (m, 2H), 7.18 (d, $J=8.4 \mathrm{~Hz}, 1 \mathrm{H}), 1.49$ (d, $J=$ $1.7 \mathrm{~Hz}, 18 \mathrm{H}) .{ }^{13} \mathrm{C}$ NMR $\delta 149.23,139.27,138.67,137.81,134.83,133.15,132.01,131.51,131.36$, 130.64, 130.46, 129.59, 128.97, 127.73, 126.62, 125.59, 125.40, 123.68, 120.19, 119.65, 119.17, 118.63, 118.41, 35.10, 31.48. HRMS (ESI): calculated for $\mathrm{C}_{34} \mathrm{H}_{31} \mathrm{~N}_{3}, 481.25180[\mathrm{M}]^{+}$; found, 481.25241 [M] ${ }^{+}$IR (FTIR): 821.5269, 836.9546, 877.4524, 908.3079, 958.448 977.7327, 1089.584, 1110.797, 1130.082, 1182.15, 1209.149, 1259.289, 1290.144, 1347.998, 1363.426, 1374.997, 1392.353, 1427.065, 1465.635, 1477.206, 1504.204, 1600.627, 1623.769, 2088.53, 2121.313, 2856.059, 2867.63, 2925.484, $2962.125 \mathrm{~cm}-1$

\section{Ethyl 1-(4-(8,11-di-tert-butylperylen-3-yl)phenyl)-1H-1,2,3-triazole-4-carboxylate (11a): A}

two-neck r.b. flask was charged with a mixture of $\mathbf{1 0}(30 \mathrm{mg}, 0.062 \mathrm{mmol})$ in $\mathrm{H}_{2} \mathrm{O}$ :THF (2:1, 6 $\mathrm{mL}$ ) followed by the addition of ethyl propiolate $(12 \mathrm{mg}, 0.124 \mathrm{mmol})$. To the resulting suspension, sodium ascorbate ( $2.5 \mathrm{mg}, 0.0124 \mathrm{mmol}$ ) and copper sulfate (2 mg, 10\%) were added, the flask was degassed and backfilled with nitrogen and stirred for 5 days. The reaction mixture was than diluted with water, extracted with ethyl acetate, washed with brine, and dried over $\mathrm{Na}_{2} \mathrm{SO}_{4}$ then concentrated in vacuo. Purification of the crude product via column chromatography (silica gel, hexanes: ethyl acetate $=10: 1)$ to yield 11a as a brown glassy solid (35 mg, 97\%). ${ }^{1} \mathrm{H}$ NMR $\delta 8.59$ (s, 1H), $8.31-8.26$ (m, 4H), $7.92-7.86$ (m, 2H), $7.73-7.66$ (m, 6H), 7.47 (dd, $J=8.4,7.4 \mathrm{~Hz}$, 1H), 7.43 (d, $J=7.6 \mathrm{~Hz}, 1 \mathrm{H}), 4.51$ (q, $J=7.1 \mathrm{~Hz}, 2 \mathrm{H}), 1.50$ (d, $J=2.8 \mathrm{~Hz}, 18 \mathrm{H}), 1.48$ (t, $J=7.3$ Hz, 3H). ${ }^{13} \mathrm{C}$ NMR $\delta$ 160.59, 149.10, 149.07, 142.38, 140.89, 137.48, 135.34, 134.59, 132.71, 131.91, 131.74, 131.40, 130.25, 130.02, 129.36, 127.62, 126.70, 125.39, 125.12, 124.98, 123.73, 
123.61, 120.72, 120.09, 119.36, 118.58, 118.40, 61.48, 34.89, 31.25, 14.29. HRMS (ESI): calculated for $\mathrm{C}_{39} \mathrm{H}_{37} \mathrm{~N}_{3} \mathrm{O}_{2}, 580.29640[\mathrm{M}+\mathrm{H}]^{+}$; found, 580.29694 [M+H] ${ }^{+}$IR (FT-IR): 3133, 2954, 2919, 2850, 1704, 1599, 1541, 1462, 1365, 1252, 1173, 1147, 1090, 1038, 874, 835 cm-1.

1-(4-(8,11-di-tert-Butylperylen-3-yl)phenyl)-1H-1,2,3-triazole-4-carboxylic acid (11b): A two-neck r.b. flask was charged with a solution of 11a (11mg, 0.019mmol) in THF (10mL) under nitrogen. $\mathrm{LiOH}$ (8 $\mathrm{mg}, 0.19 \mathrm{mmol}$ ) was then added and the reaction was allowed to stir overnight. The reaction was then acidified with $\mathrm{HCl}(1 \mathrm{~N}, \mathrm{aq})$ and the precipitate was filtered, and triturated with water, then pentane to yield $\mathbf{1 1 b}$ as a dark brown solid (9 mg, 81\%). ${ }^{1} \mathrm{H}$ NMR (Methanol- $d 4$ ) $\delta 8.34-8.28$ (m, 4H), 7.93 (d, $J=7.9 \mathrm{~Hz}, 2 \mathrm{H}), 7.67$ (s, 2H), $7.65-7.58$ (m, 3H), 7.44 (dd, $J=7.9$ Hz, 1H), 7.38 (d, $J=7.6 \mathrm{~Hz}, 1 \mathrm{H}), 1.49$ (d, $J=3.1 \mathrm{~Hz}, 18 \mathrm{H}) .{ }^{13} \mathrm{C}$ NMR (Methanol-d4) $\delta$ 172.97, 150.46, 150.43, 143.44, 139.10, 136.29, 134.03, 133.09, 132.79, 132.40, 131.57, 131.36, 130.57, 128.98, 127.97, 126.40, 126.16, 124.92, 124.81, 124.21, 121.78, 121.36, 120.73, 119.71, 119.54, 48.71, 34.75, 31.73. HRMS (ESI): calculated for $\mathrm{C}_{37} \mathrm{H}_{33} \mathrm{~N}_{3} \mathrm{O}_{2}, 552.26510[\mathrm{M}+\mathrm{H}]^{+}$; found, $552.26468[\mathrm{M}+\mathrm{H}]^{+}$ 


\section{${ }^{1} \mathrm{H}$ and ${ }^{13} \mathrm{C}$ NMR Figures}

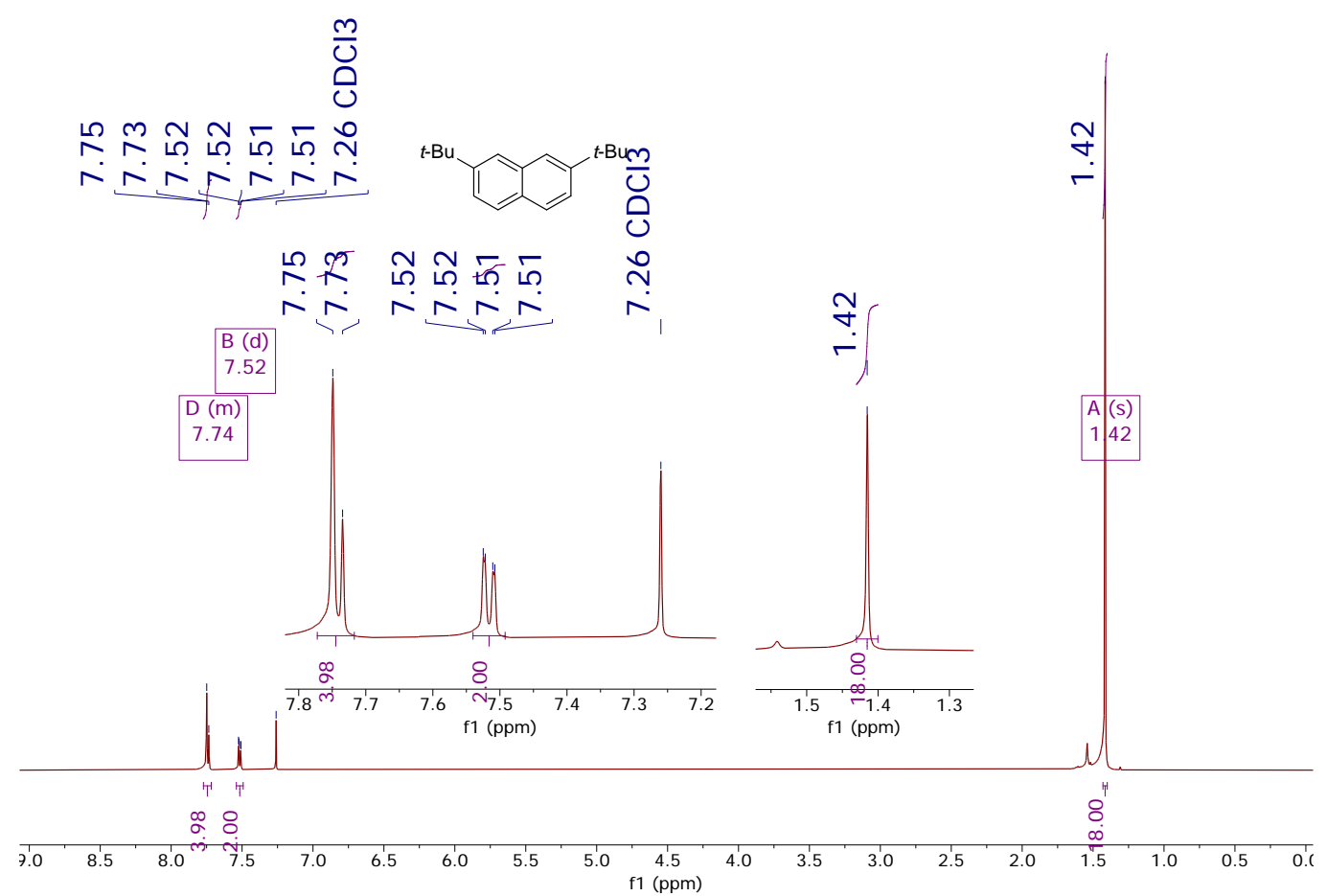

Figure S8. ${ }^{1} \mathrm{H}$ NMR of 2,7-di-tert-Butylnaphthalene (1a) in $\mathrm{CDCl}_{3}$

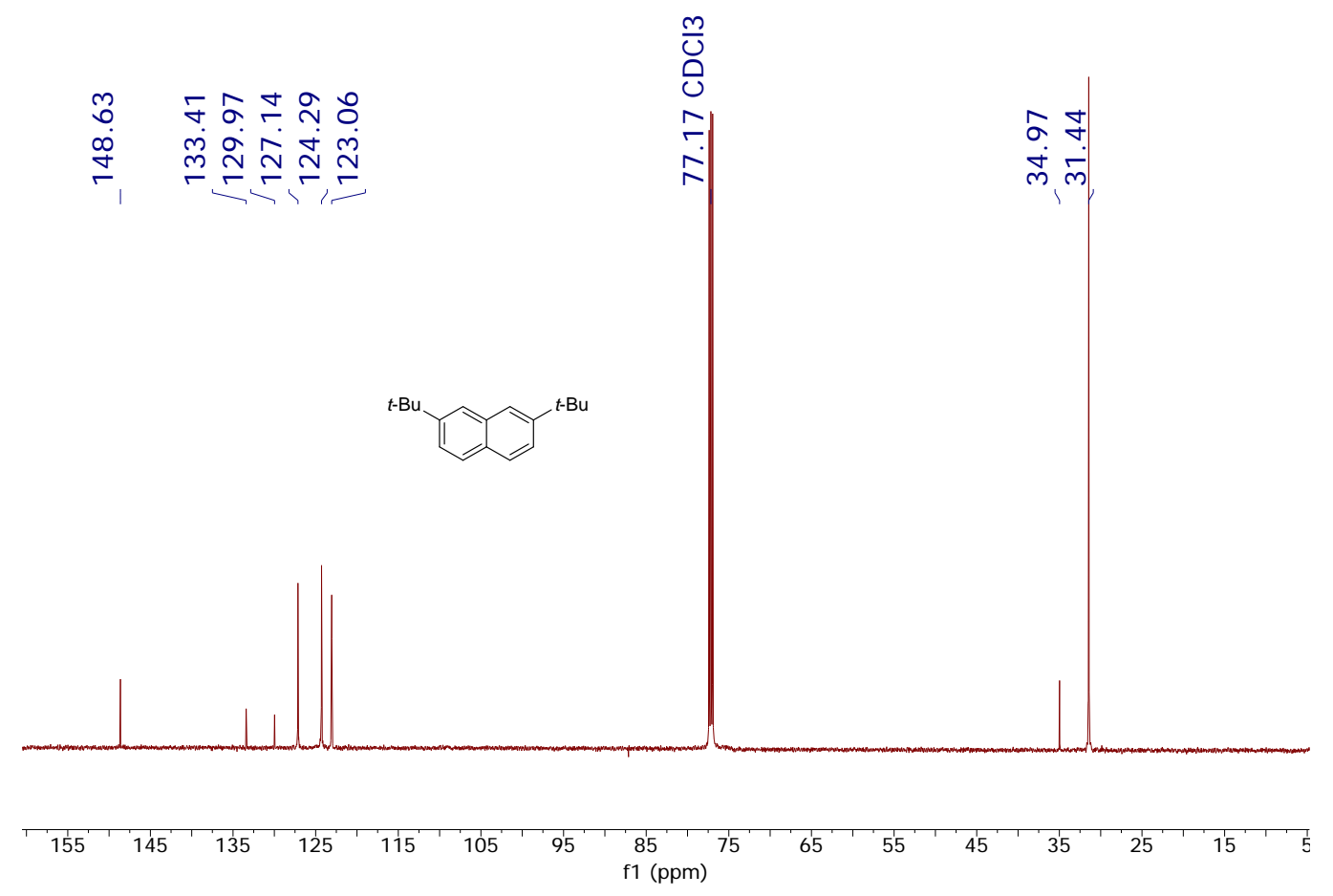

Figure S9. ${ }^{13} \mathrm{C}$ NMR of 2,7-di-tert-Butylnaphthalene (1a) in $\mathrm{CDCl}_{3}$ 


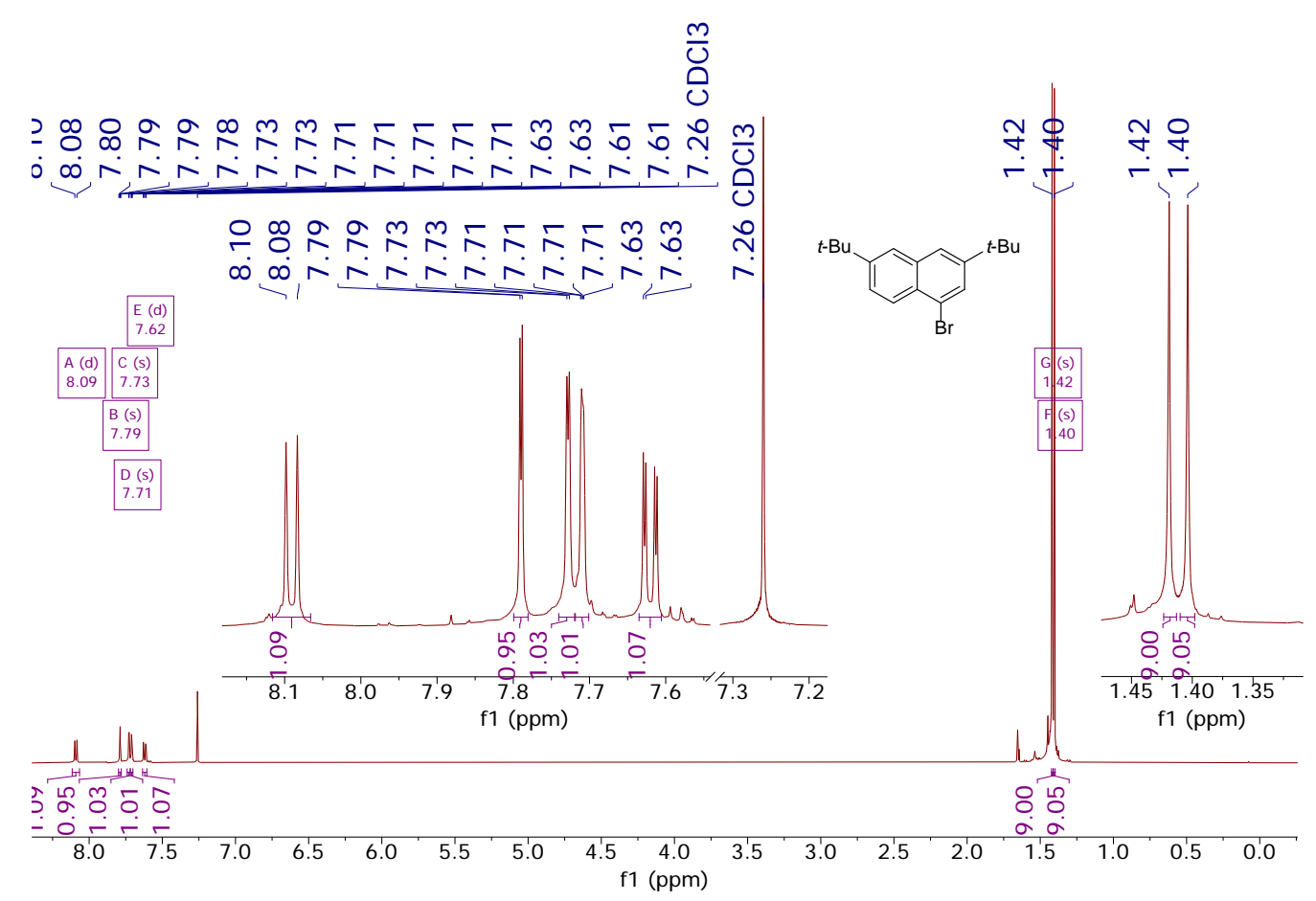

Figure S10. ${ }^{1} \mathrm{H}$ NMR of 1-Bromo-3,6-di-tert-Butylnaphthalene (2) in $\mathrm{CDCl}_{3}$

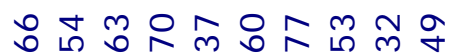

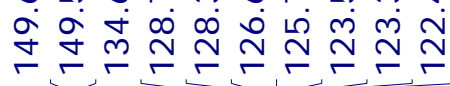
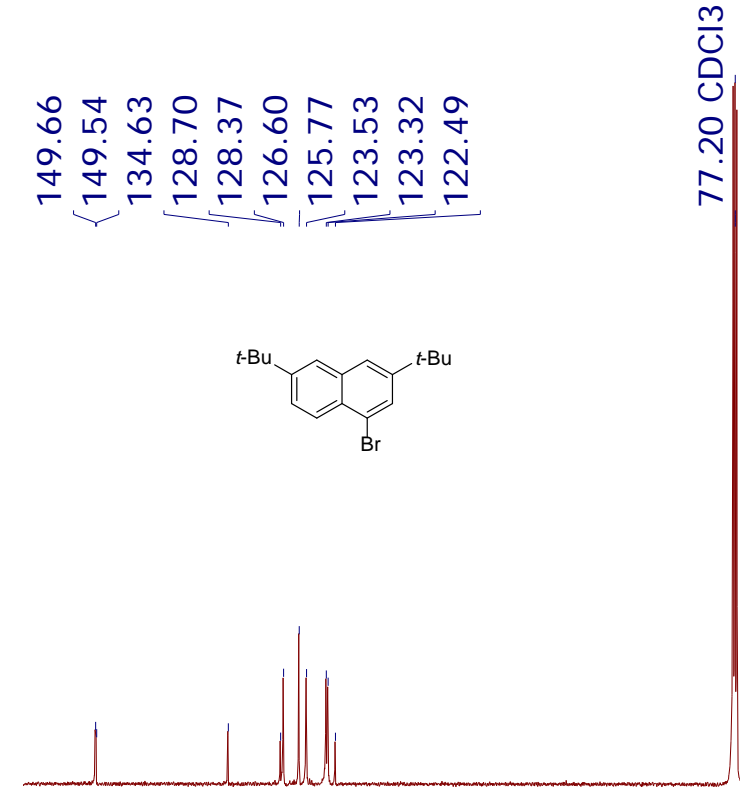

$\varnothing \infty$

กิ่ mें mं
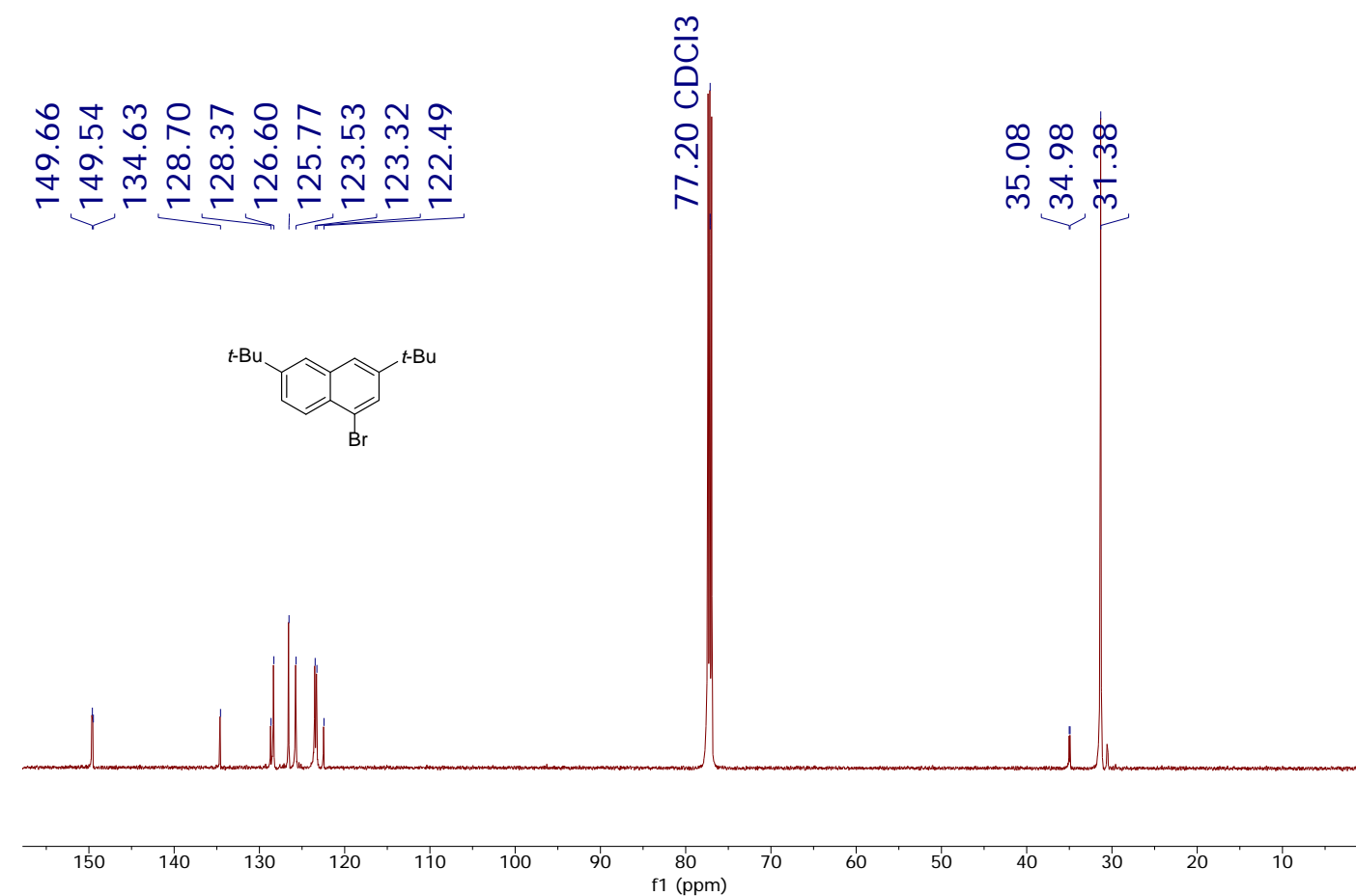

Figure S11. ${ }^{13} \mathrm{C}$ NMR of 1-Bromo-3,6-di-tert-Butylnaphthalene (2) in $\mathrm{CDCl}_{3}$ 
ผn̆

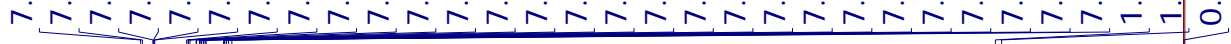

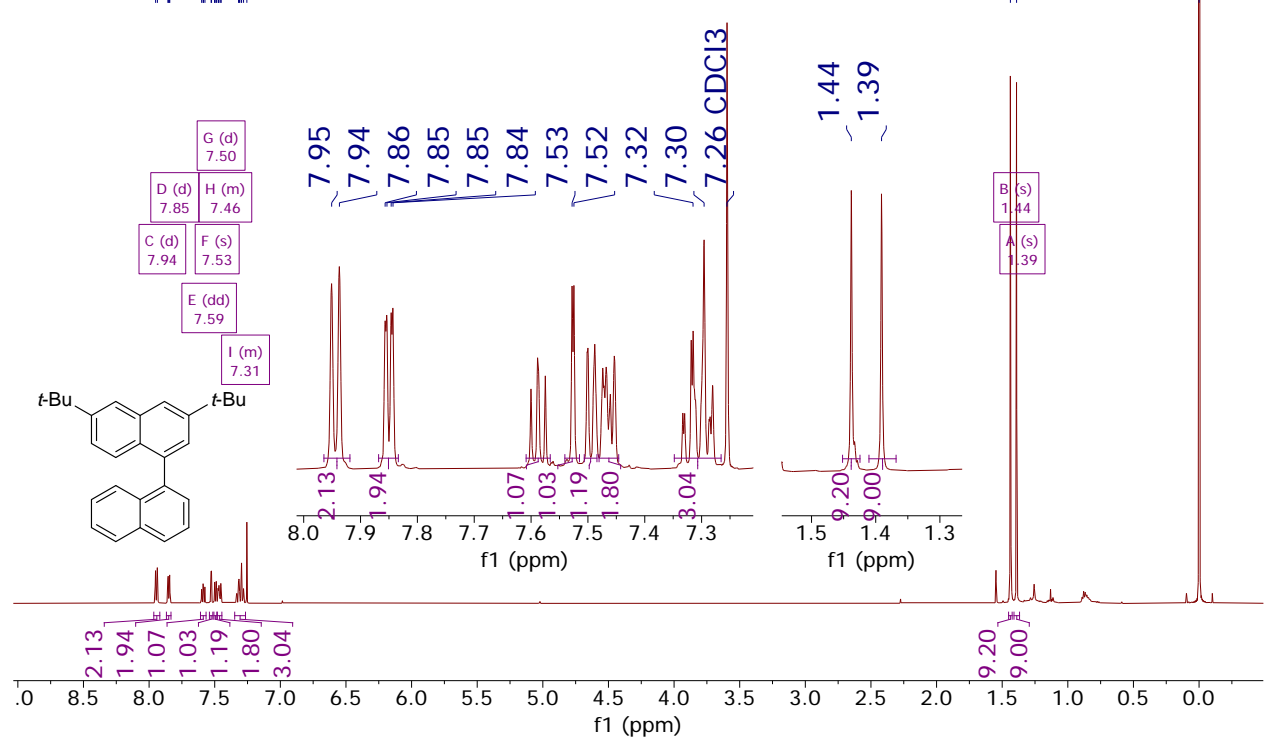

Figure S12. ${ }^{1} \mathrm{H}$ NMR of 3,6-di-tert-butyl-1,1'-Binaphthalene (3) in $\mathrm{CDCl}_{3}$

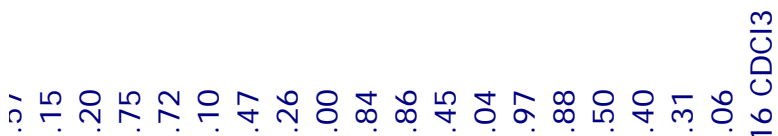

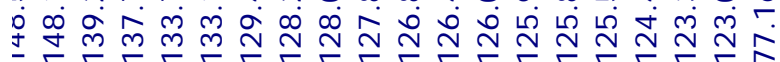

굴
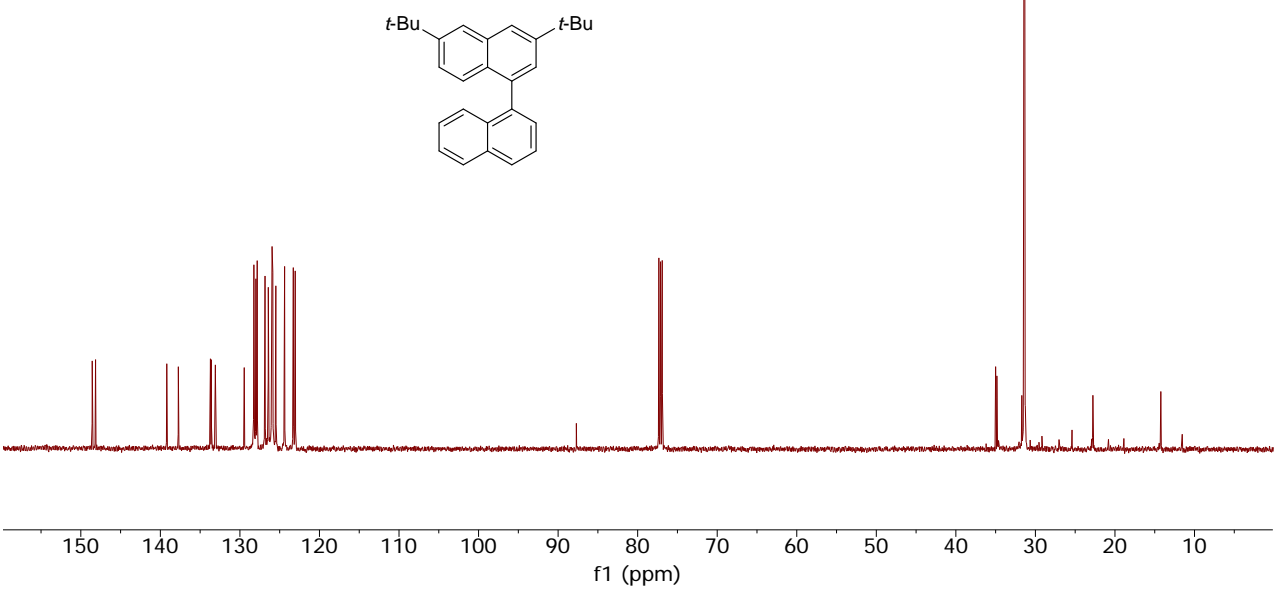

8왕ㅇ

மें $\dot{m} \dot{m} \dot{m}$

Figure S13. ${ }^{13} \mathrm{C}$ NMR of 3,6-di-tert-butyl-1,1'-Binaphthalene (3) in $\mathrm{CDCl}_{3}$ 


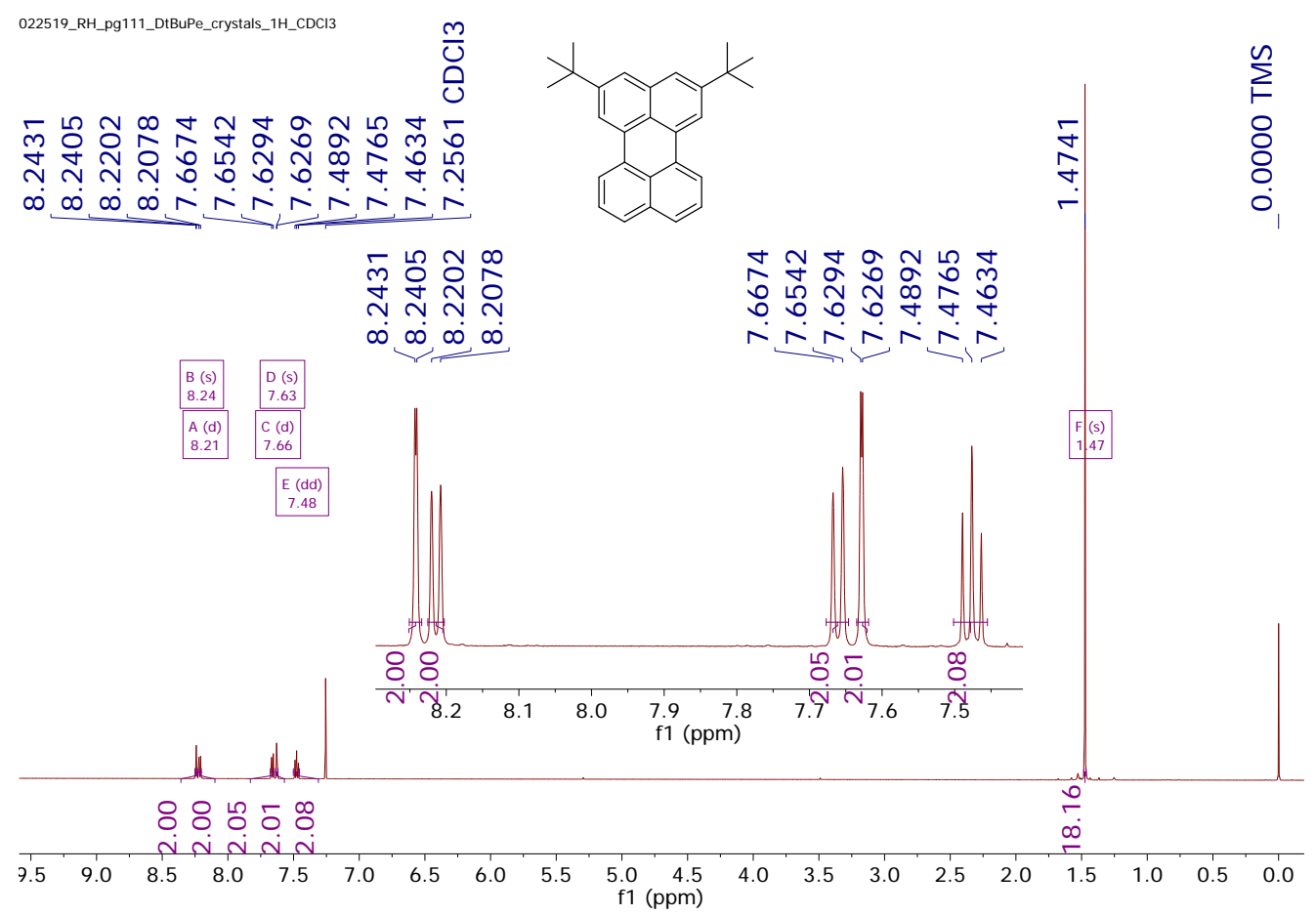

Figure S14. ${ }^{1} \mathrm{H}$ NMR of 2,5-di-tert-butylperylene (from potassium RouteA) (4) in $\mathrm{CDCl}_{3}$

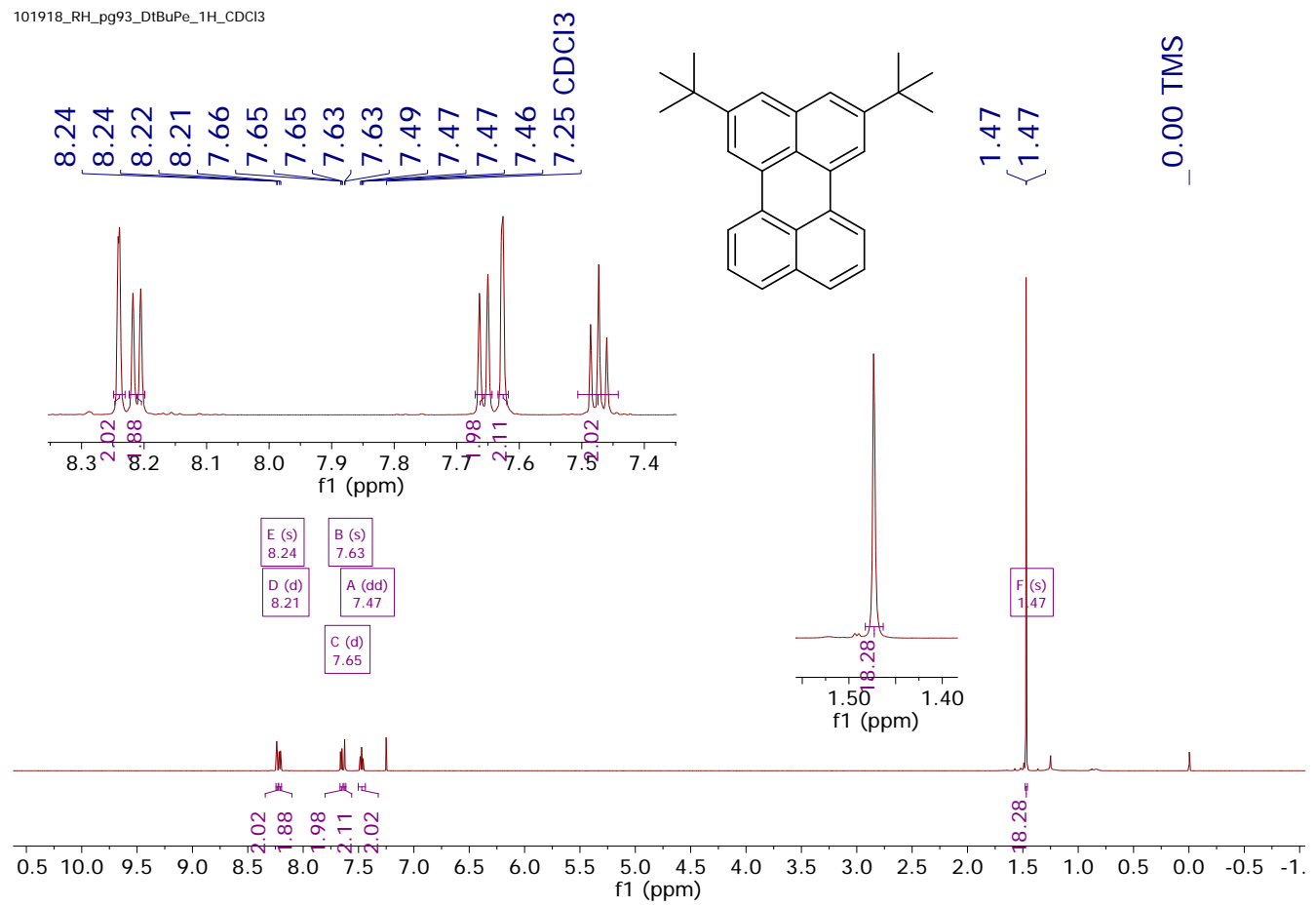

Figure S15. ${ }^{1} \mathrm{H}$ NMR of 2,5-di-tert-butylperylene (from Friedel-Crafts Route B) (4) in $\mathrm{CDCl}_{3}$ 


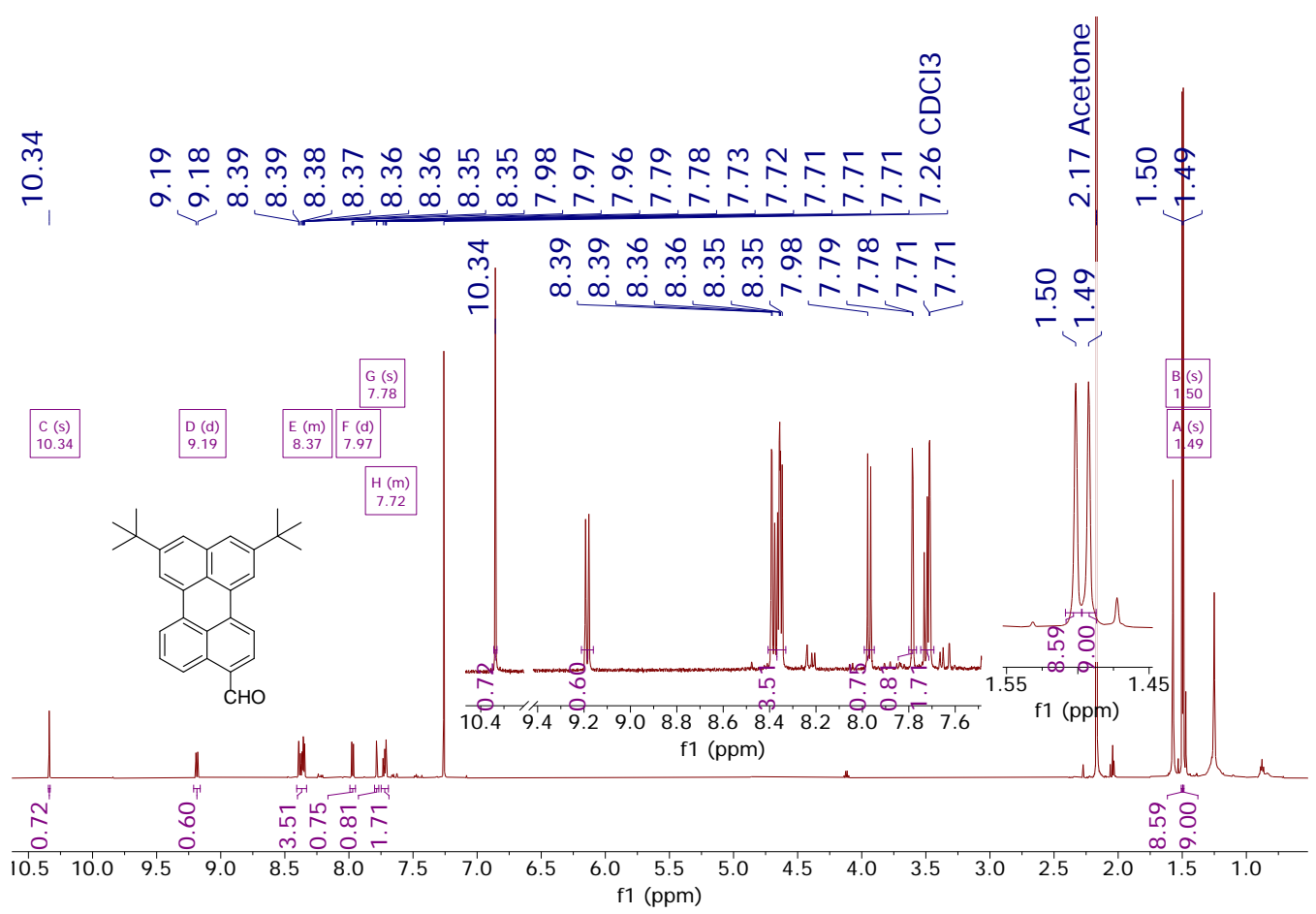

Figure S16. ${ }^{1} \mathrm{H}$ NMR of 8,11-di-tert-Butylperylene-3-carbaldehyde (5) in $\mathrm{CDCl}_{3}$

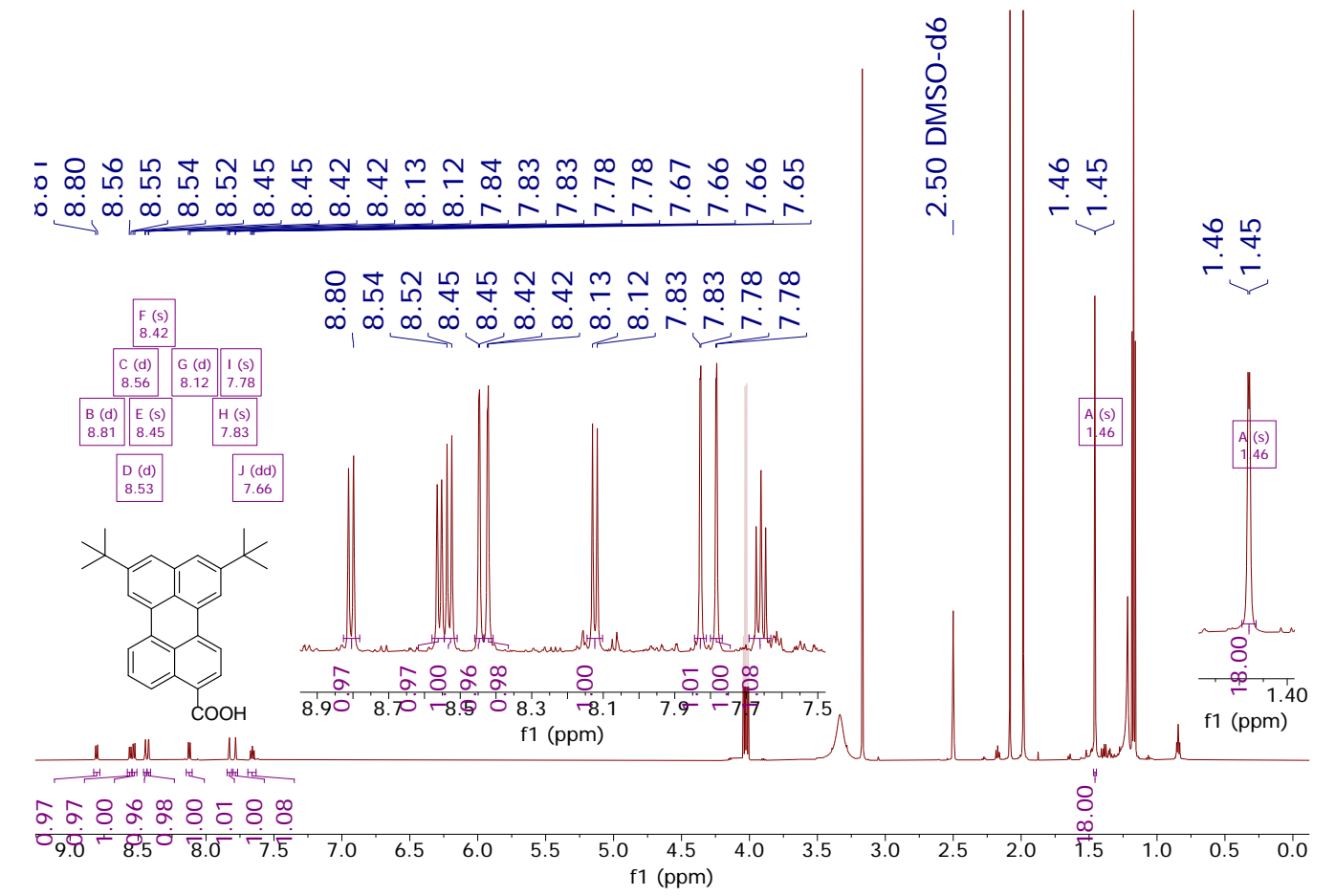

Figure S17. ${ }^{1} \mathrm{H}$ NMR of 8,11-di-tert-Butylperylene-3-carboxylic acid (6) in DMSO-d 6 

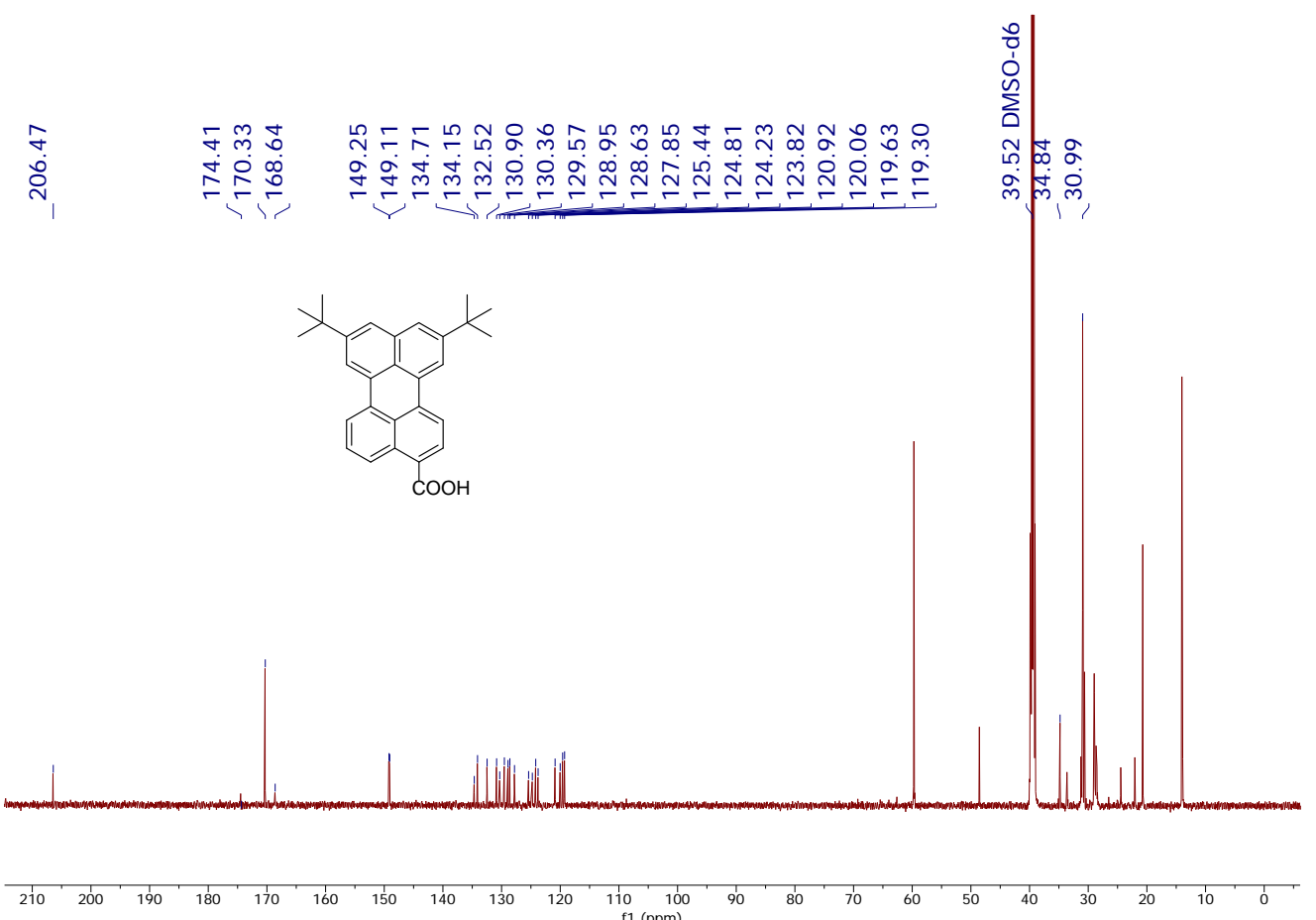

Figure S18. ${ }^{13} \mathrm{C}$ NMR of 8,11-di-tert-Butylperylene-3-carboxylic acid (6) in DMSO-d 6

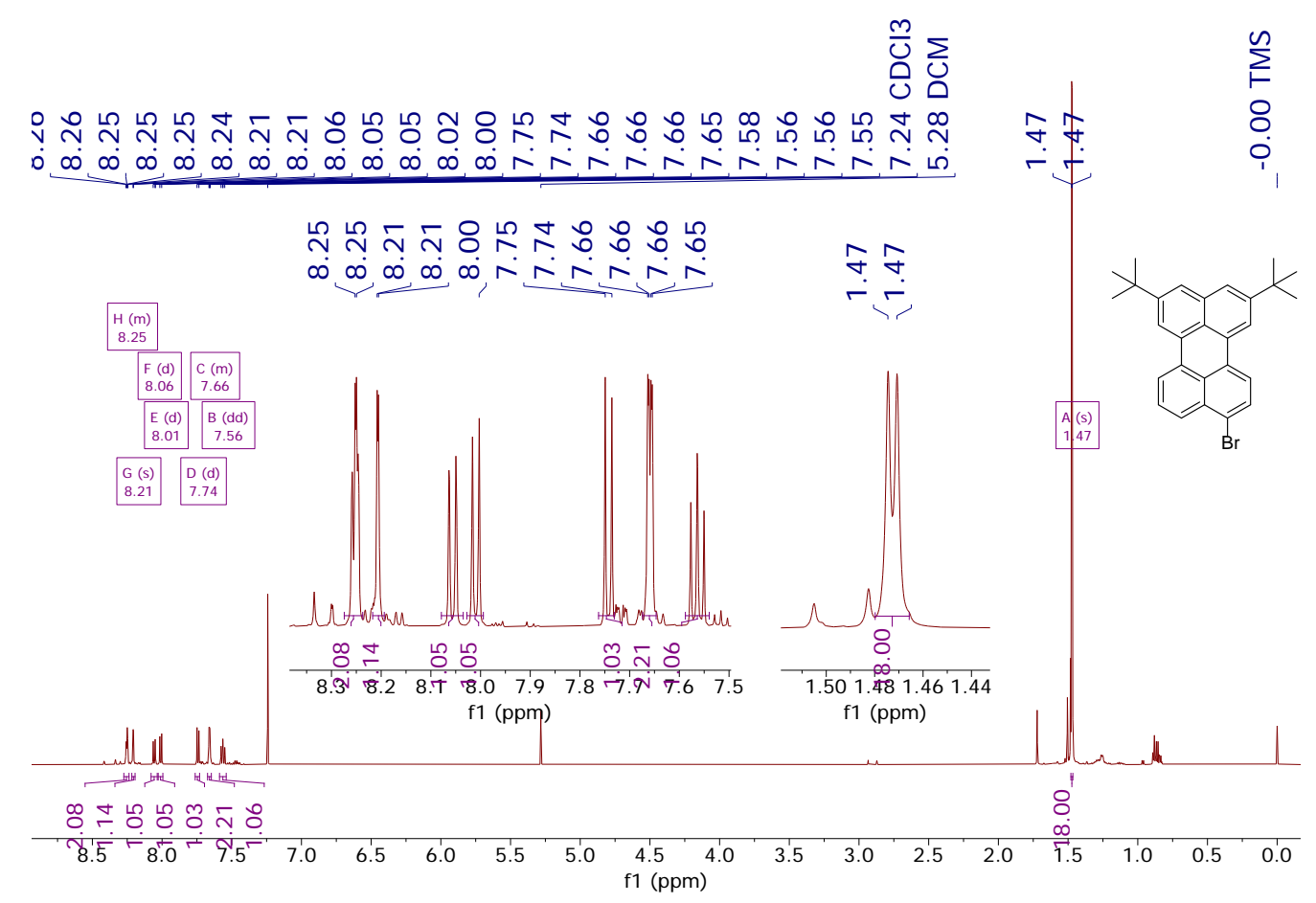

Figure S19. ${ }^{1} \mathrm{H}$ of 9-bromo-2,5-di-tert-Butylperylene (7) in $\mathrm{CDCl}_{3}$ 


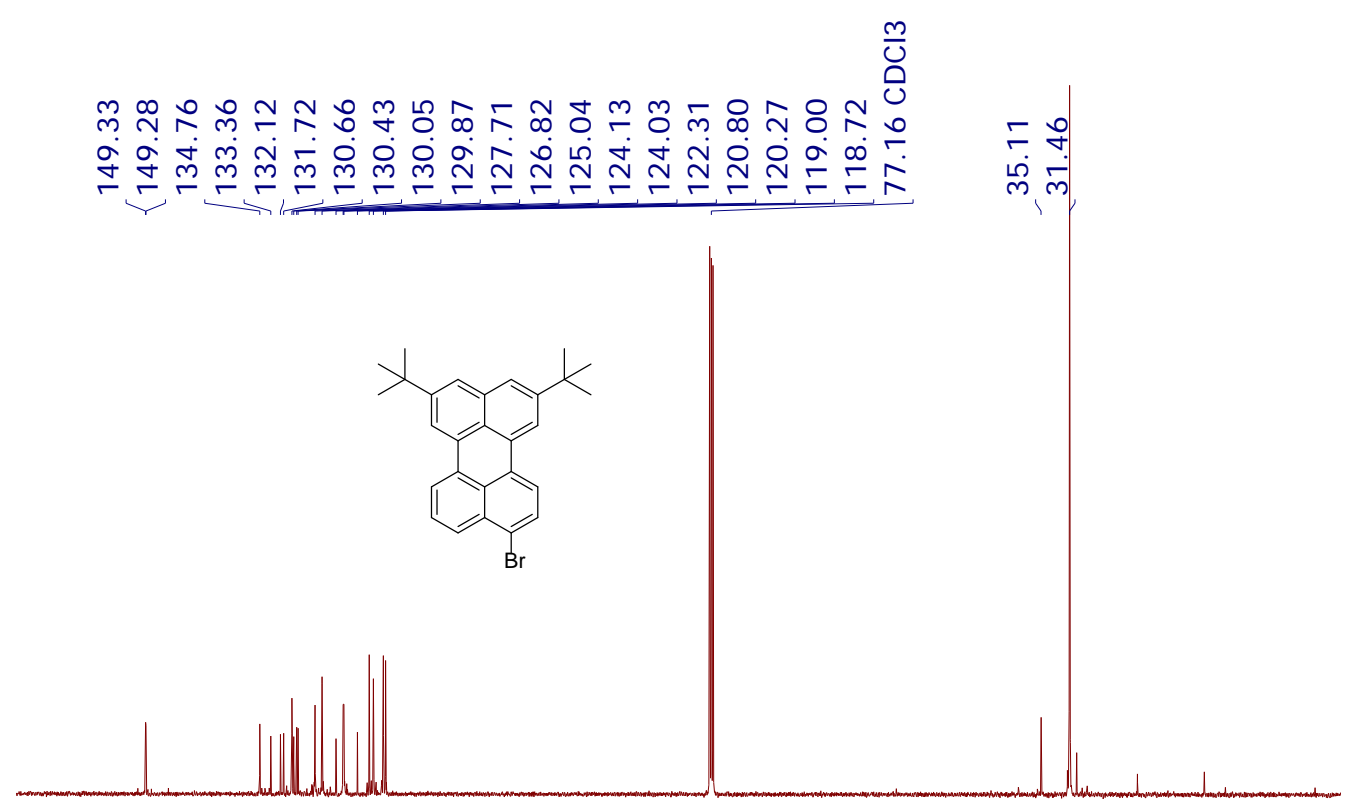

\begin{tabular}{lllllllllllllllll}
\hline 160 & 150 & 140 & 130 & 120 & 110 & 100 & 90 & $\begin{array}{c}80 \\
\mathrm{f} 1(\mathrm{ppm})\end{array}$ & 70 & 60 & 50 & 40 & 30 & 20 & 10 & 0 \\
\hline
\end{tabular}

Figure S20. ${ }^{13} \mathrm{C}$ of 9-bromo-2,5-di-tert-Butylperylene (7) in $\mathrm{CDCl}_{3}$

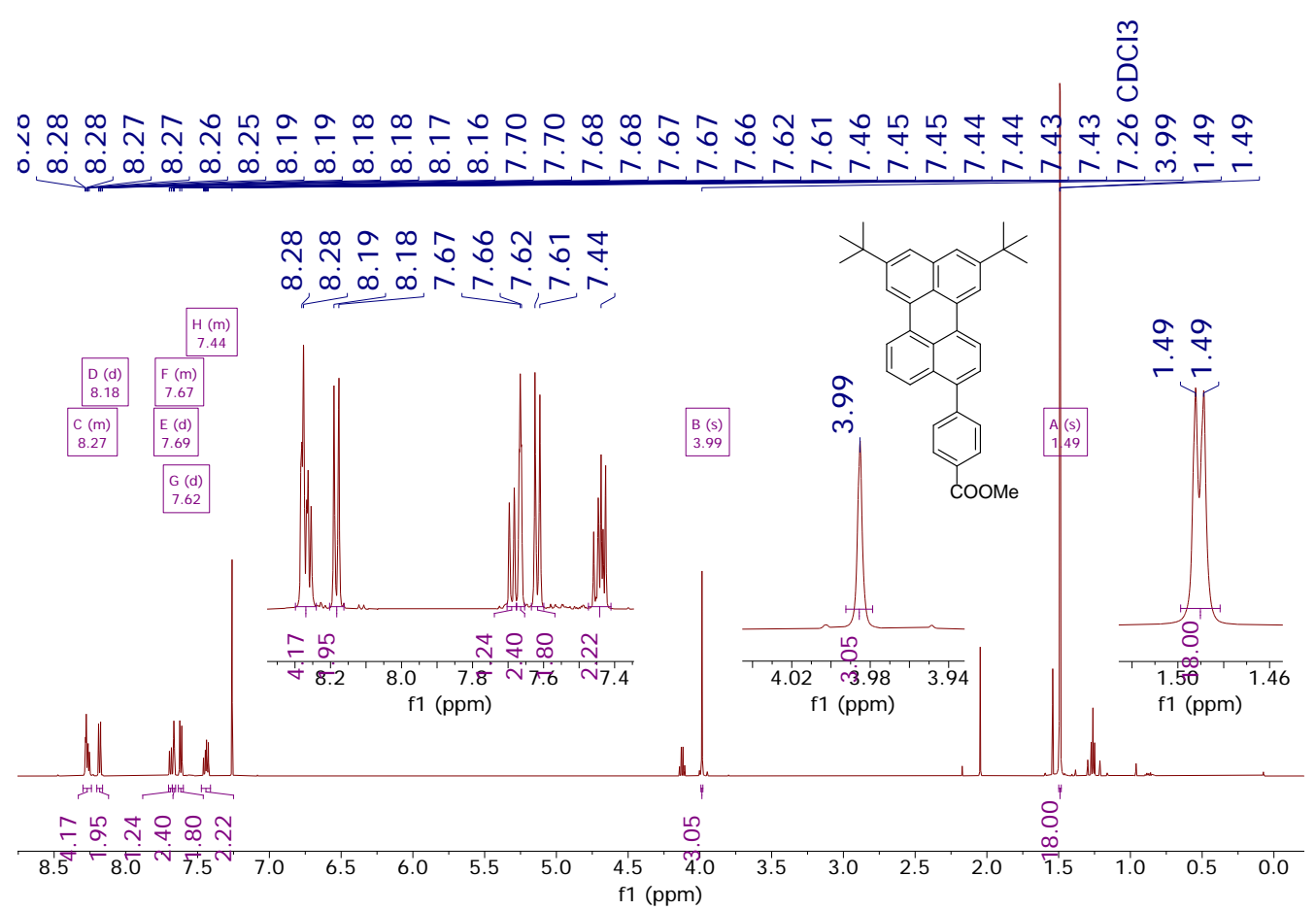

Figure S21. ${ }^{1} \mathrm{H}$ NMR of Methyl 4-(8,11-di-tert-butylperylen-3-yl)benzoate (8a) in $\mathrm{CDCl}_{3}$ 


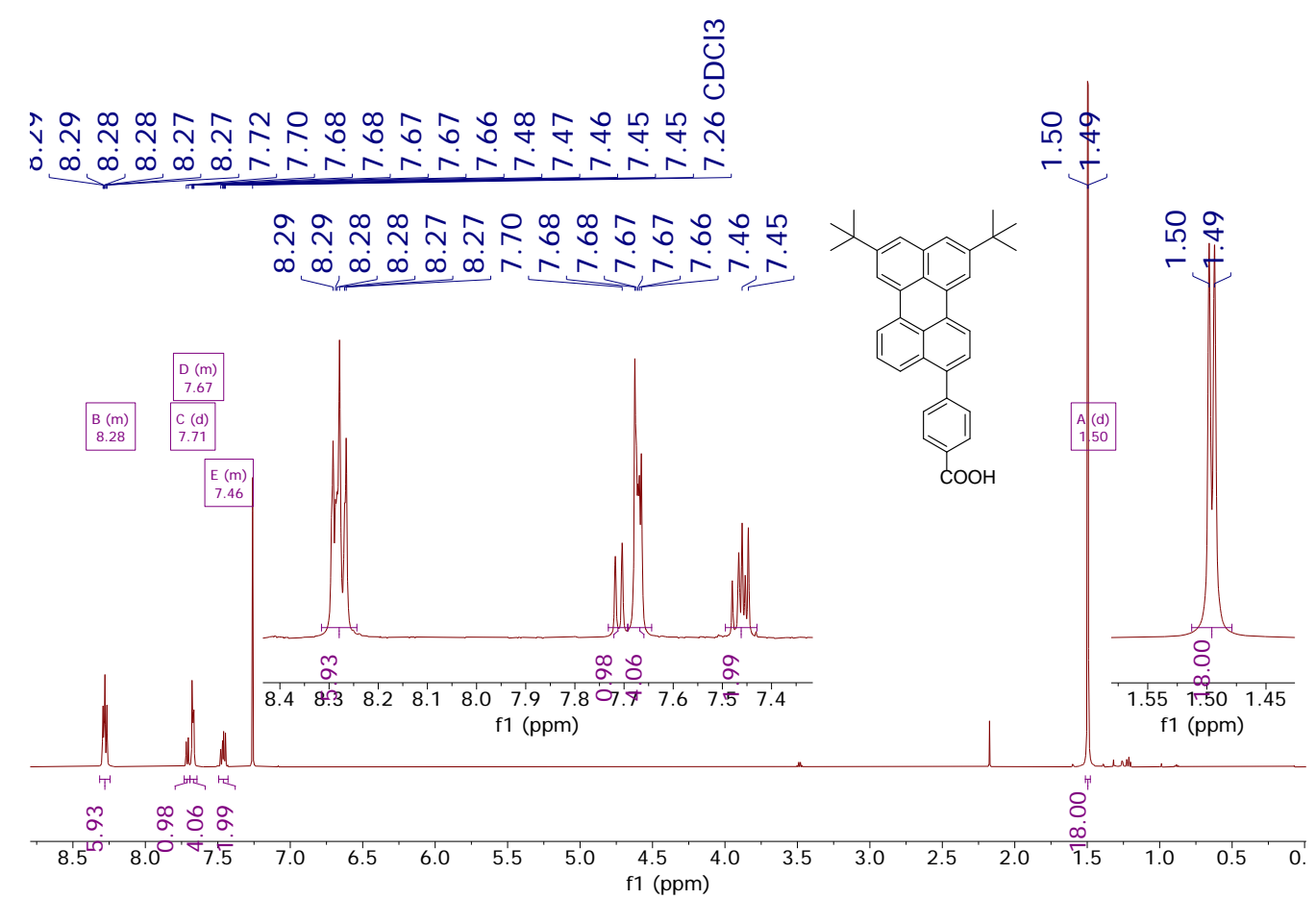

Figure S22. ${ }^{1} \mathrm{H}$ NMR of 4-(8,11-di-tert-Butylperylen-3-yl)benzoic acid (8b) in $\mathrm{CDCl}_{3}$

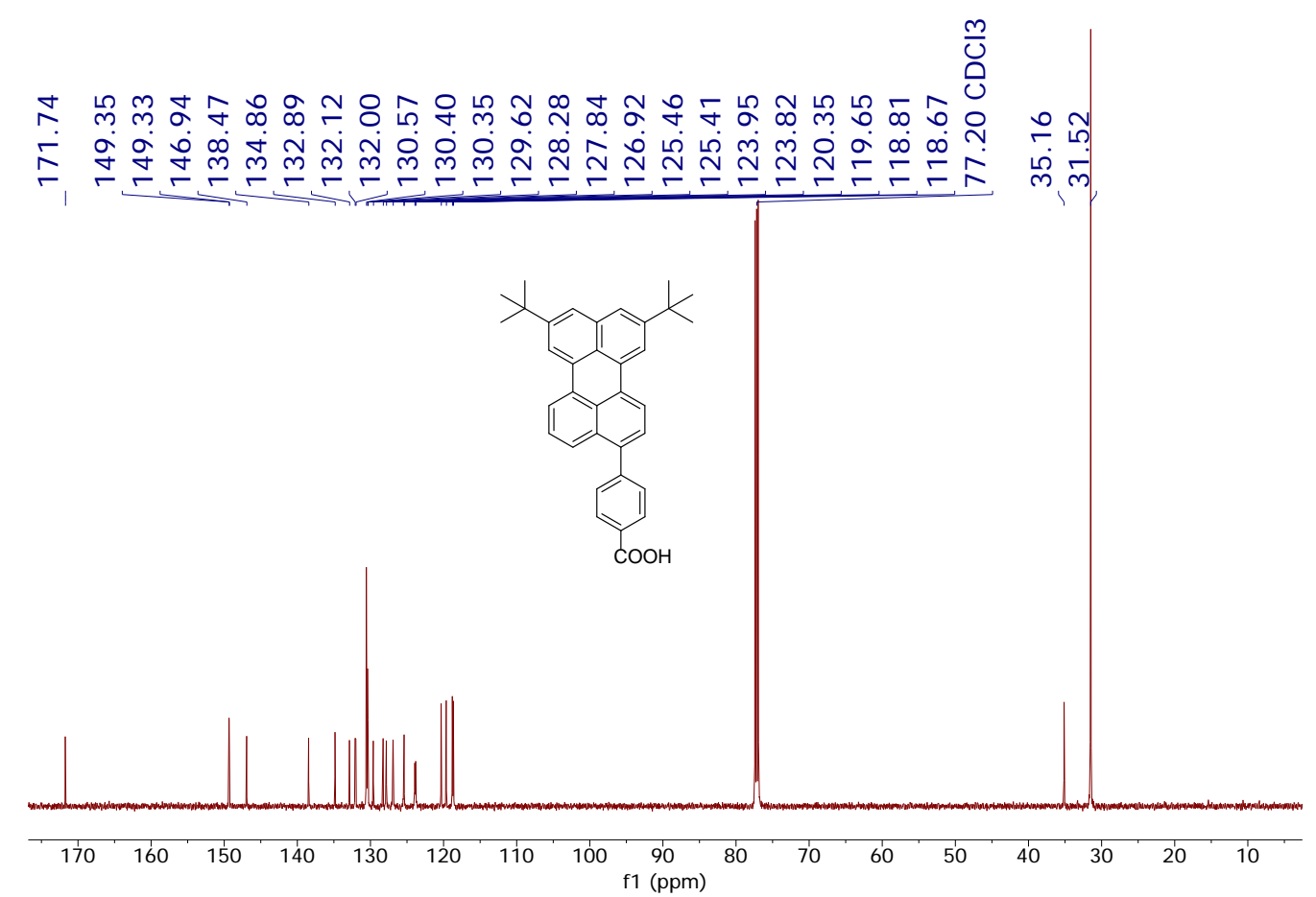

Figure S23. ${ }^{13} \mathrm{C}$ NMR of 4-(8,11-di-tert-Butylperylen-3-yl)benzoic acid (8b) in $\mathrm{CDCl}_{3}$ 
อั

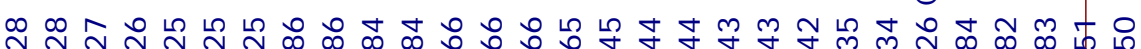

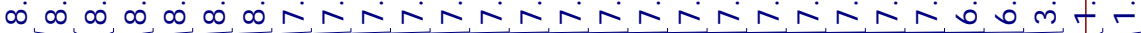

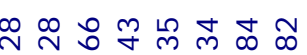

$\infty$
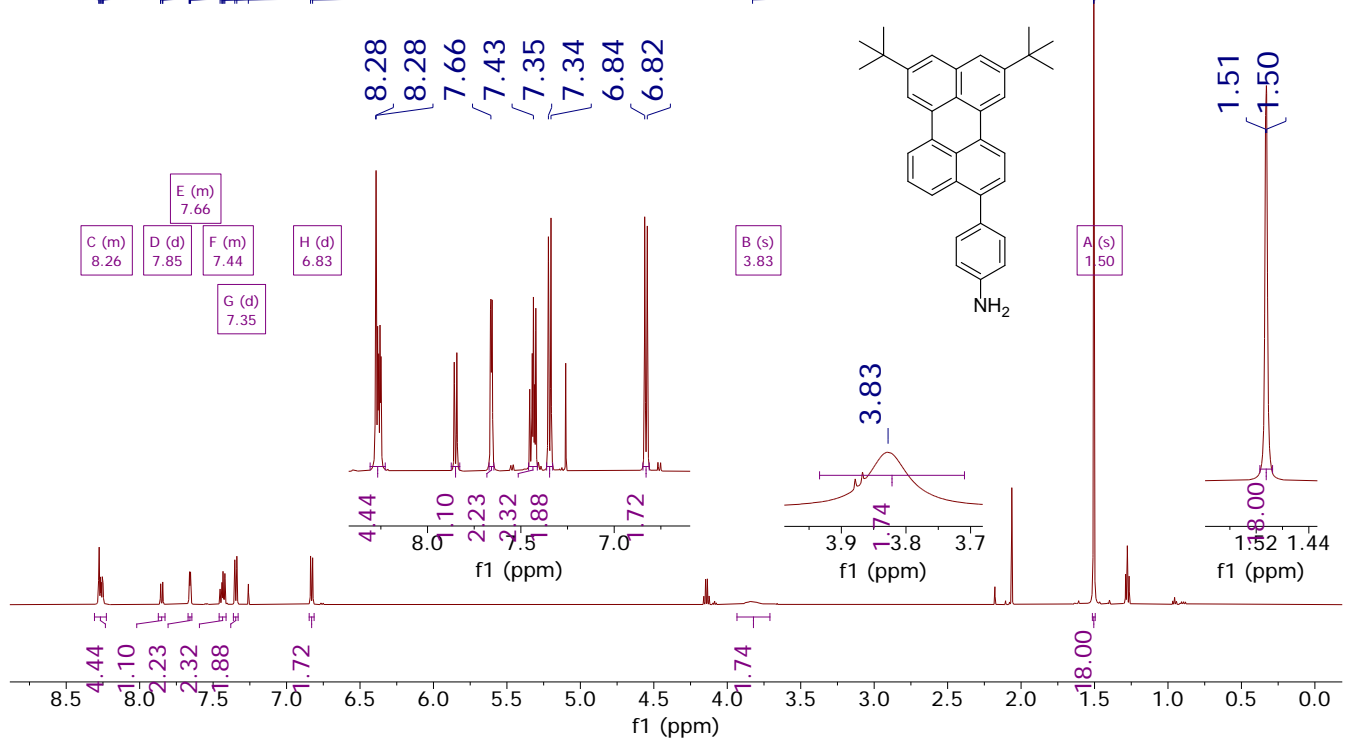

Figure S24. ${ }^{1} \mathrm{H}$ NMR of 4-(8,11-di-tert-Butylperylen-3-yl)aniline (9) in $\mathrm{CDCl}_{3}$
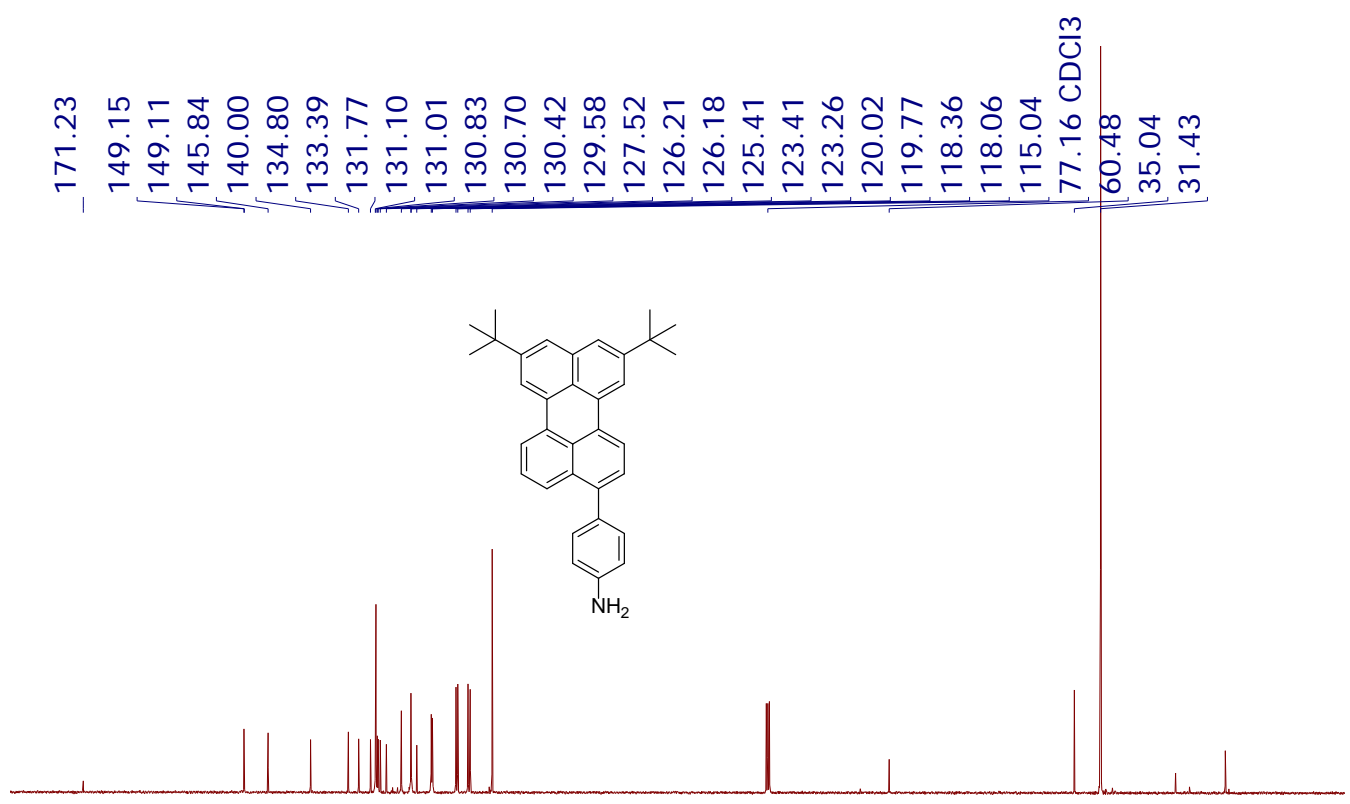

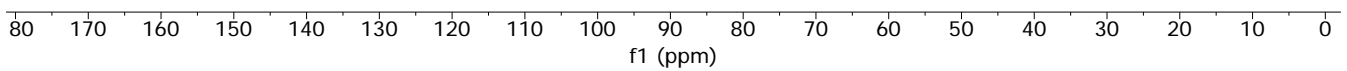

Figure S25. ${ }^{13} \mathrm{C}$ NMR of 4-(8,11-di-tert-Butylperylen-3-yl)aniline (9) in $\mathrm{CDCl}_{3}$ 


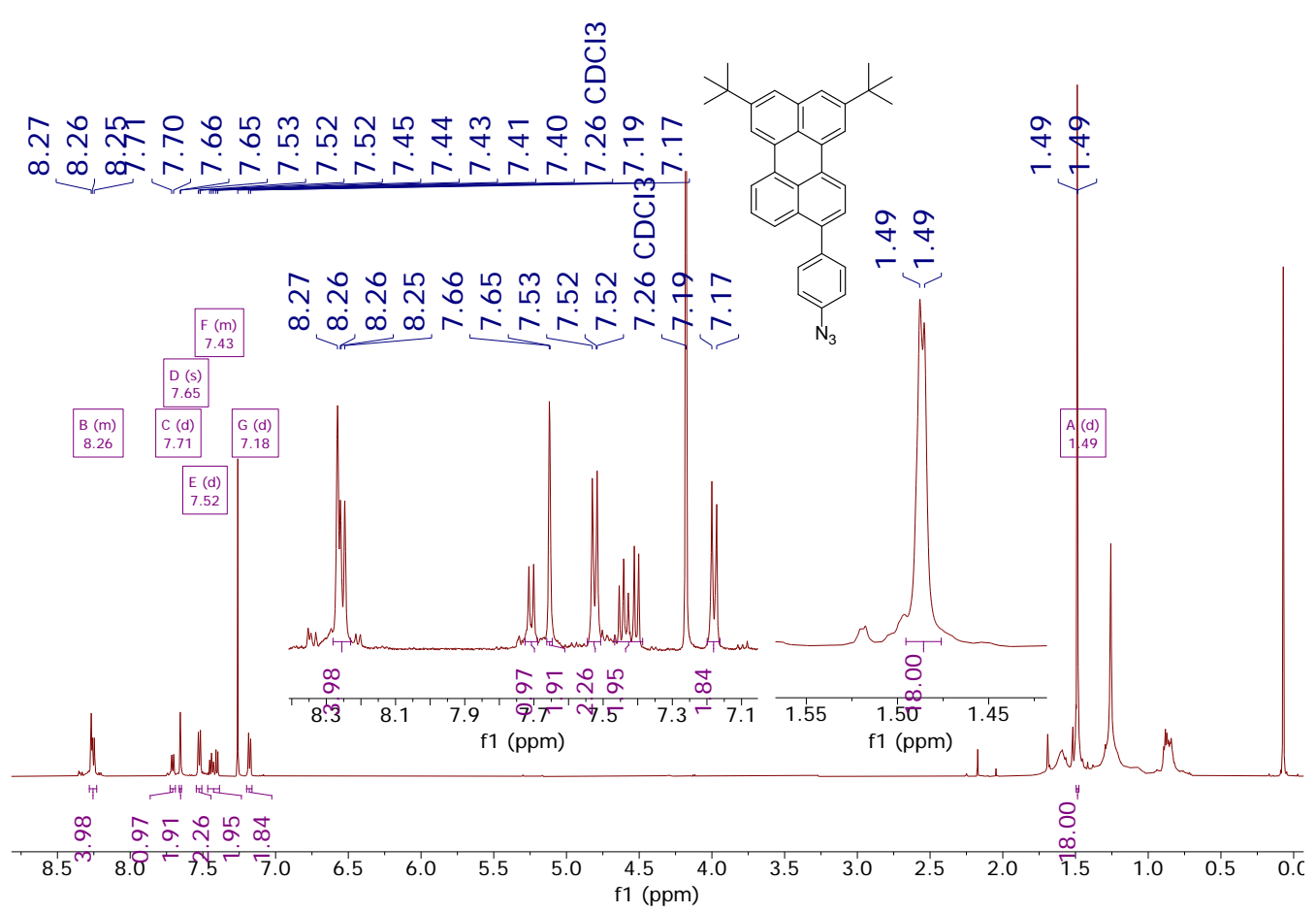

Figure S26. ${ }^{1} \mathrm{H}$ NMR of 9-(4-Azidophenyl)-2,5-di-tert-butylperylene (10) in $\mathrm{CDCl}_{3}$
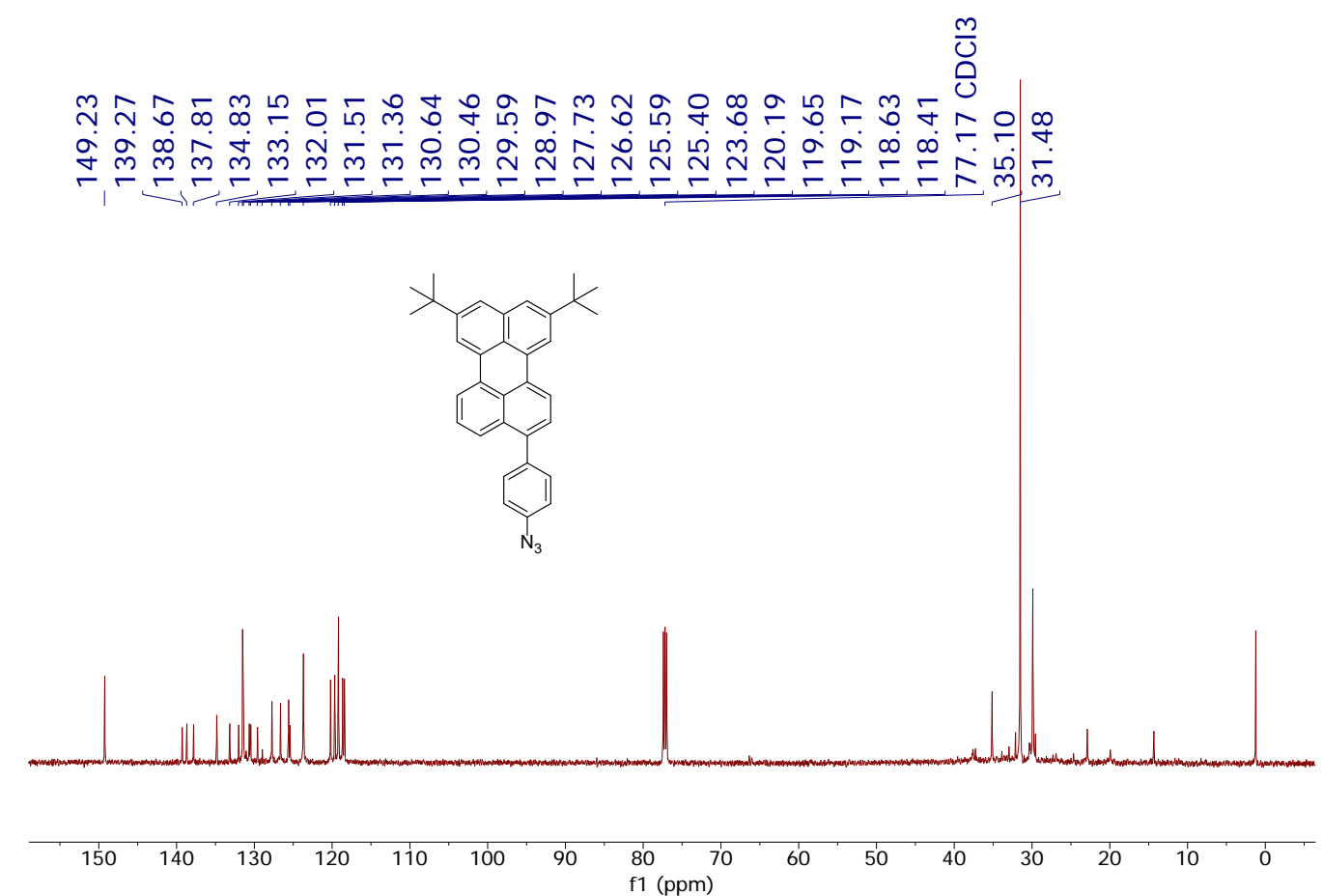

Figure S27. ${ }^{13} \mathrm{C}$ NMR of 9-(4-Azidophenyl)-2,5-di-tert-butylperylene (10) in $\mathrm{CDCl}_{3}$ 


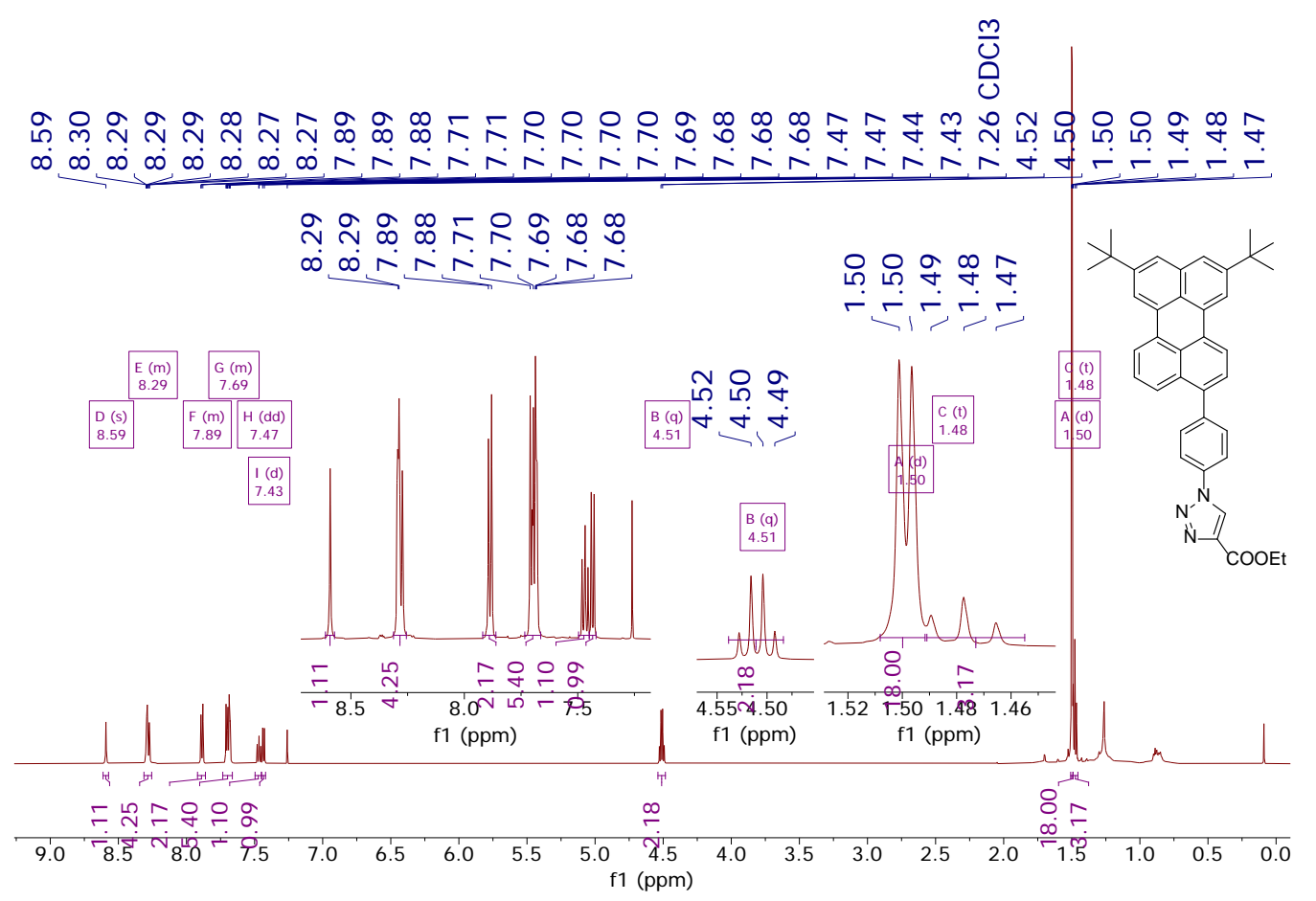

Figure S28. ${ }^{1} \mathrm{H}$ NMR of Ethyl 1-(4-(8,11-di-tert-butylperylen-3-yl)phenyl)-1H-1,2,3-triazole-4carboxylate (11a) in $\mathrm{CDCl}_{3}$

บู

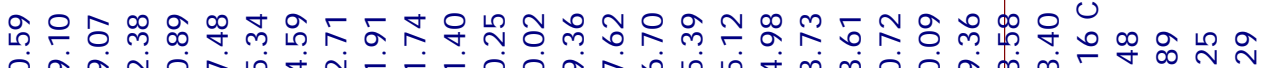

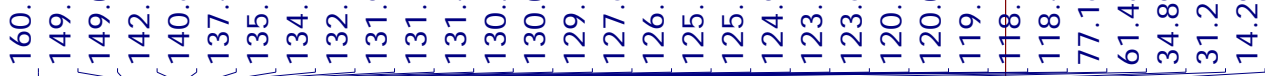

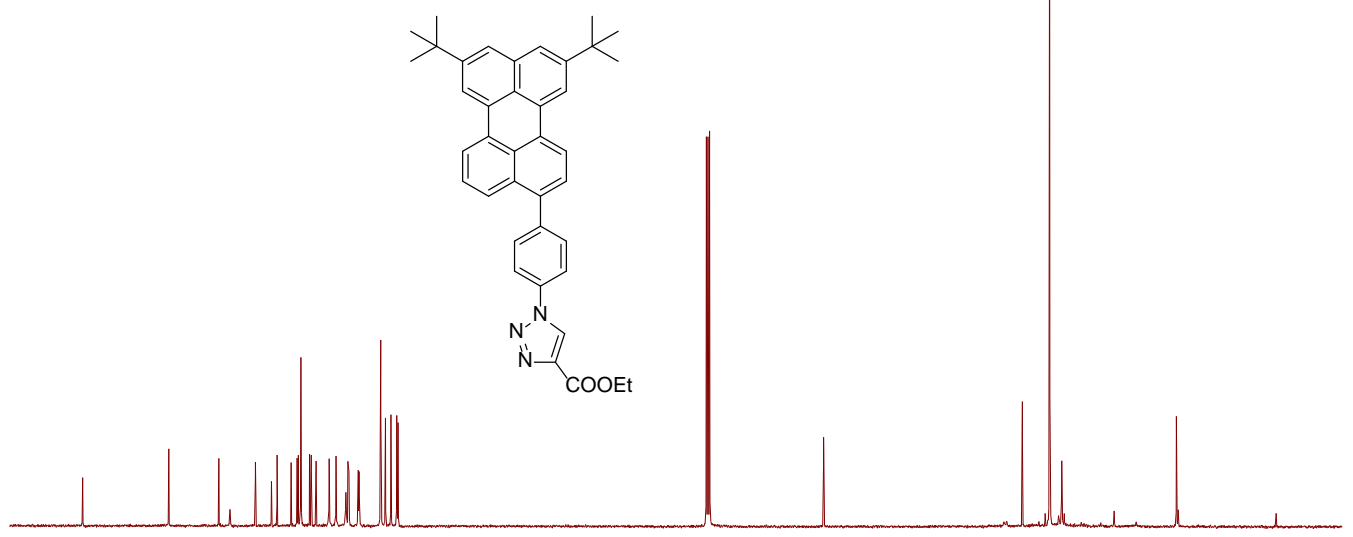

\begin{tabular}{llllllllllllllllll}
\hline 70 & 160 & 150 & 140 & 130 & 120 & 110 & 100 & 90 & $\begin{array}{c}80 \\
\mathrm{f} 1(\mathrm{ppm})\end{array}$ & 70 & 60 & 50 & 40 & 30 & 20 & 10 & 0
\end{tabular}

Figure S29. ${ }^{13} \mathrm{C}$ NMR of Ethyl 1-(4-(8,11-di-tert-butylperylen-3-yl)phenyl)-1H-1,2,3-triazole-4carboxylate (11a) in $\mathrm{CDCl}_{3}$ 


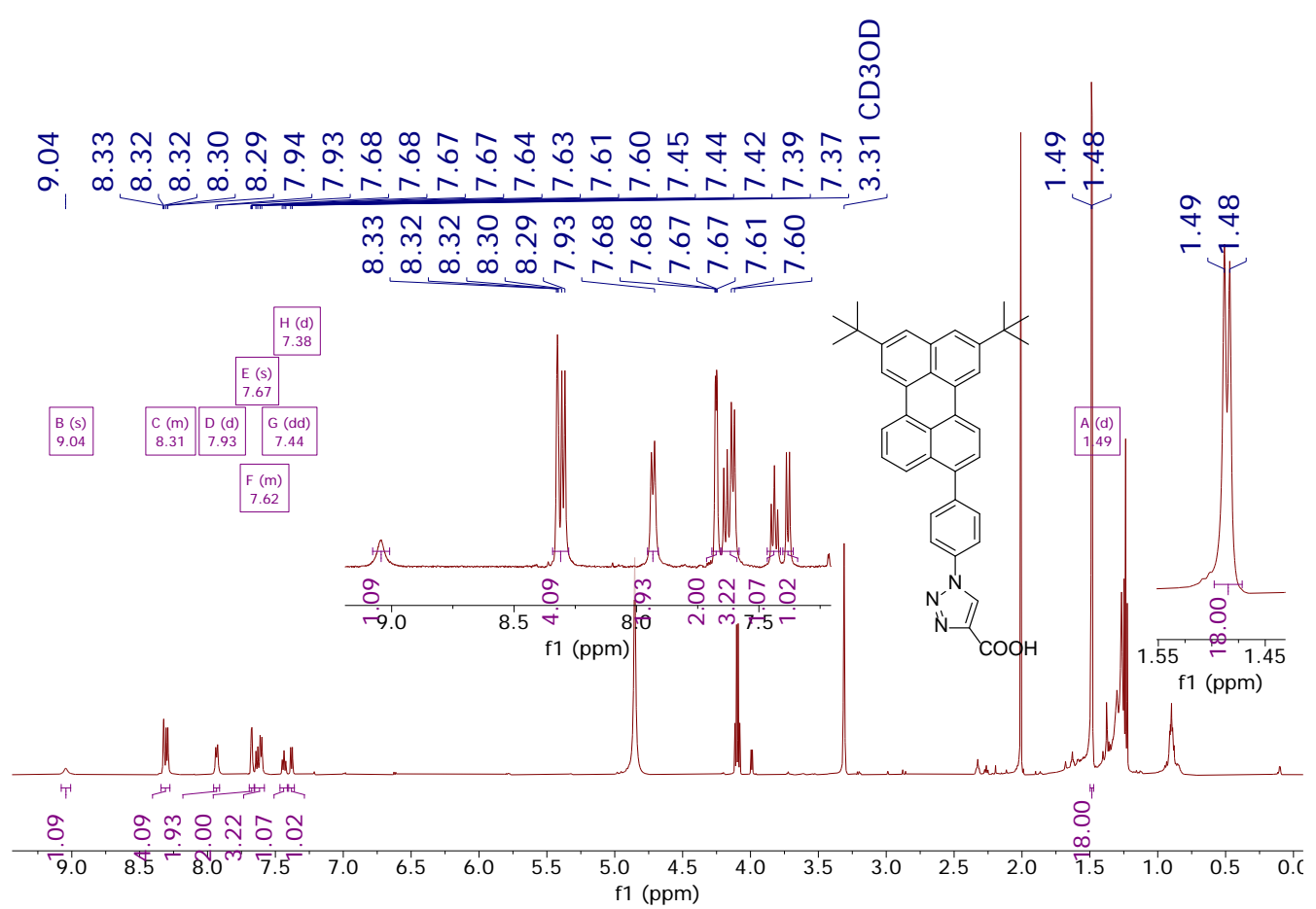

Figure S30. ${ }^{1} \mathrm{H}$ NMR of 1-(4-(8,11-di-tert-Butylperylen-3-yl)phenyl)-1H-1,2,3-triazole-4carboxylic acid (11b) in $\mathrm{CD}_{3} \mathrm{OD}$

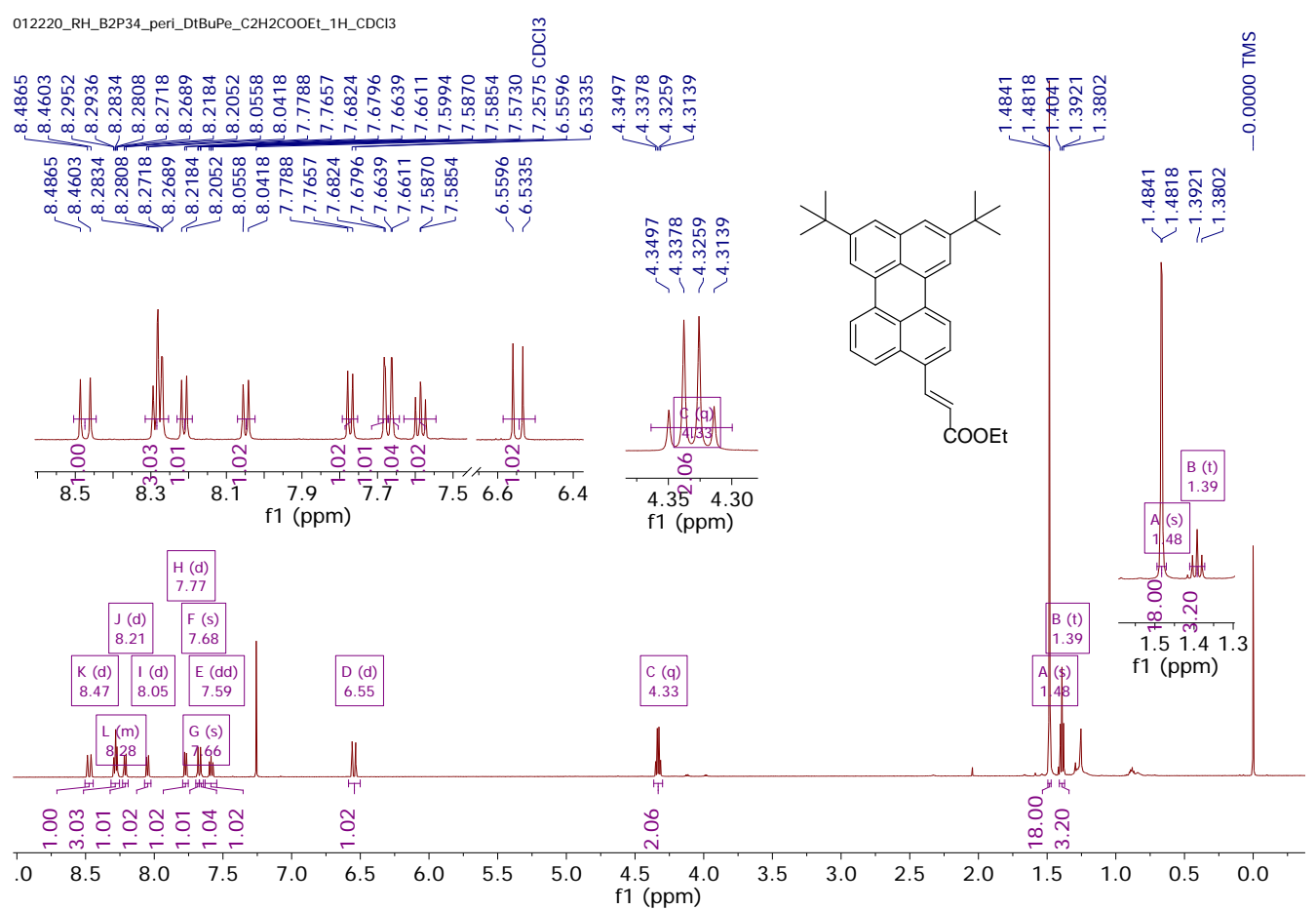

Figure S31. ${ }^{1} \mathrm{H}$ NMR of Ethyl (E)-3-(8,11-di-tert-butylperylen-3-yl)acrylate (12a) in $\mathrm{CDCl}_{3}$ 


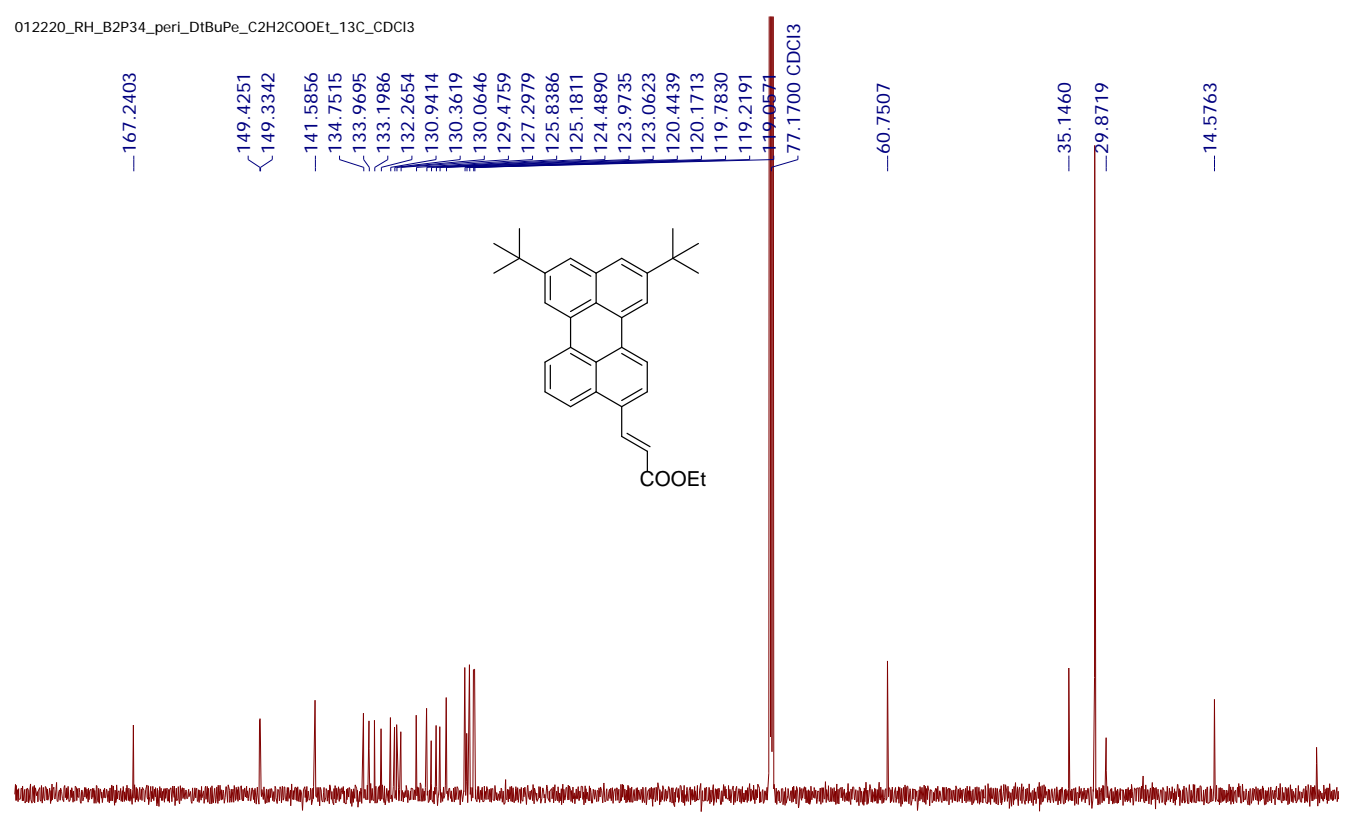

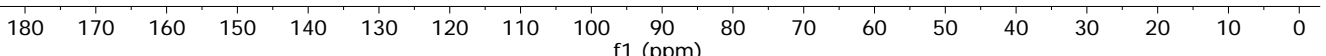

Figure S32. ${ }^{13} \mathrm{C}$ NMR of Ethyl (E)-3-(8,11-di-tert-butylperylen-3-yl)acrylate (12a) in CDCl3

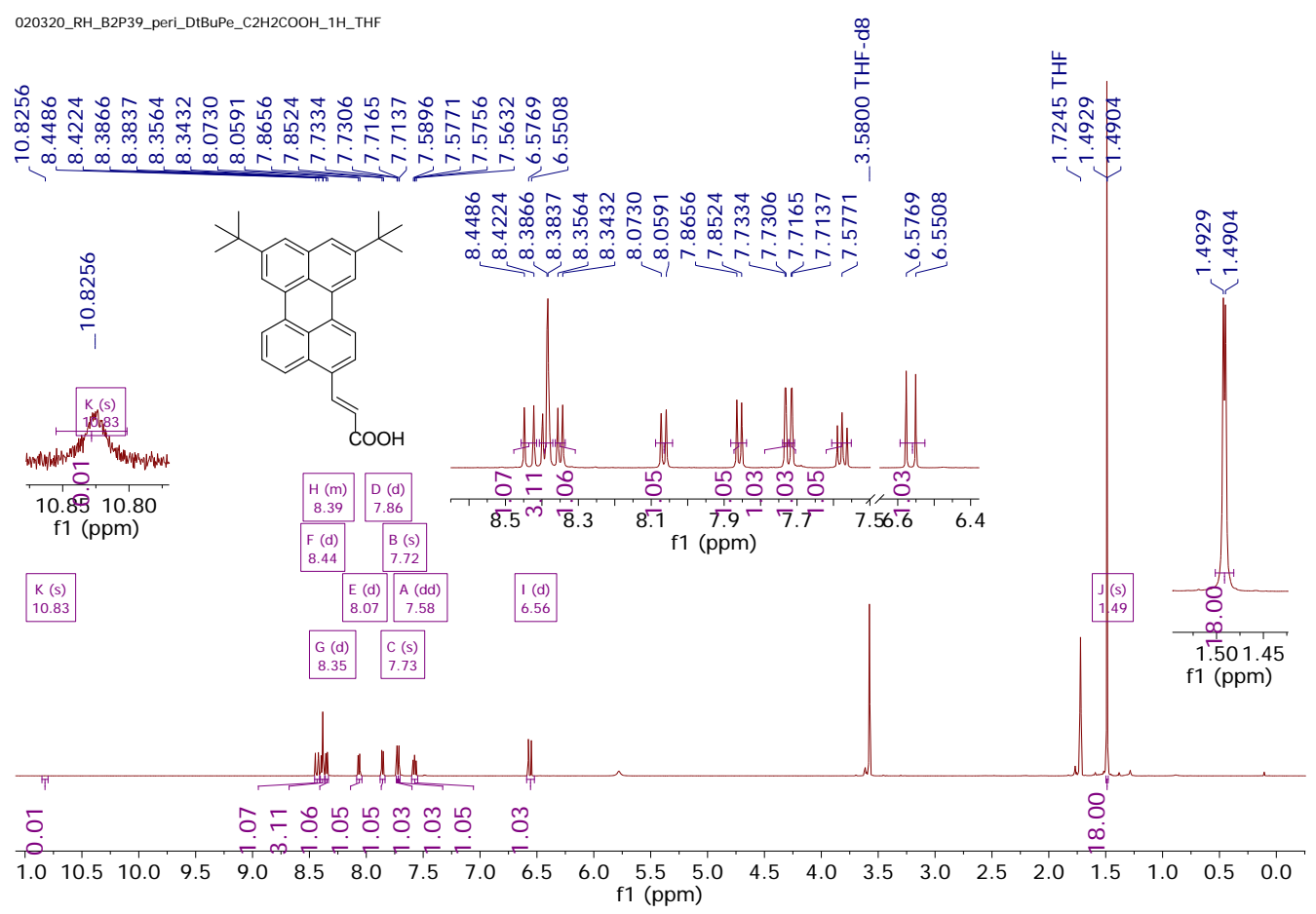

Figure S33. ${ }^{1} \mathrm{H}$ NMR of (E)-3-(8,11-di-tert-butylperylen-3-yl)acrylic acid (12b) in THF-d 8 
020320_RH_B2P39_peri_DtBuPe_C2H2COOH_13C_THF
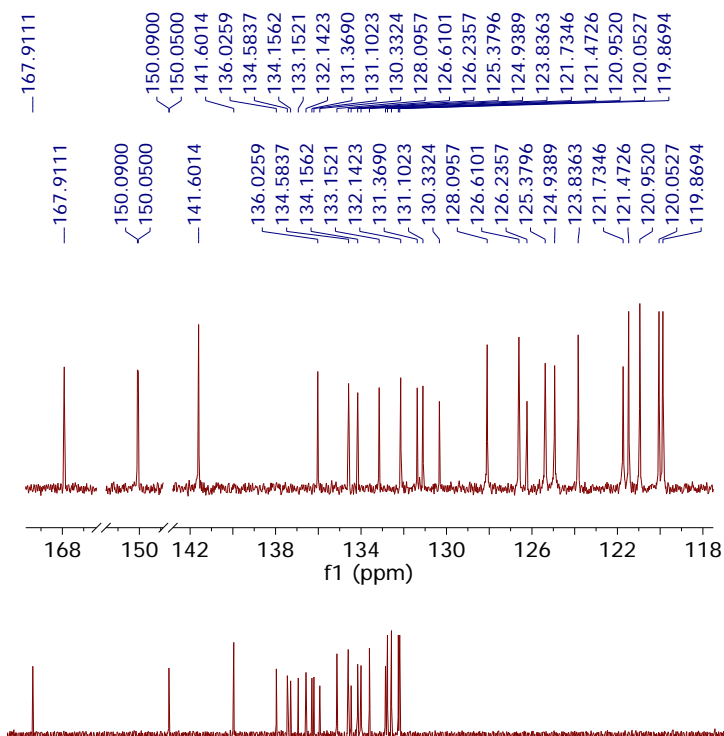

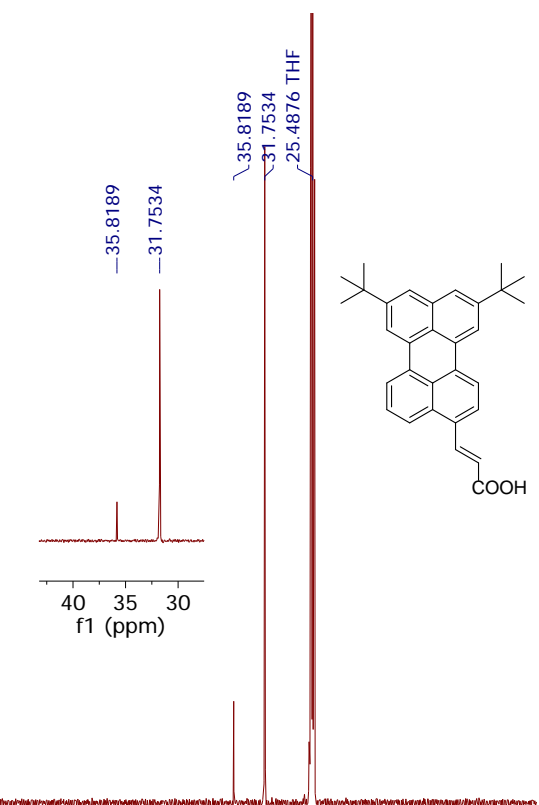

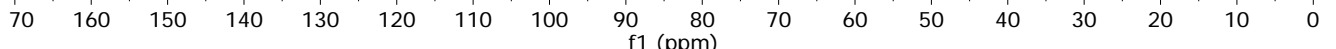

Figure S34. ${ }^{13} \mathrm{C}$ NMR of (E)-3-(8,11-di-tert-butylperylen-3-yl)acrylic acid (12b) in THF-d8

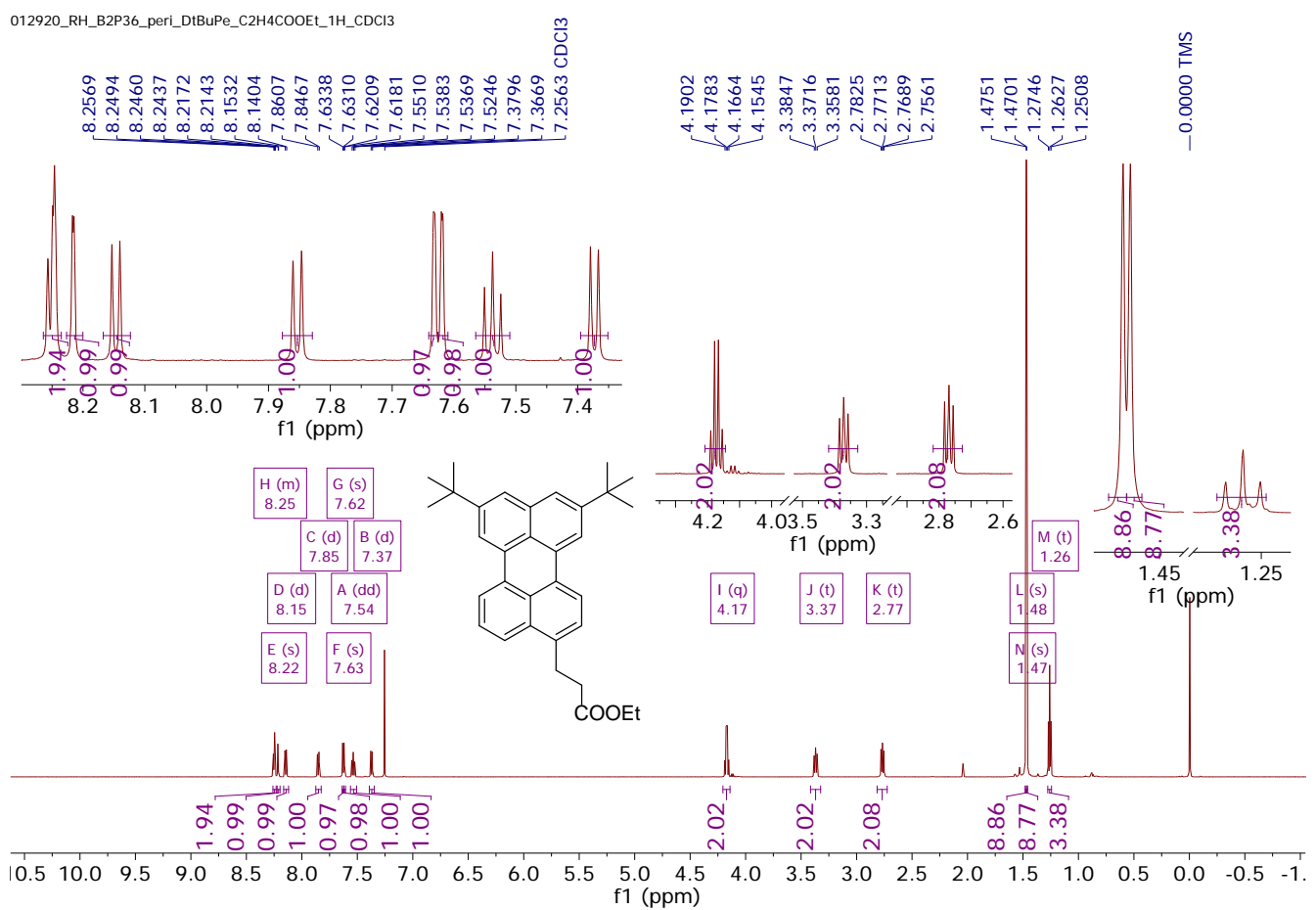

Figure S35. ${ }^{1} \mathrm{H}$ NMR of ethyl 3-(8,11-di-tert-butylperylen-3-yl)propanoate (13a) in $\mathrm{CDCl}_{3}$ 

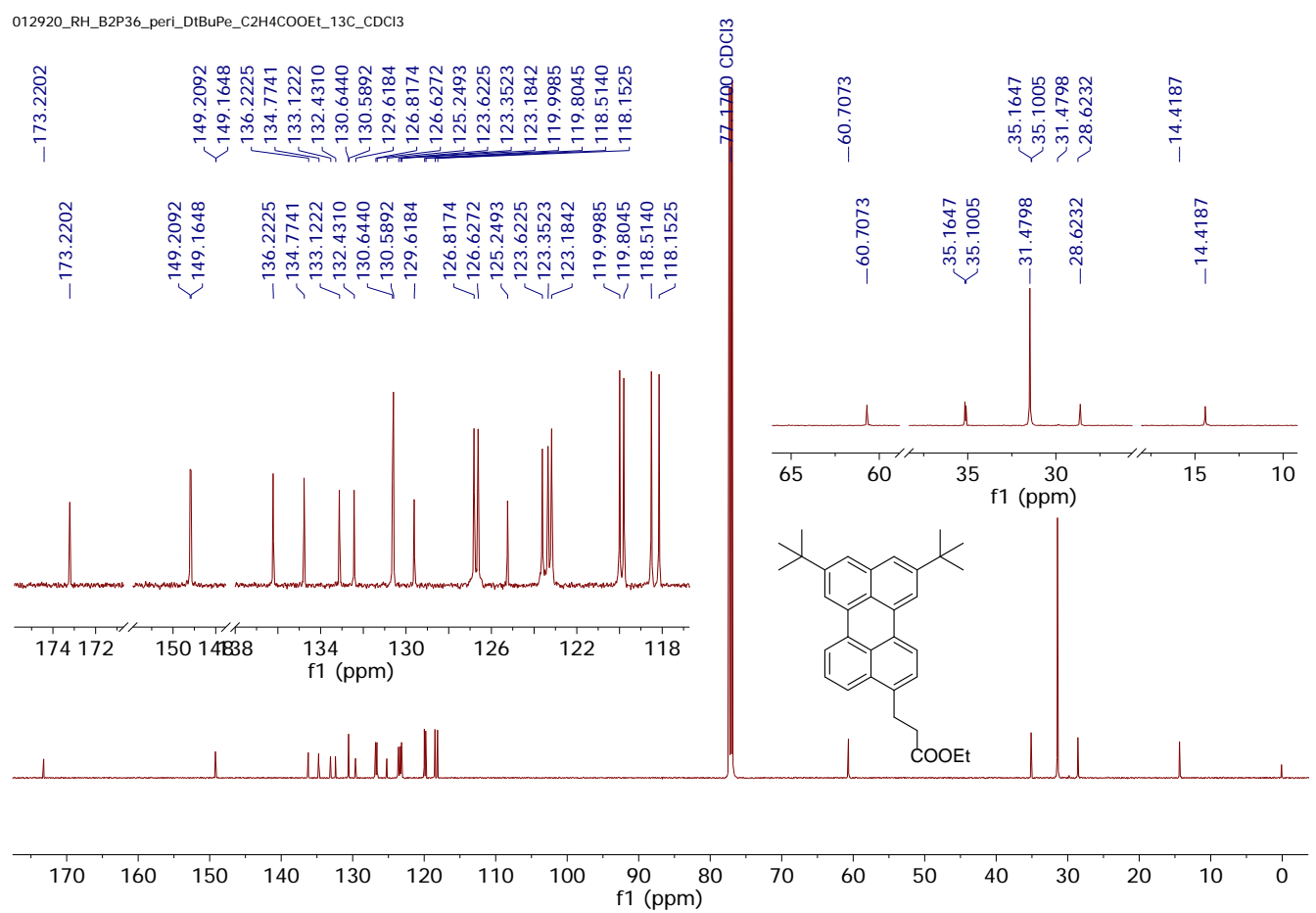

Figure S36. ${ }^{13} \mathrm{C}$ NMR of ethyl 3-(8,11-di-tert-butylperylen-3-yl)propanoate (13a) in $\mathrm{CDCl}_{3}$

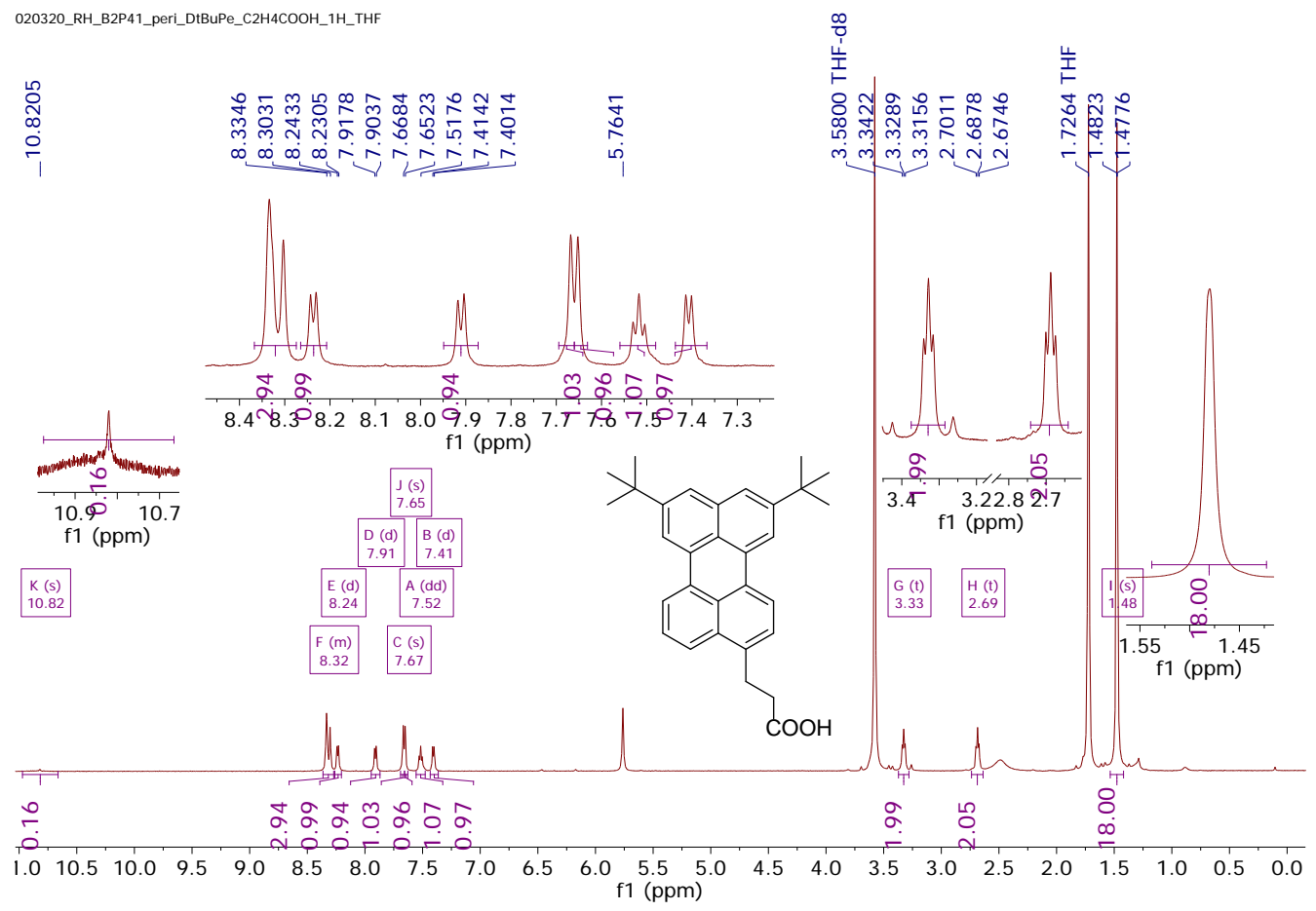

Figure S37. ${ }^{1} \mathrm{H}$ NMR of 3-(8,11-di-tert-butylperylen-3-yl)propanoic acid (13b) in THF-d 8 

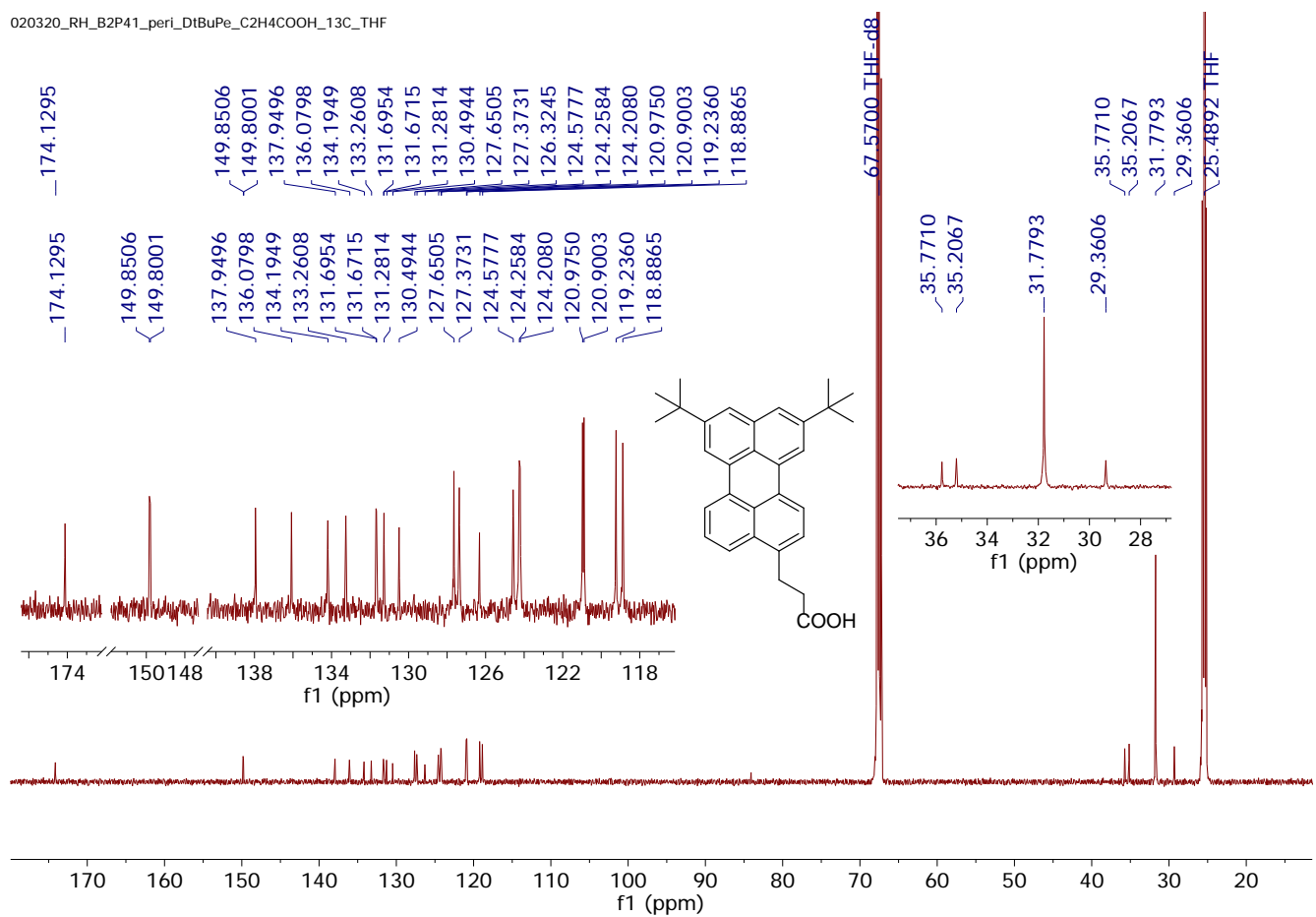

Figure S38. ${ }^{13} \mathrm{C}$ NMR of 3-(8,11-di-tert-butylperylen-3-yl)propanoic acid (13b) in THF-d8

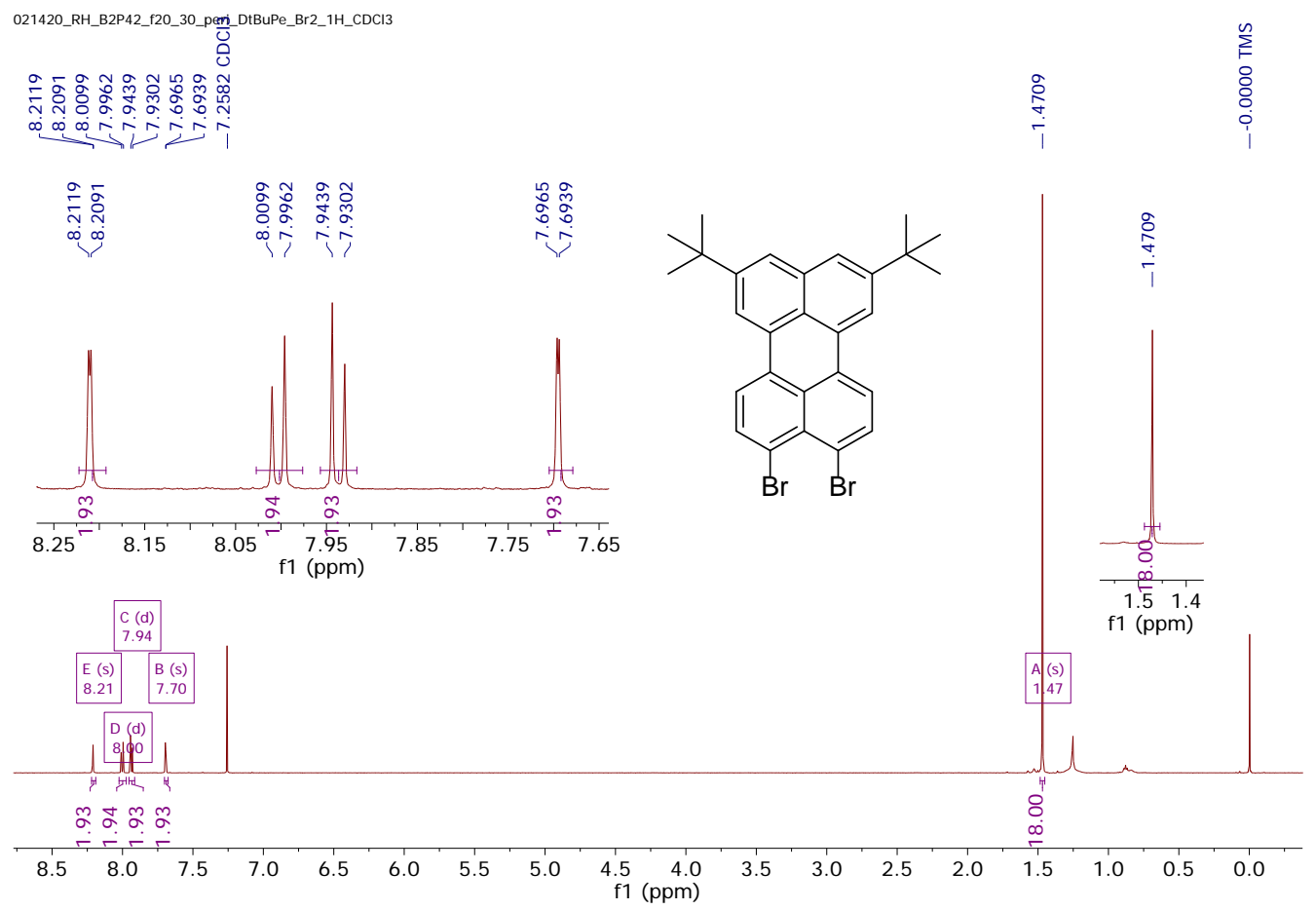

Figure S39. ${ }^{1} \mathrm{H}$ NMR of 9,10-dibromo-2,5-di-tert-butylperylene (14) in $\mathrm{CDCl}_{3}$ 


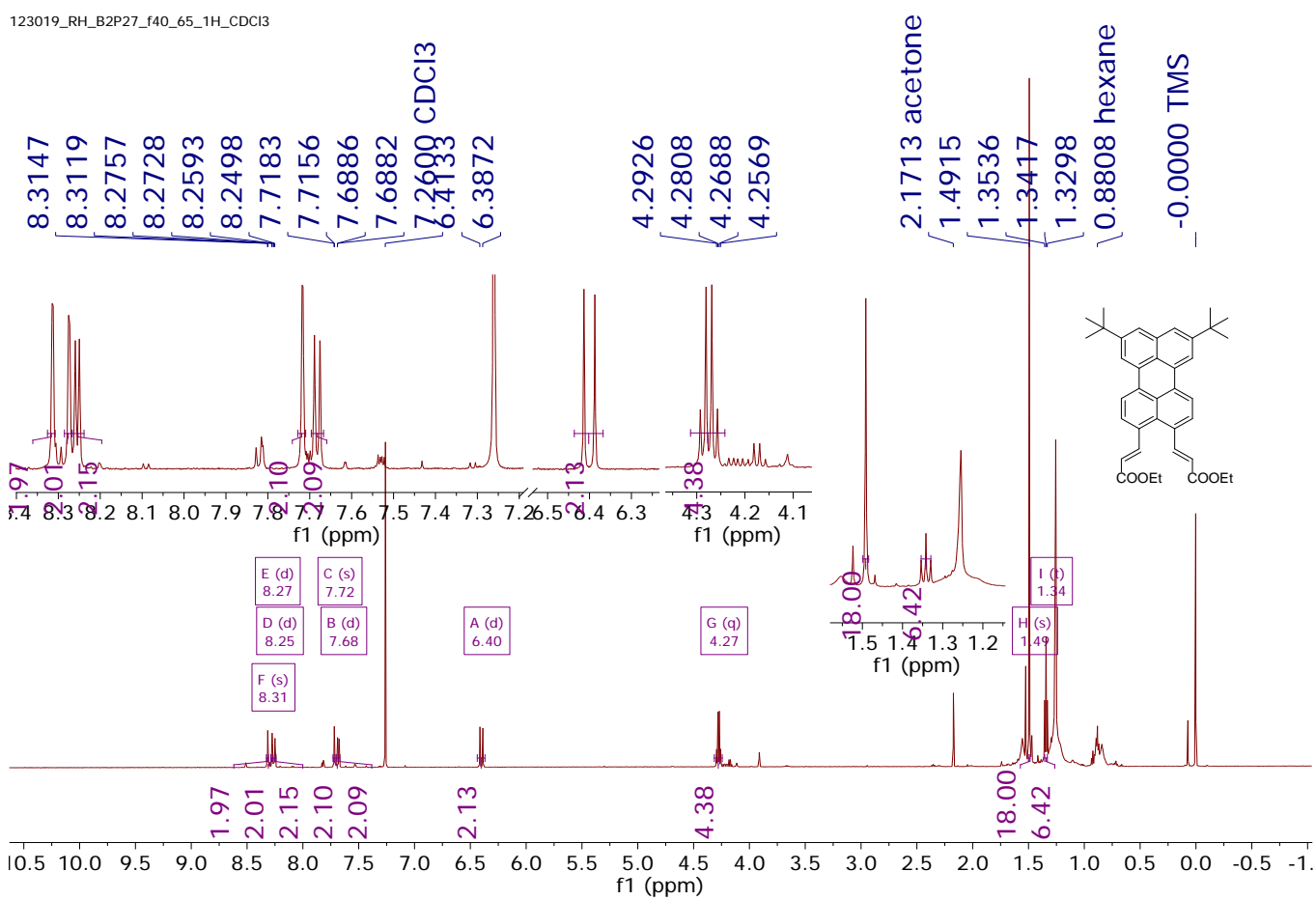

Figure S40. ${ }^{1} \mathrm{H}$ NMR of diethyl 3,3'-(8,11-di-tert-butylperylene-3,4-diyl)(2E,2'E)-diacrylate (15a) in $\mathrm{CDCl}_{3}$

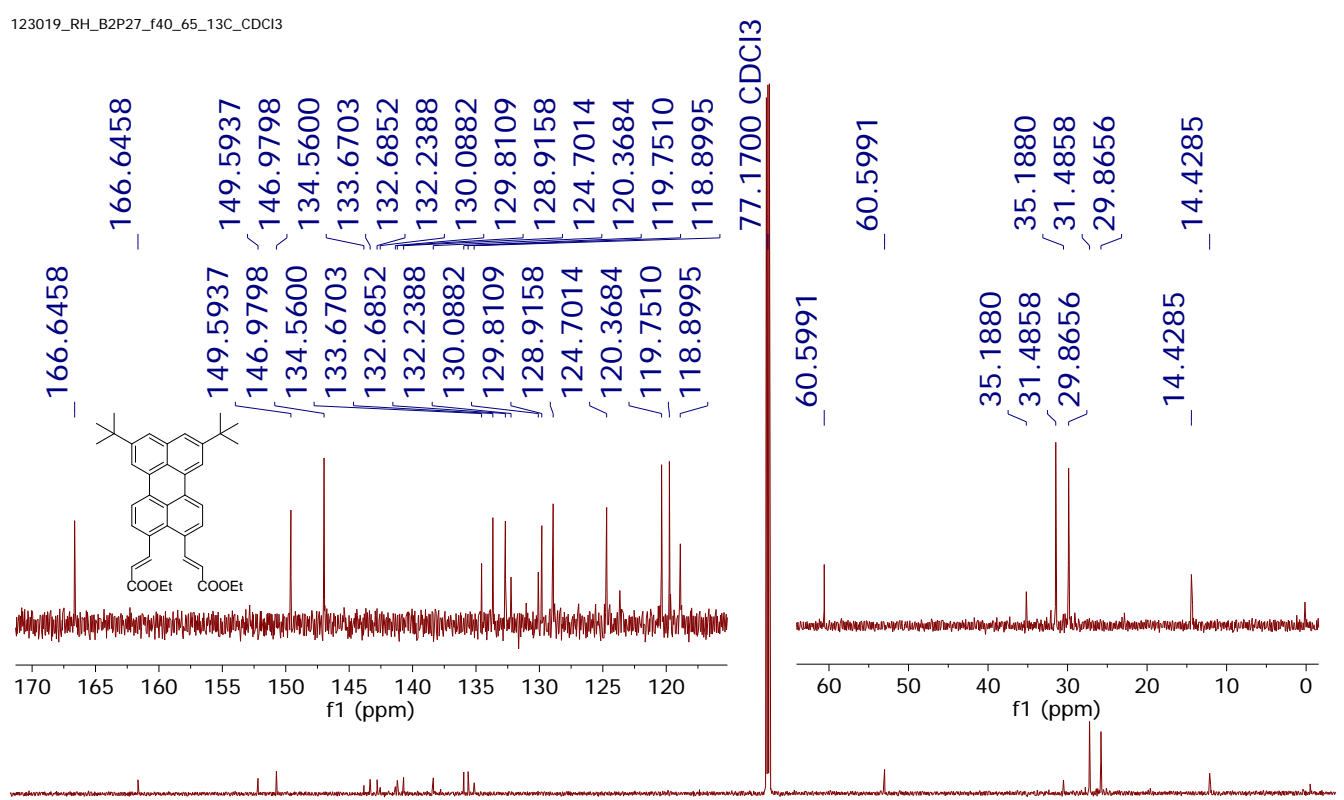

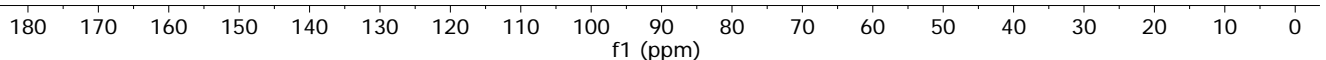

Figure S41. ${ }^{13} \mathrm{C}$ NMR of diethyl 3,3'-(8,11-di-tert-butylperylene-3,4-diyl)(2E,2'E)-diacrylate (15a) in $\mathrm{CDCl}_{3}$ 


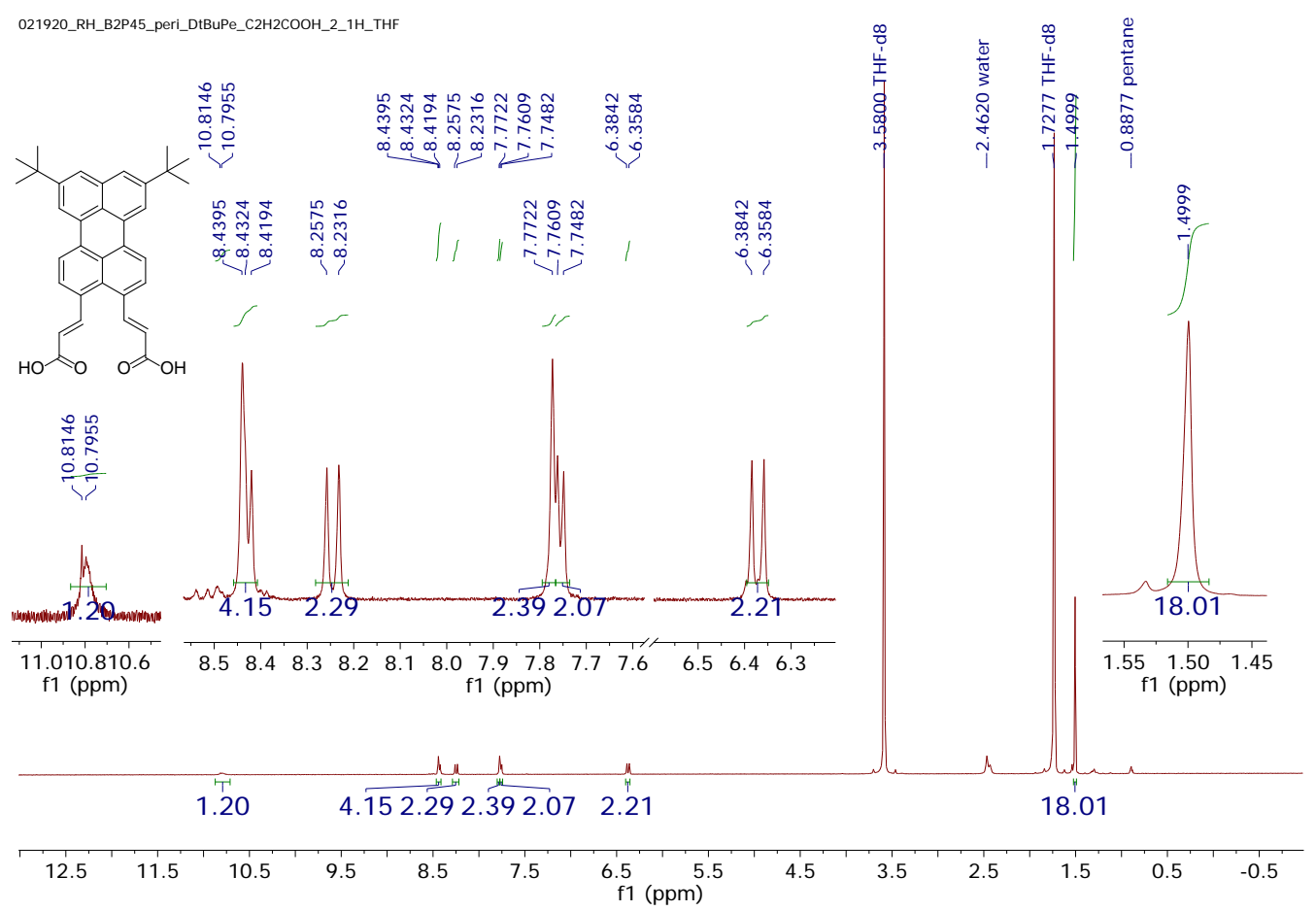

Figure S42. ${ }^{1} \mathrm{H}$ NMR of (2E,2'E)-3,3'-(8,11-di-tert-butylperylene-3,4-diyl)diacrylic acid (15b) in THF-d 8

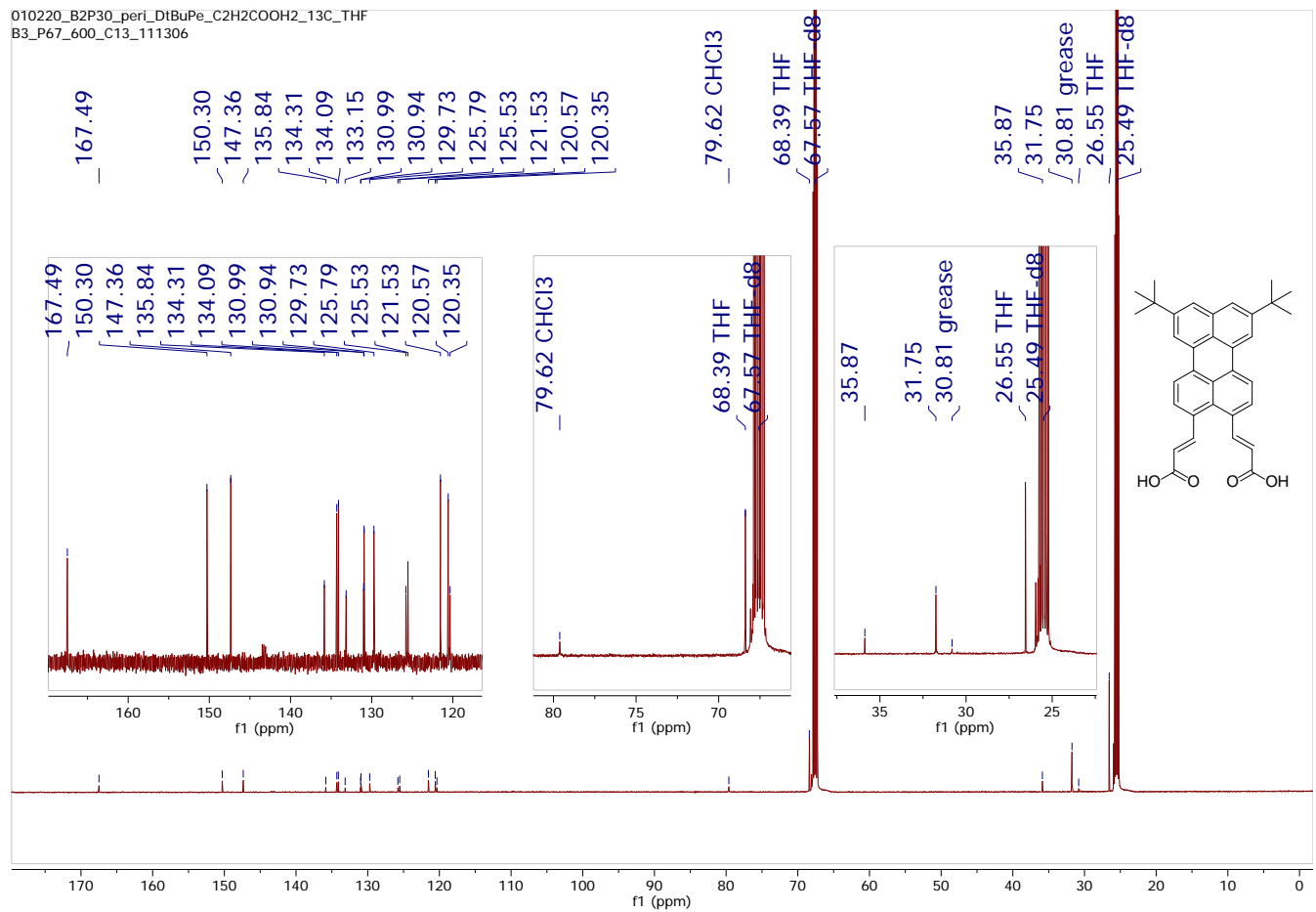

Figure S43. ${ }^{13} \mathrm{C}$ NMR of (2E,2'E)-3,3'-(8,11-di-tert-butylperylene-3,4-diyl)diacrylic acid (15b) in THF-d 8 


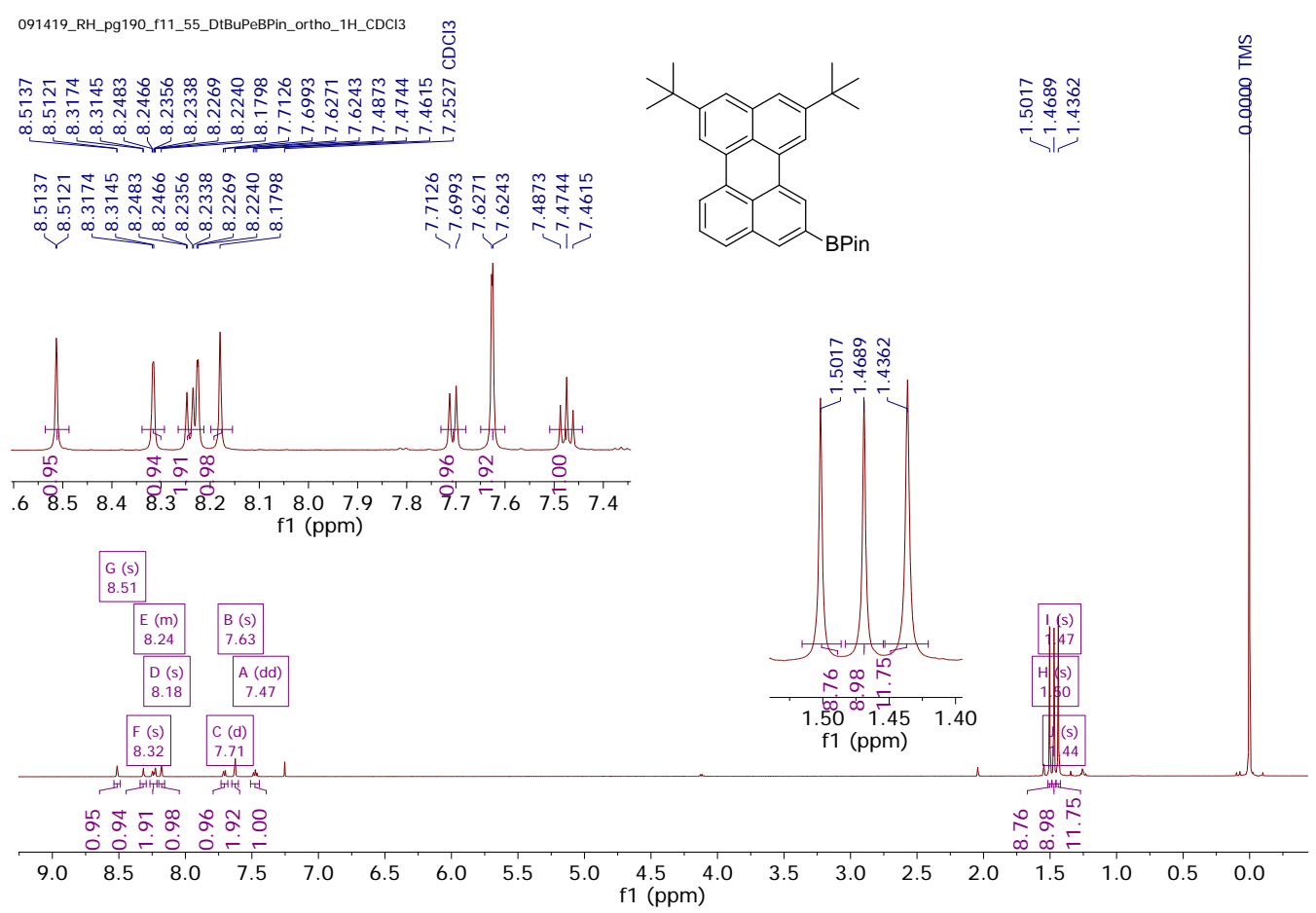

Figure S44. ${ }^{1} \mathrm{H}$ NMR of 2-(8,11-di-tert-butylperylen-2-yl)-4,4,5,5-tetramethyl-1,3,2dioxaborolane (16) in $\mathrm{CDCl}_{3}$

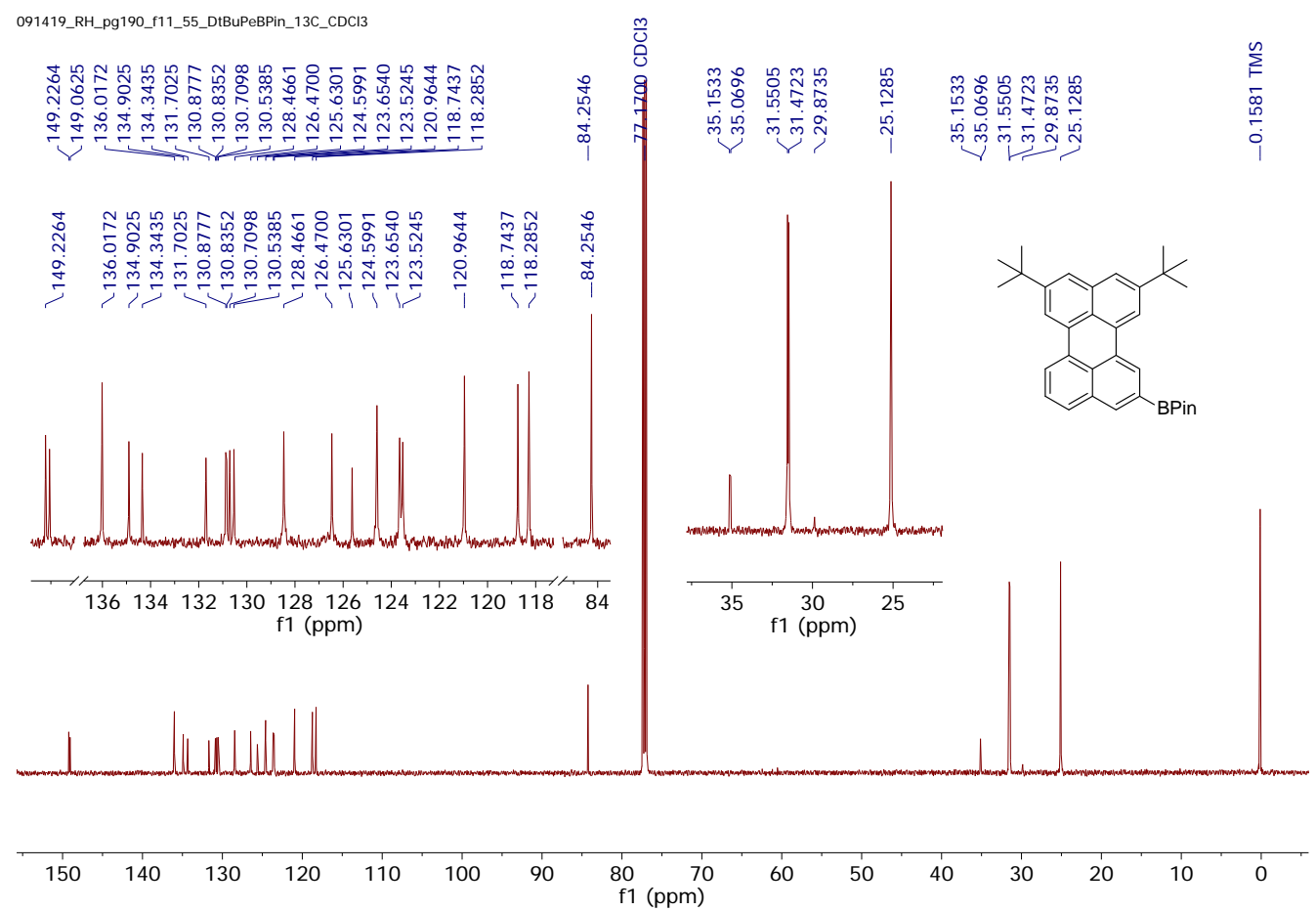

Figure S45. ${ }^{13} \mathrm{C}$ NMR of 2-(8,11-di-tert-butylperylen-2-yl)-4,4,5,5-tetramethyl-1,3,2dioxaborolane (16) in $\mathrm{CDCl}_{3}$ 


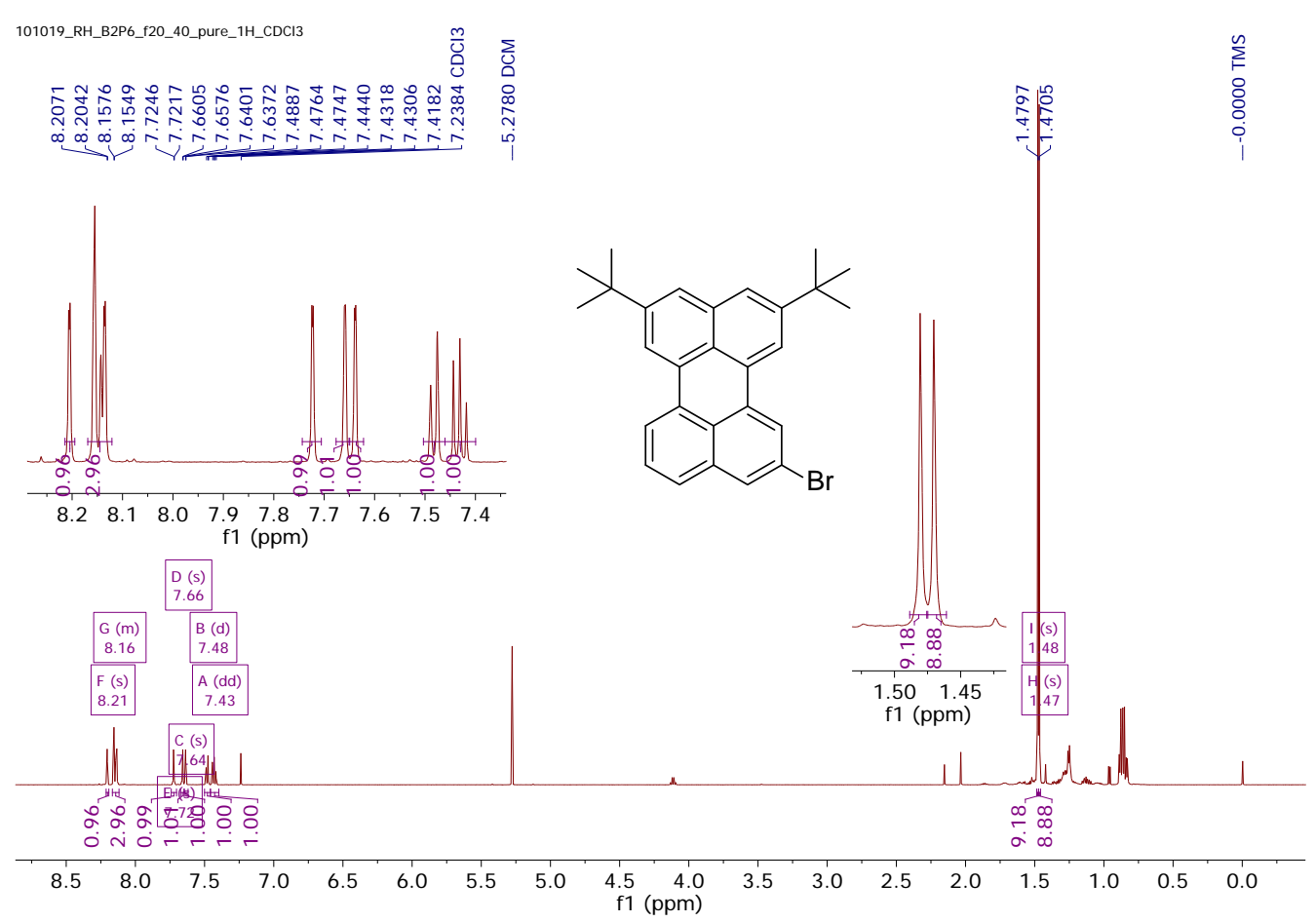

Figure S46. ${ }^{1} \mathrm{H}$ NMR of 8-bromo-2,5-di-tert-butylperylene (17) in $\mathrm{CDCl}_{3}$

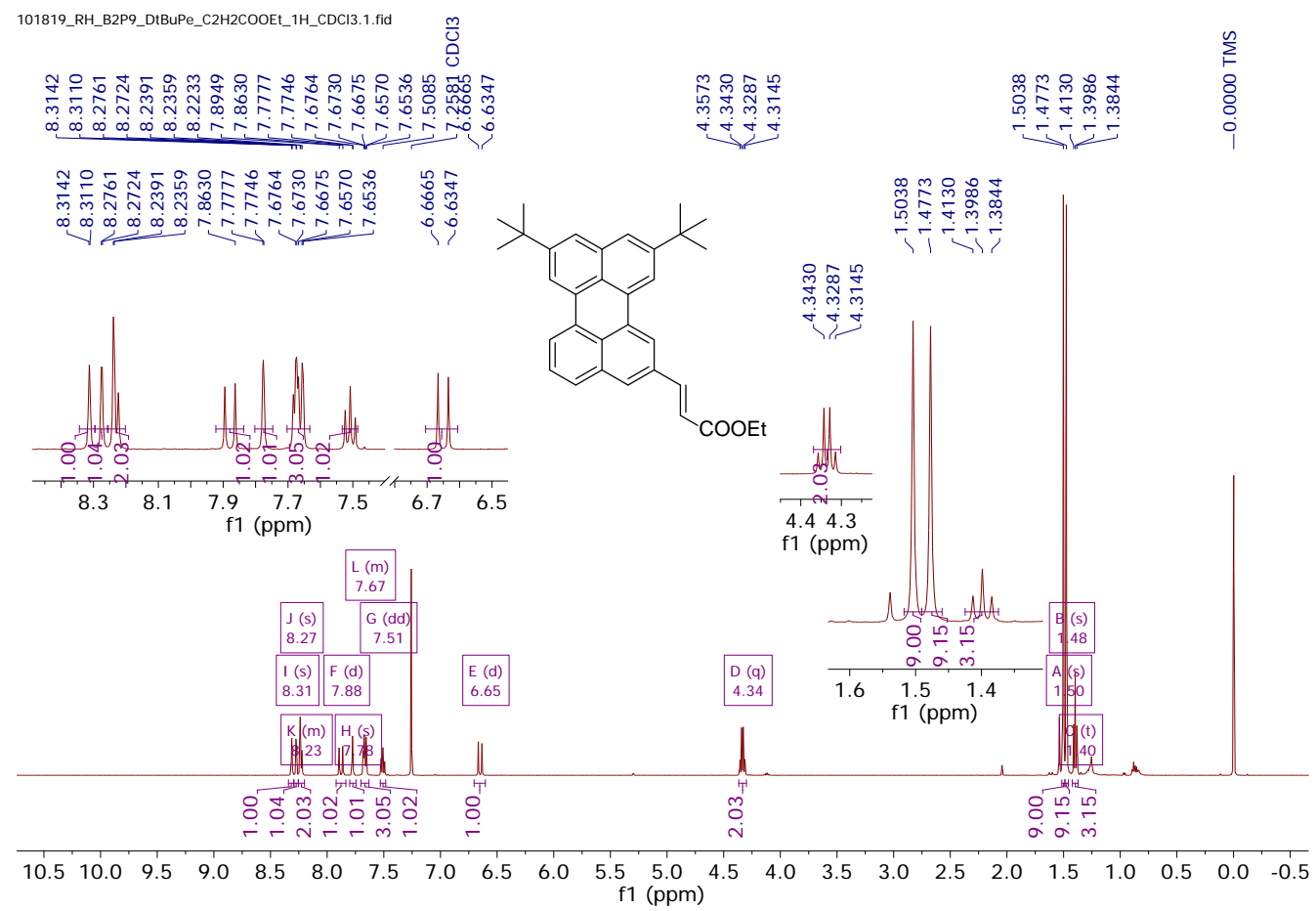

Figure S47. ${ }^{1} \mathrm{H}$ NMR of ethyl (E)-3-(8,11-di-tert-butylperylen-2-yl)acrylate (18a) in $\mathrm{CDCl}_{3}$ 


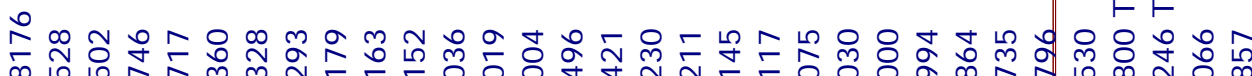

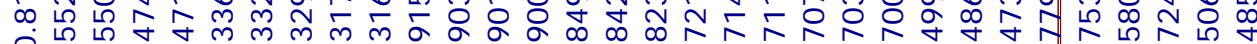

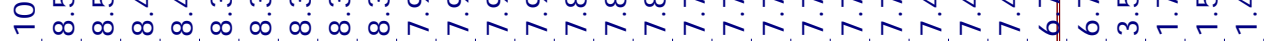

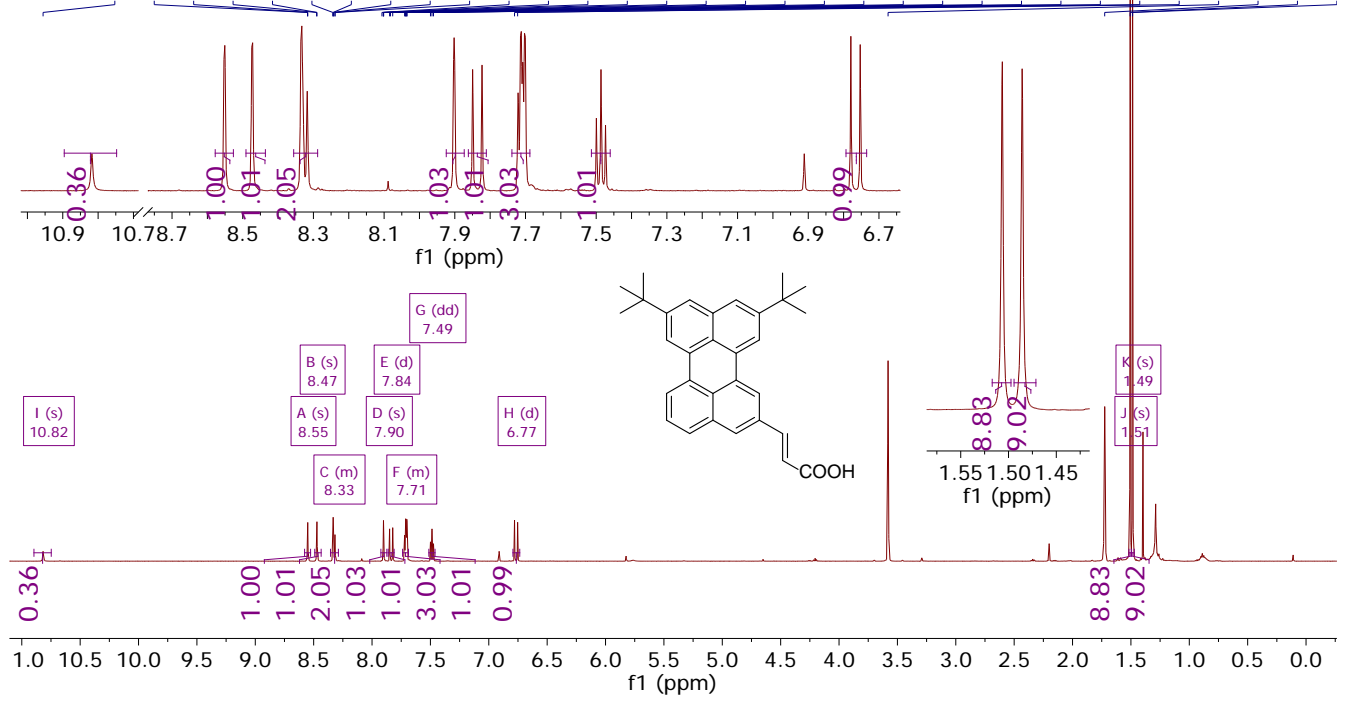

Figure S48. ${ }^{1} \mathrm{H}$ NMR of (E)-3-(8,11-di-tert-butylperylen-2-yl)acrylic acid (18b) in THF-d 8

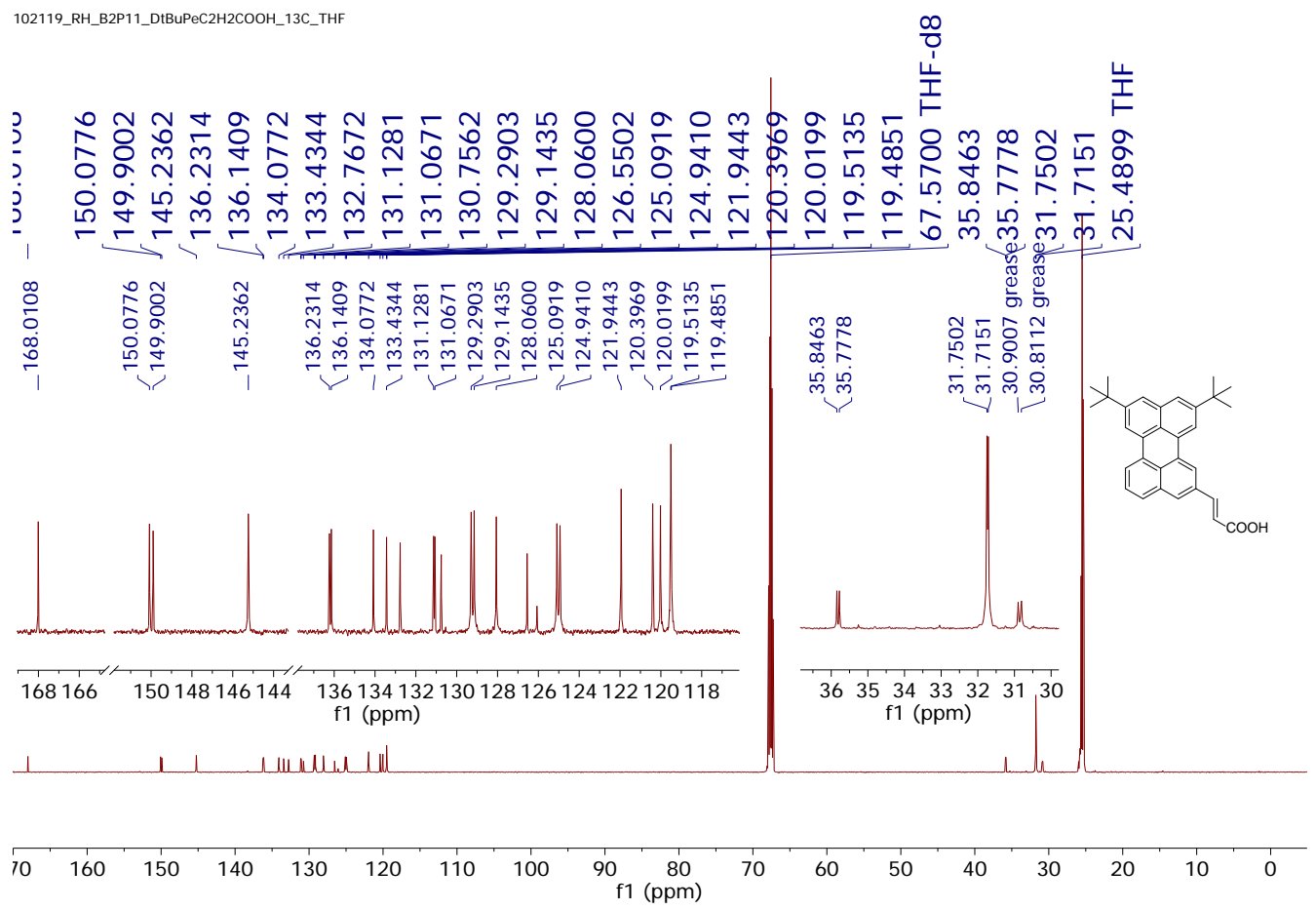

Figure S49. ${ }^{13} \mathrm{C}$ NMR of (E)-3-(8,11-di-tert-butylperylen-2-yl)acrylic acid (18b) in THF-d 8 


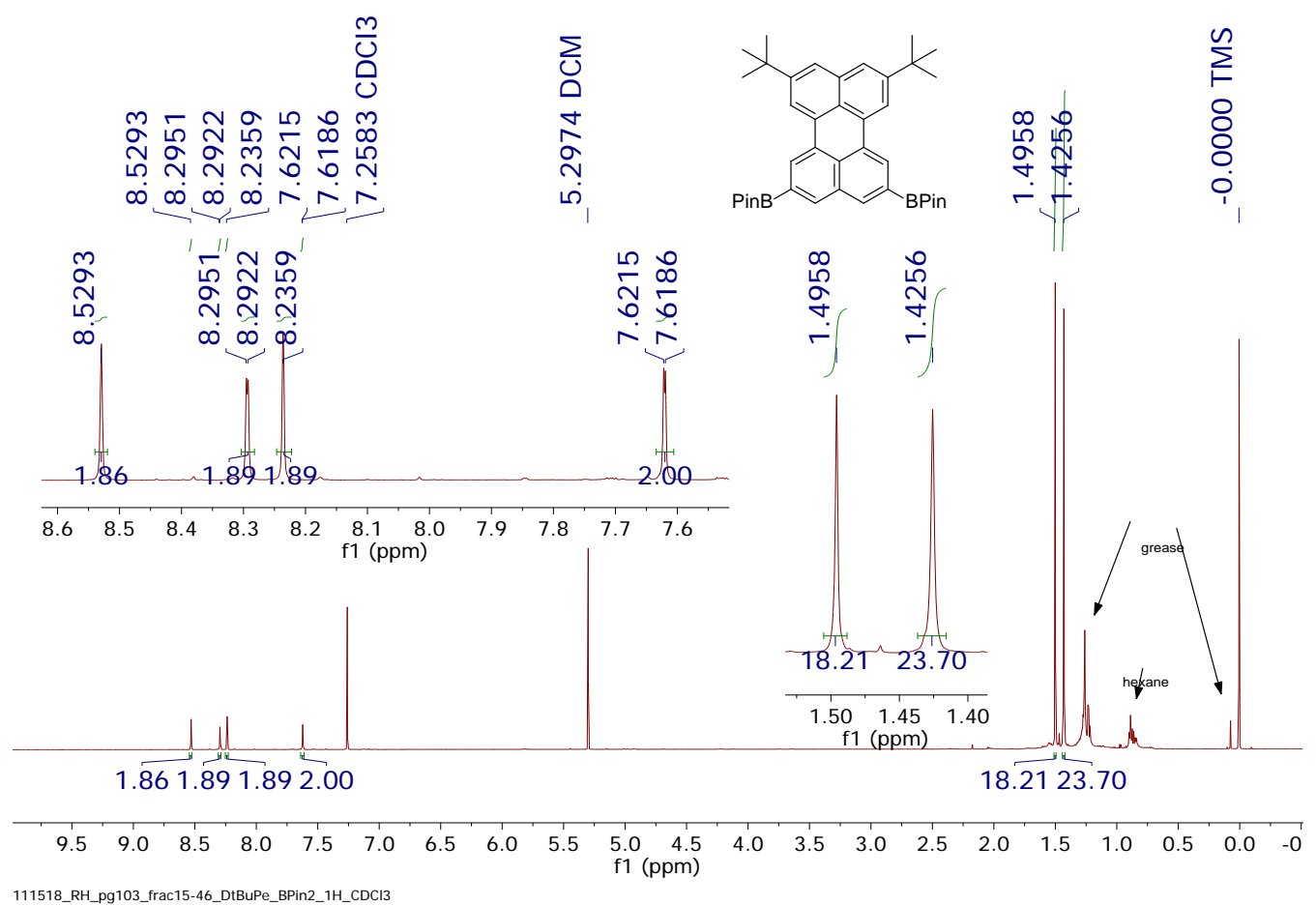

Figure S50. ${ }^{1} \mathrm{H}$ NMR of 2,2'-(8,11-di-tert-butylperylene-2,5-diyl)bis(4,4,5,5-tetramethyl-1,3,2dioxaborolane) (19) in $\mathrm{CDCl}_{3}$

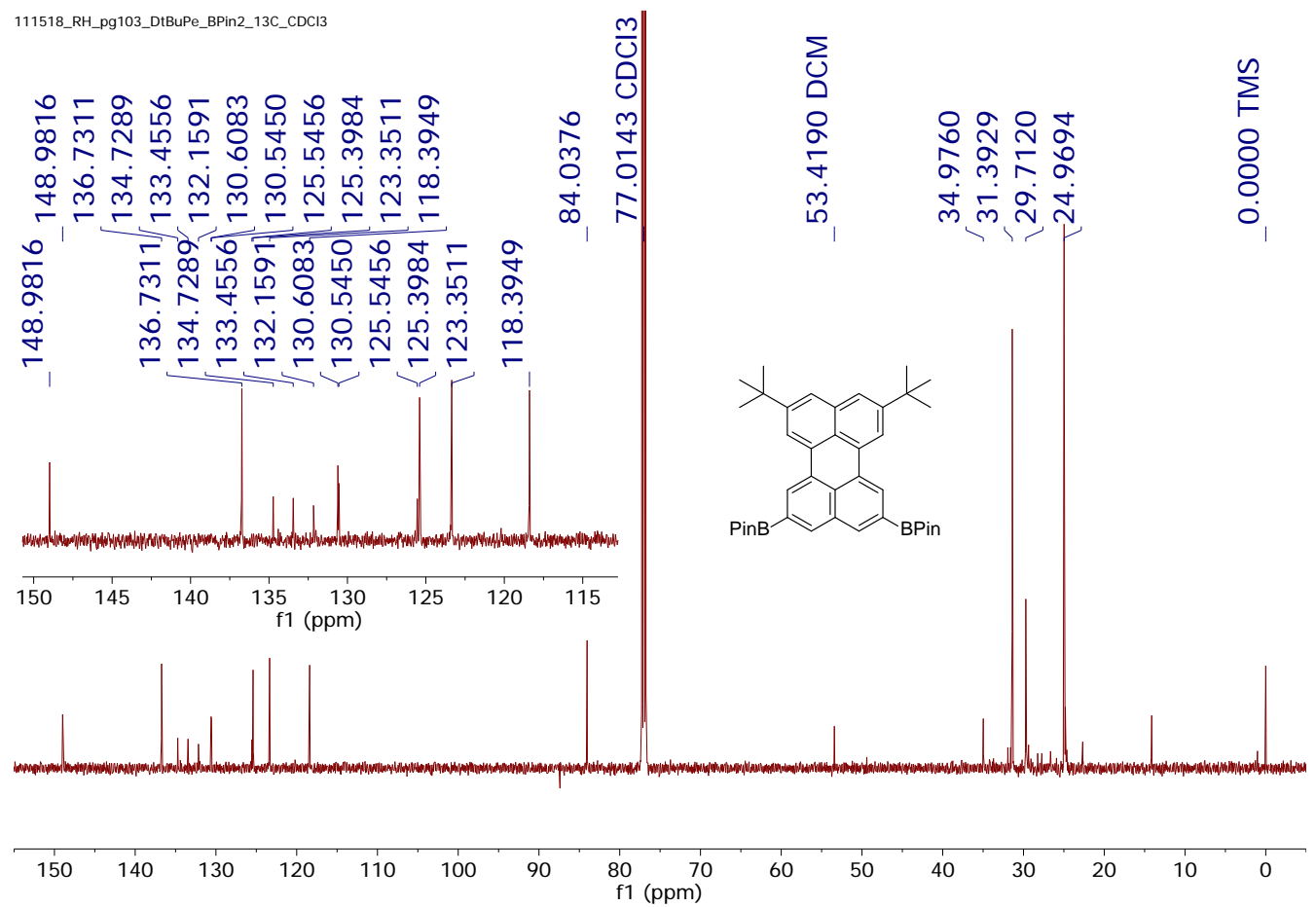

Figure S51. ${ }^{13} \mathrm{C}$ NMR of 2,2'-(8,11-di-tert-butylperylene-2,5-diyl)bis(4,4,5,5-tetramethyl-1,3,2dioxaborolane) (19) in $\mathrm{CDCl}_{3}$ 


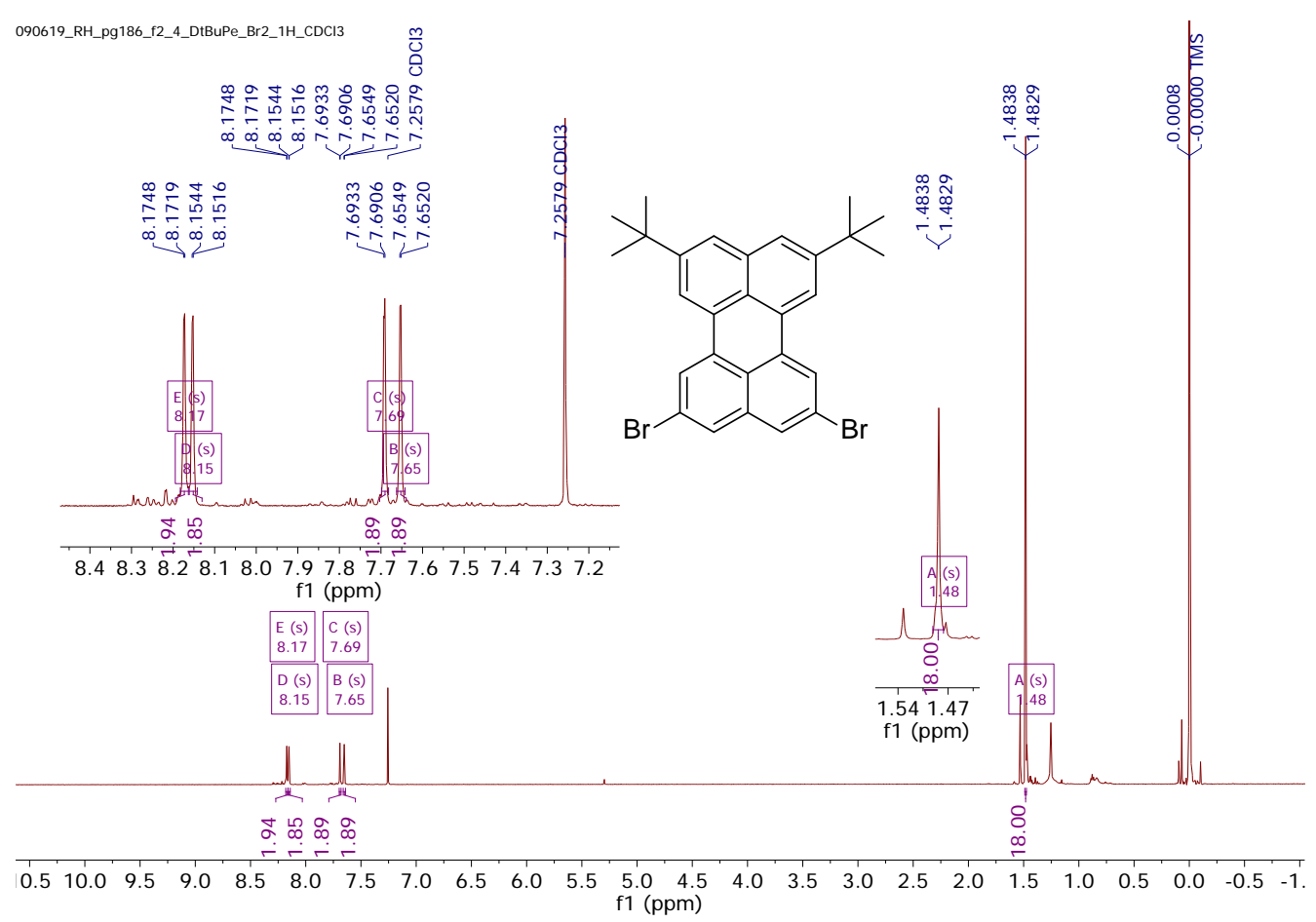

Figure S52. ${ }^{1} \mathrm{H}$ NMR of 2,5-dibromo-8,11-di-tert-butylperylene (20) in $\mathrm{CDCl}_{3}$

090919_RH_pg186_f2_4_DtBuPe_Br2_ortho_13C_CDC13
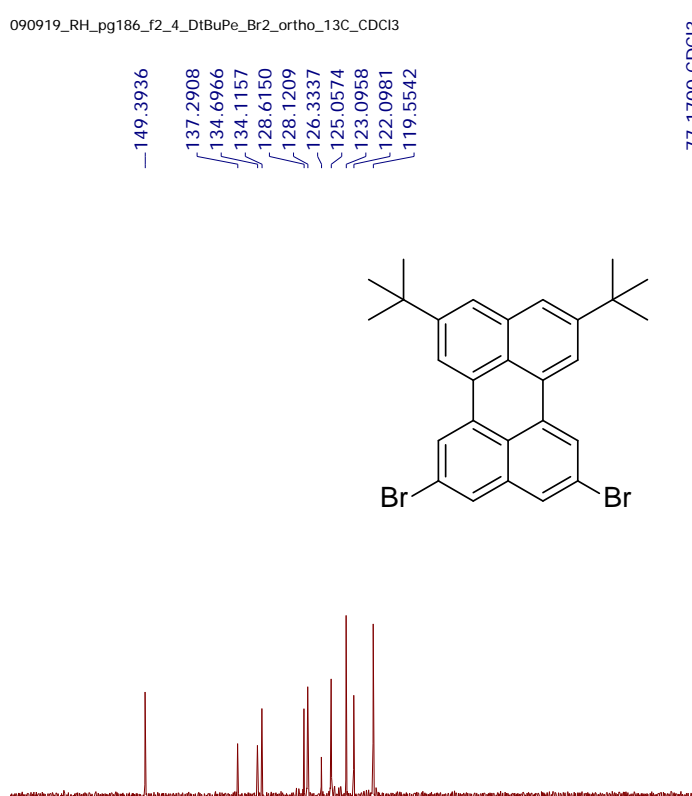

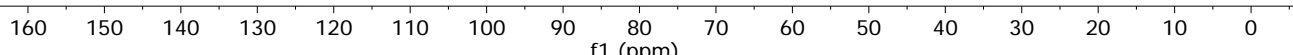

Figure S53. ${ }^{13} \mathrm{C}$ NMR of 2,5-dibromo-8,11-di-tert-butylperylene (20) in $\mathrm{CDCl}_{3}$ 


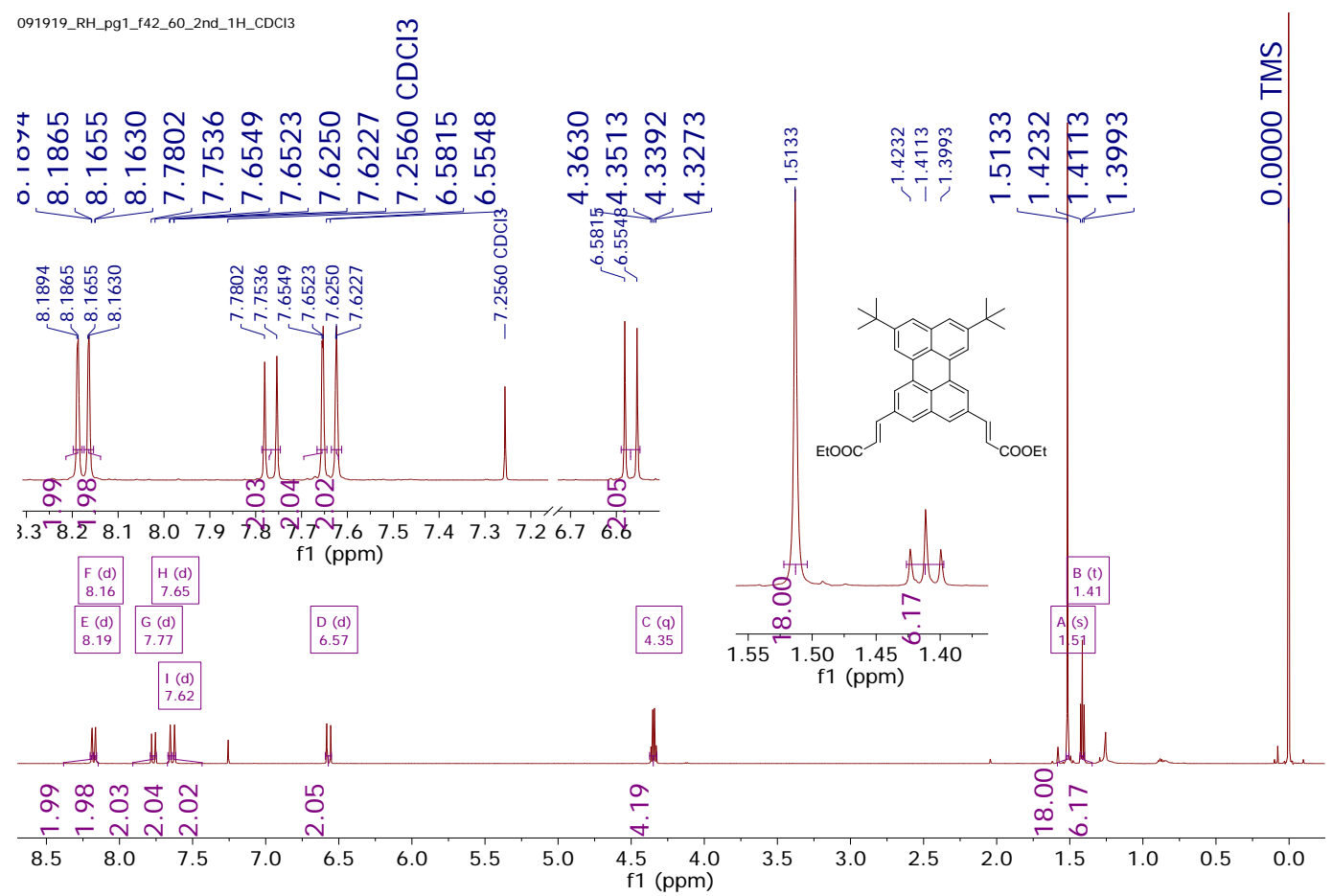

Figure S54. ${ }^{1} \mathrm{H}$ NMR of diethyl 3,3'-(8,11-di-tert-butylperylene-2,5-diyl)(2E,2'E)-diacrylate (21a) in $\mathrm{CDCl}_{3}$

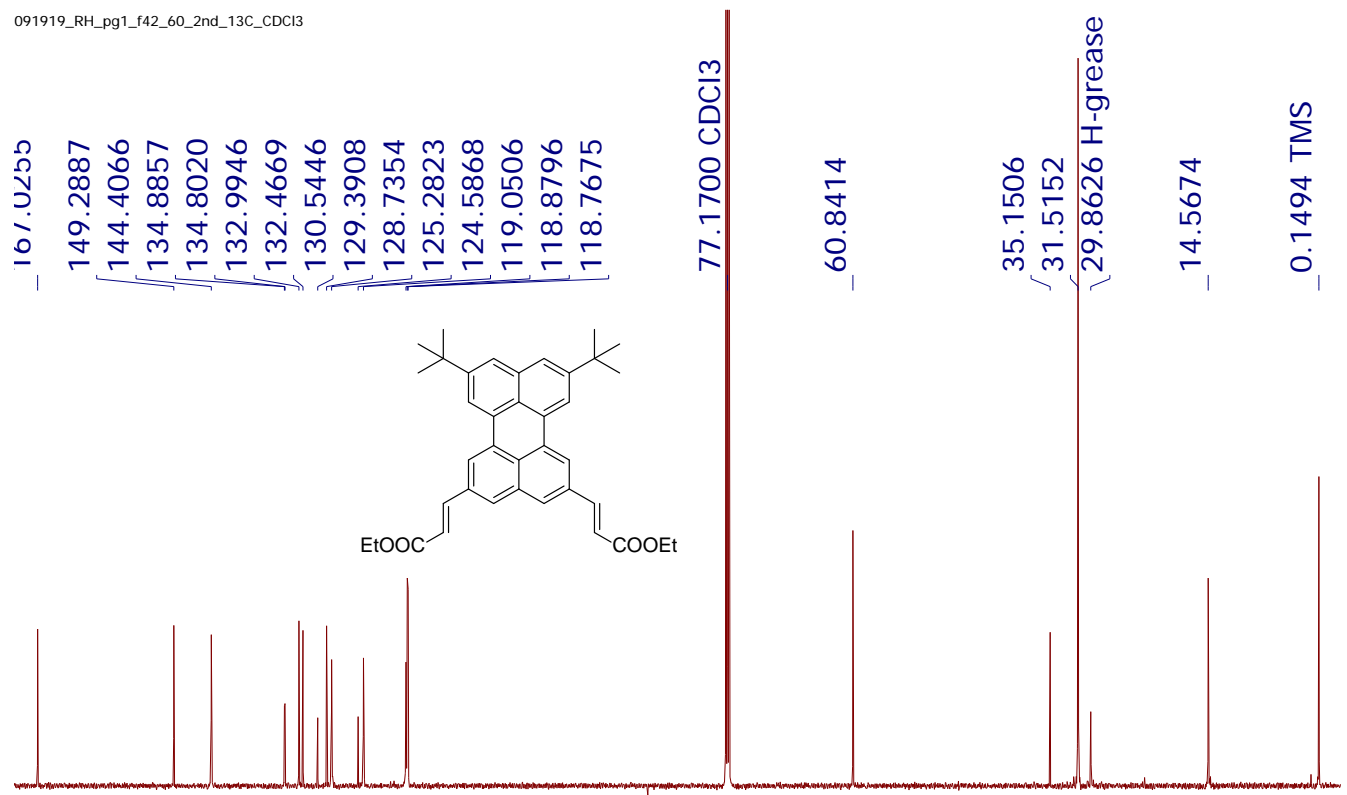

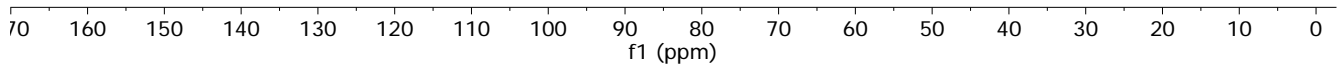

Figure S55. ${ }^{13} \mathrm{C}$ NMR of diethyl 3,3'-(8,11-di-tert-butylperylene-2,5-diyl)(2E,2'E)-diacrylate (21a) in $\mathrm{CDCl}_{3}$ 


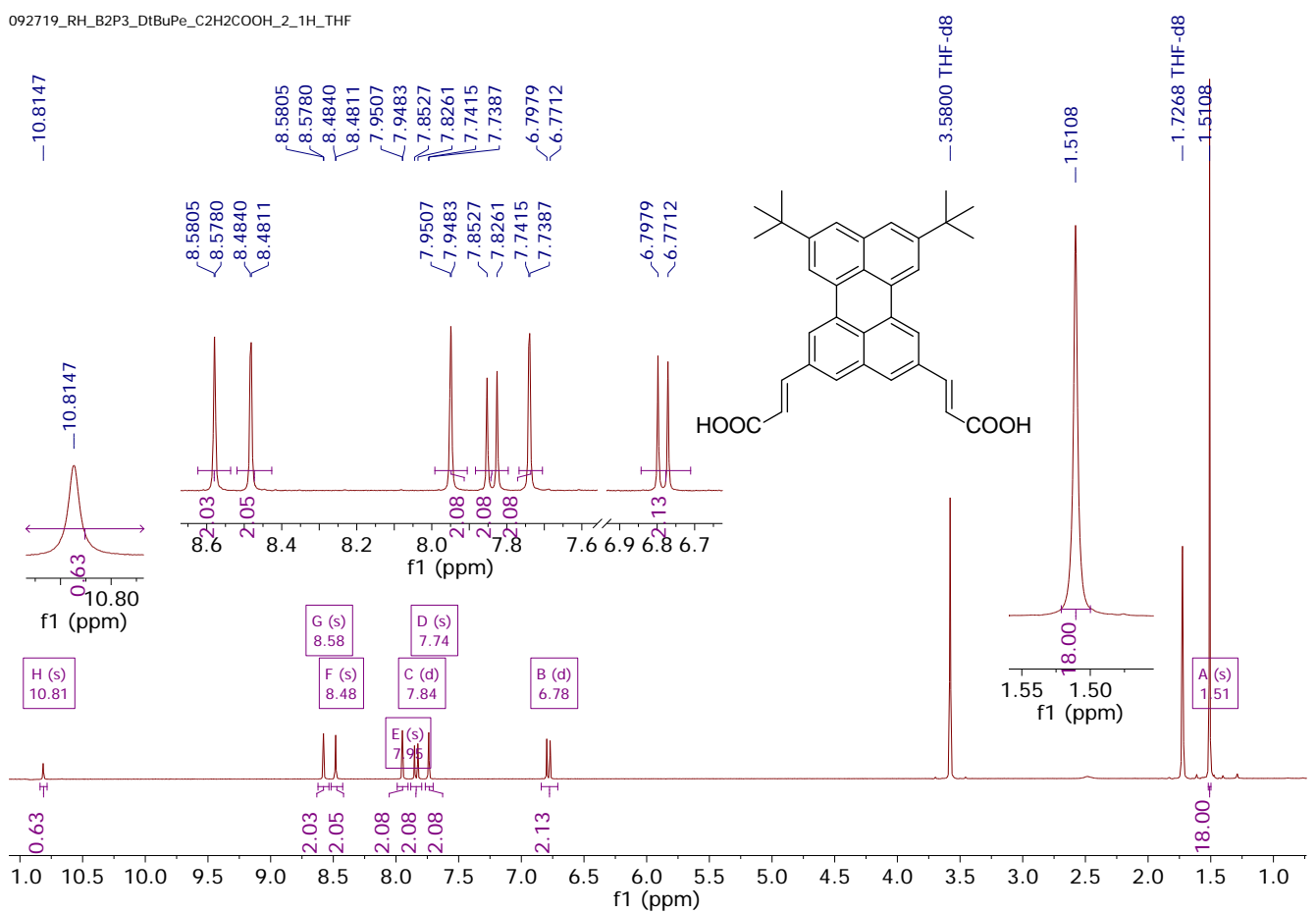

Figure S56. ${ }^{1} \mathrm{H}$ NMR of (2E,2'E)-3,3'-(8,11-di-tert-butylperylene-2,5-diyl)diacrylic acid (21b) in THF-d 8

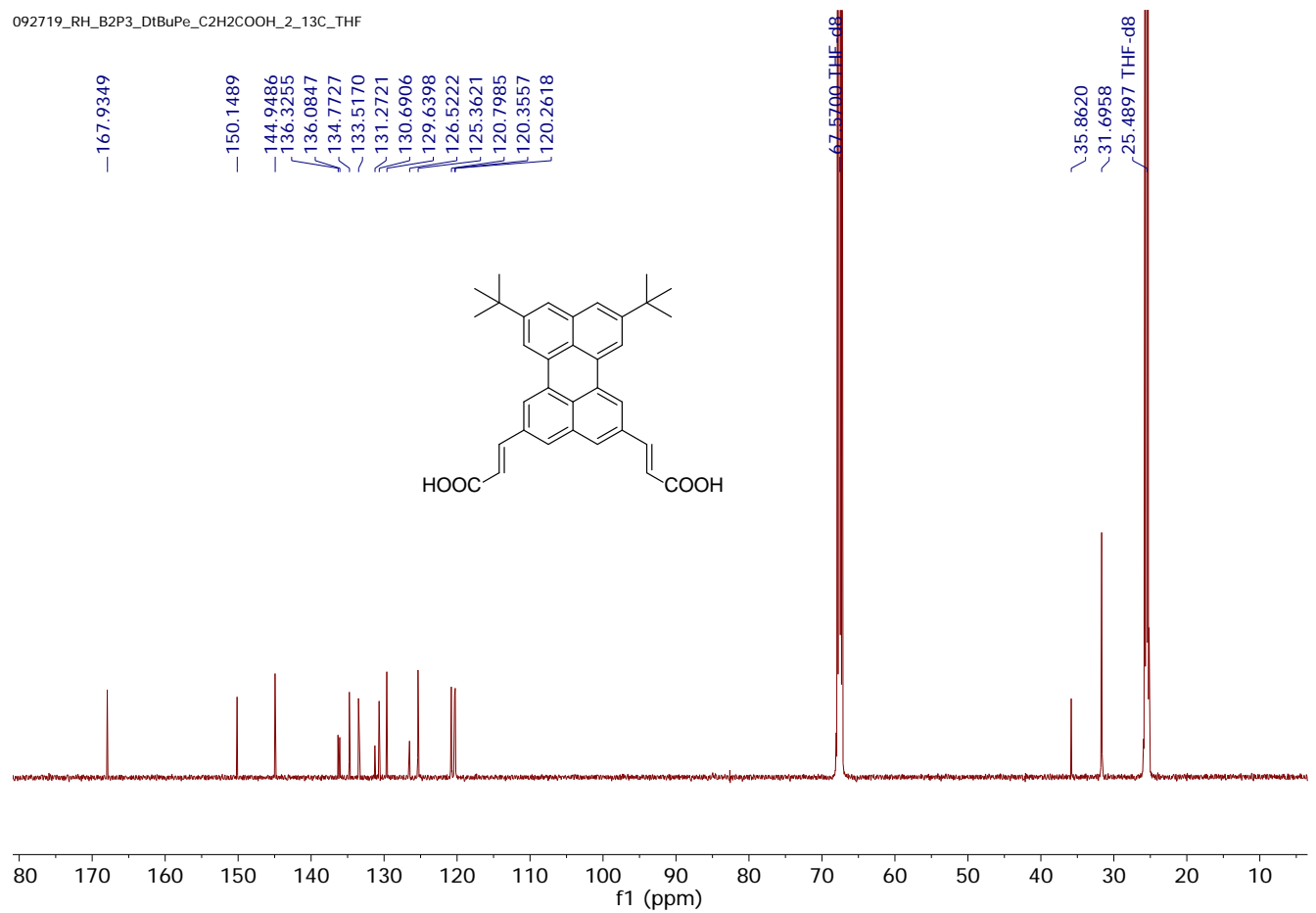

Figure S57. ${ }^{13} \mathrm{C}$ NMR of (2E,2'E)-3,3'-(8,11-di-tert-butylperylene-2,5-diyl)diacrylic acid (21b) in THF-d 8 


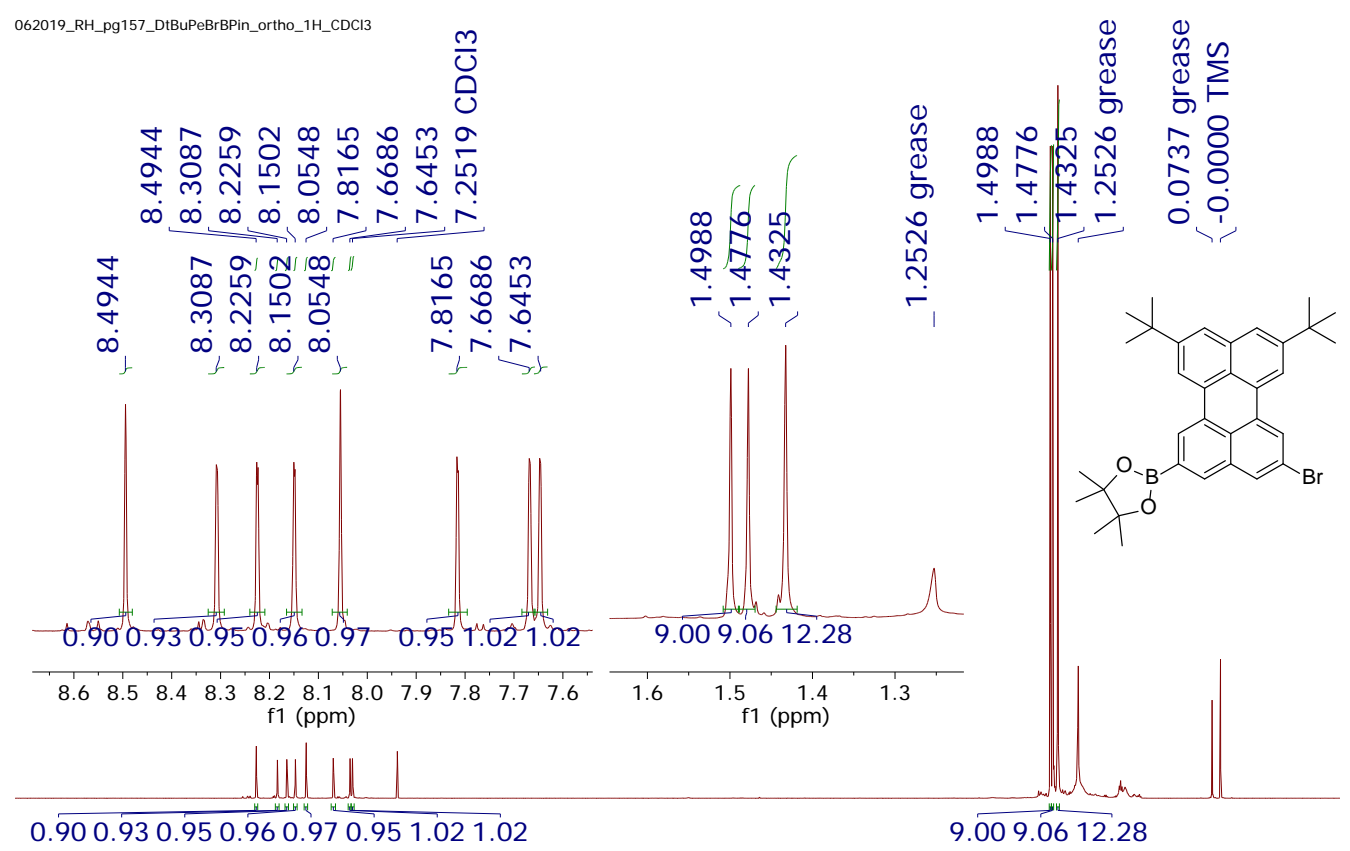

$\begin{array}{llllllllllllllllllllllll}0.5 & 10.0 & 9.5 & 9.0 & 8.5 & 8.0 & 7.5 & 7.0 & 6.5 & 6.0 & 5.5 & \begin{array}{c}5.0 \\ f 1(\mathrm{ppm})\end{array} & 4.5 & 3.5 & 3.0 & 2.5 & 2.0 & 1.5 & 1.0 & 0.5 & 0.0 & -0.5 & -1 .\end{array}$

Figure S58. ${ }^{1} \mathrm{H}$ NMR of 2-(5-bromo-8,11-di-tert-butylperylen-2-yl)-4,4,5,5-tetramethyl-1,3,2dioxaborolane (22) in $\mathrm{CDCl}_{3}$

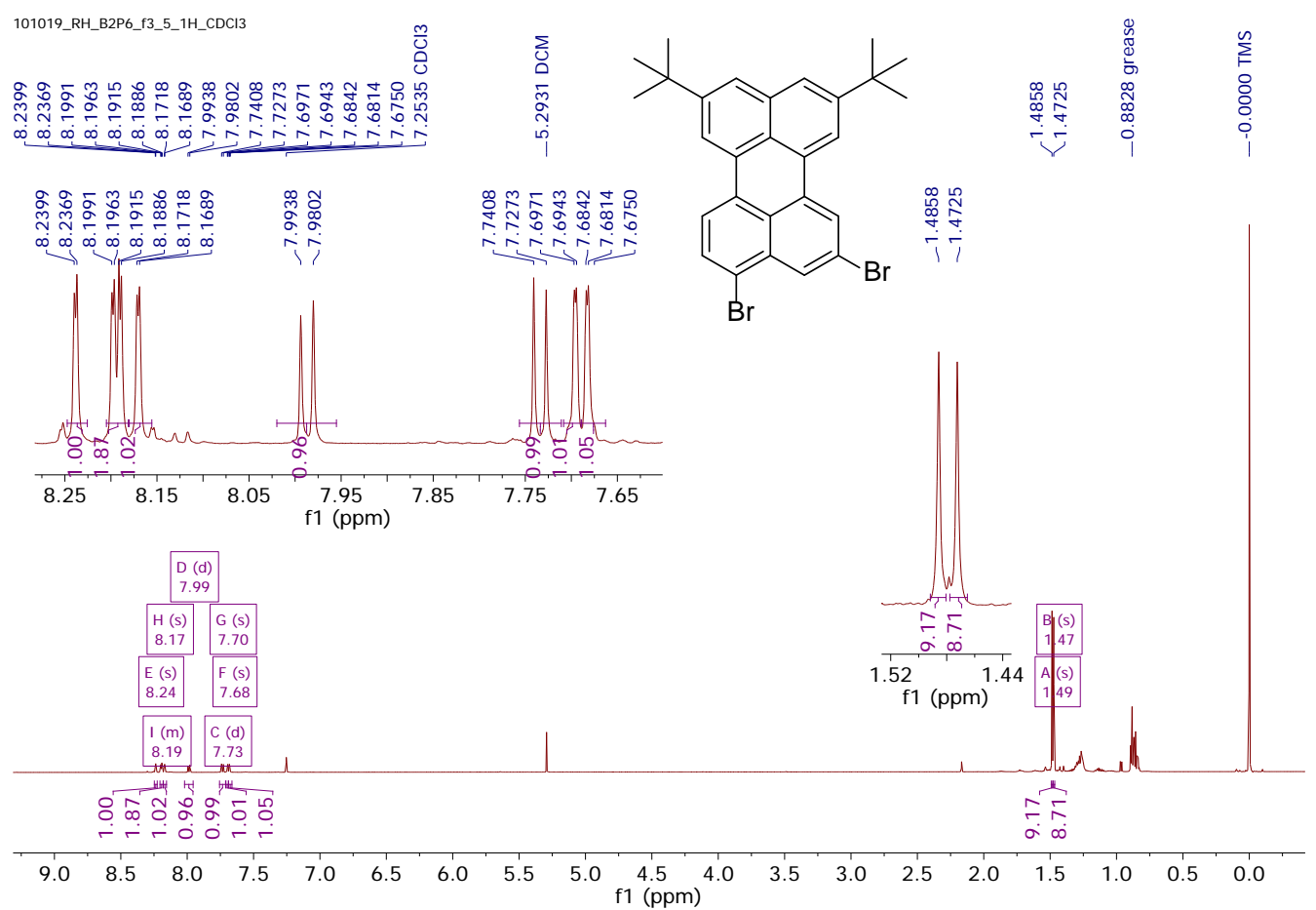

Figure S59. ${ }^{1} \mathrm{H}$ NMR of 2,4-dibromo-8,11-di-tert-butylperylene (23) in $\mathrm{CDCl}_{3}$ 


\section{References}

1. Zdetsis, A. D., Bridging the Physics and Chemistry of Graphene(S): From Hückel's Aromaticity to Dirac’s Cones and Topological Insulators. J. Phys. Chem. A 2020, 124, 976-986.

2. Libit, L.; Hoffmann, R., Detailed Orbital Theory of Substituent Effects. Charge Transfer, Polarization, and the Methyl Group. J. Am. Chem. Soc. 1974, 96, 1370-1383.

3. Frisch, M. J.; Trucks, G. W.; Schlegel, H. B.; Scuseria, G. E.; Robb, M. A.; Cheeseman, J. R.; Scalmani, G.; Barone, V.; Petersson, A.; Nakatsuji, H. et. al. Gaussian 09, Revision E.01, Gaussian Inc., Wallingford CT, 2009.

4. Dauben, H. J.; McCoy, L. L., N-Bromosuccinimide. I. Allylic Bromination, a General Survey of Reaction Variables1-3. J. Am. Chem. Soc. 1959, 81, 4863-4873.

5. Kodomari, M.; Satoh, H.; Yoshitomi, S., Selective Halogenation of Aromatic Hydrocarbons with Alumina-Supported Copper(Ii) Halides. J. Org. Chem. 1988, 53, 2093-2094. 